\title{
Visual vestibular mismatch : a poorly understood presentation of balance system disease
}

Citation for published version (APA):

Mallinson, A. I. (2011). Visual vestibular mismatch : a poorly understood presentation of balance system disease. [Doctoral Thesis, Maastricht University]. Maastricht University.

https://doi.org/10.26481/dis.20110303am

Document status and date:

Published: 01/01/2011

DOI:

10.26481/dis.20110303am

Document Version:

Publisher's PDF, also known as Version of record

\section{Please check the document version of this publication:}

- A submitted manuscript is the version of the article upon submission and before peer-review. There can be important differences between the submitted version and the official published version of record.

People interested in the research are advised to contact the author for the final version of the publication, or visit the DOI to the publisher's website.

- The final author version and the galley proof are versions of the publication after peer review.

- The final published version features the final layout of the paper including the volume, issue and page numbers.

Link to publication

\footnotetext{
General rights rights.

- You may freely distribute the URL identifying the publication in the public portal. please follow below link for the End User Agreement:

www.umlib.nl/taverne-license

Take down policy

If you believe that this document breaches copyright please contact us at:

repository@maastrichtuniversity.nl

providing details and we will investigate your claim.
}

Copyright and moral rights for the publications made accessible in the public portal are retained by the authors and/or other copyright owners and it is a condition of accessing publications that users recognise and abide by the legal requirements associated with these

- Users may download and print one copy of any publication from the public portal for the purpose of private study or research.

- You may not further distribute the material or use it for any profit-making activity or commercial gain

If the publication is distributed under the terms of Article $25 \mathrm{fa}$ of the Dutch Copyright Act, indicated by the "Taverne" license above, 


\title{
Visual Vestibular Mismatch:
}

\author{
A poorly understood presentation \\ of balance system disease
}

\section{DISSERTATION}

to obtain the degree of Doctor at the Maastricht University, on the authority of Prof. dr. G.P.M.F. Mols, rector magnificus

in accordance with the decision of the Board of Deans,

to be defended in public on Thursday 3 March 2011, at 14:00 hours

by

Arthur Ian Mallinson

Vancouver, CANADA 


\section{Promotor}

Prof. dr. H. Kingma

\section{Assessment Committee}

Prof. dr. R. Stokroos, chairman

Prof. dr. B. Kremer

Prof. dr. M. Magnusson (Lund University Hospital, Sweden)

Prof. dr. J. Patijn

Prof. dr. Ph. Perrin (Université Henri Poincaré, Nancy-Université) 


\section{TABLE OF CONTENTS}

\section{Chapter 1}

Chapter 2

Chapter 3

Chapter 4

Chapter 5

Chapter 6

Chapter 7

Chapter 8

Chapter 9

Chapter 10

\section{Chapter 11}

Chapter 12

Chapter 13

References
Preamble - goals of thesis

Introduction to visual-vestibular mismatch

Dizziness, imbalance and whiplash.

Journal of Musculoskeletal Pain 1996;4(4):105-112.

Specific vocalized complaints in whiplash and minor head injury patients.

Am J Otol 1998;20(4):809-813.

Dizziness from whiplash and head injury: differences between whiplash and head injury.

Am J Otol 1998;20(4):814-818.

Visual vestibular mismatch in patients treated with intratympanic gentamicin for Ménière's disease.

J. Otolaryngol 2002 Feb;3 1 (1):5-8

Motion sickness and vestibular hypersensitivity.

J Otolaryngol 2002 Dec; 31 (6):381-385.

Caloric response does not decline with age.

J Vest Res 2004; 14(5):393-396.

Visual vestibular mismatch in work-related vestibular injury.

Otol Neurotol. 2005 Jul;26(4):69 1-4

"Across the board" posturography abnormalities in vestibular injury.

Otol Neurotol 2005 Jul;26(4):695-698

Evaluation of the effects of ethanol on static and dynamic gait.

J Otolaryngol Head Neck Surgery2008 Dec;37(6):856-9.

Discussion - Visual vestibular mismatch

Conclusions

Appendix one - Visual vestibular mismatch questionnaire

List of publications and Curriculum Vitae-Arthur Mallinson 


\section{CHAPTER ONE}

\section{Preamble - goals of the thesis}

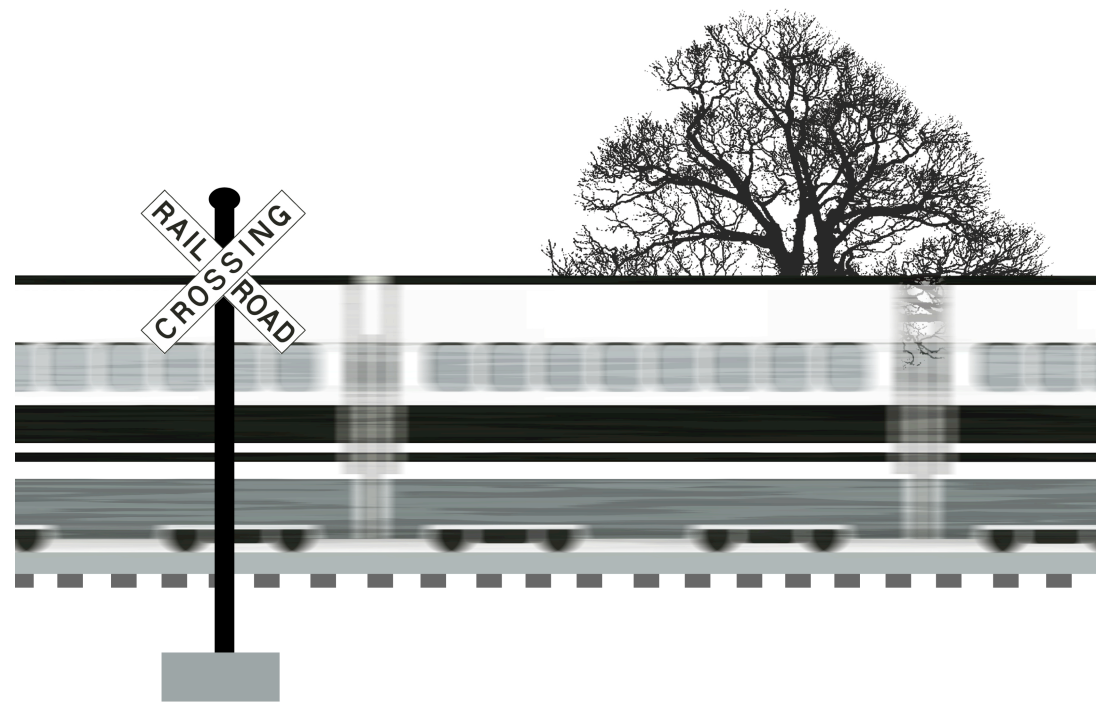


Evaluation of patients with complaints of dizziness and imbalance has been recognized as extremely challenging since the time of Romberg (Romberg, 1846). Moritz Heinrich Romberg was a German neurologist who assessed patients by having them stand with their eyes closed to see whether they could maintain stability. Romberg was testing for tabes dorsalis, a form of tertiary syphilis where the posterior columns in the spinal cord are damaged, impairing proprioceptive information from the feet. He found that an affected patient was unable to maintain stability and would fall if he closed his eyes. Over the years it was realized that Romberg's test was also positive in neurological disease other than syphilis, and it became part of the standard neurological assessment. It is insensitive at detecting acute vestibular disease (Longridge and Mallinson, 2010) and is also insensitive for detecting chronic unilateral vestibular impairment (Lanska and Goetz, 2000) but it is still in clinical use today. The sharpened Romberg developed in the 1960s (Graybiel and Fregly, 1966) is utilized clinically, and to this day has remained one of the only effective office assessments that can be used to screen for vestibular disease, although even its results can be confounded by a patient who has compensated, or even by age, which itself can be considered to be a "vestibular lesion" (Longridge and Mallinson, 2010).

Even to the present day, the assessment, diagnosis and treatment of the patient with dizziness is a challenging and often unrewarding task. As Matthews stated in 1963:

\footnotetext{
"There can be few physicians so dedicated to their art that they do not experience a slight decline in spirits when they learn that their patient's complaint is dizziness. This frequently means that after exhaustive enquiry it will still not be entirely clear what it is that the patient feels wrong and even less so why he feels it."
}

The purpose of this thesis is to address what in my opinion is a substantial shortcoming in our understanding, evaluation, assessment and clinical management of the patient with complaints of dizziness. So-called "traditional" complaints of dizziness that have long been recognized as being characteristic for balance system pathology (including spinning or similar sensations of movement) are often accompanied by nausea and imbalance. History taking 
in the patient with traditional complaints (even one presenting with a language barrier) is often a simple undertaking, and the symptom set in such patients is often easy to assess. Complaints of spinning ("vertigo" in North America) usually arise from the semicircular canals, and are indicative of pathology in these structures. There are standardly accepted evaluation techniques, such as videonystagmography and caloric testing. There are also management strategies such as particle repositioning maneuvres, Epley maneuvres, intratympanic gentamicin therapy, and vestibular rehabilitation therapy, and it is felt that the disease processes responsible for these complaints are reasonably well understood. This traditional aspect of vestibular disease will not be directly addressed in this thesis.

One of my main goals in this thesis is to address the patient with nontraditional complaints; these complaints are still probably of inner ear balance system origin. Our understanding of them is sadly lacking, and consists of clinical evidence supporting the known anatomical pathways and physiological function. Even more poorly understood is why there is such a wide range of symptomatic response to such deficits. This thesis also attempts to suggest reasons for this wide range. Some of these patients have an initial deficit, which can cause a minimal signal discrepancy, but this generates symptoms that can range from virtually unnoticeable, to quite bothersome, and in some extreme cases, totally debilitating. In my discussion, the extent to which these deficits are understood will be outlined and discussed.

A secondary goal of this thesis is to address the efforts that have been made to define these vague complaints. Controversies have arisen with regard to distinguishing different disorders (Bisdorff et al, 2009). A committee has been struck to explore this issue and classify these disorders, as it has been recognized recently that problems of terminology have arisen. One of the main focuses within this thesis has been to identify and characterize visual-vestibular symptoms. The committee unanimously thought it was important to develop a separate category for this symptom set. It has also been acknowledged that this symptom set arises from vestibular dysfunction, but this is not always well understood by practitioners outside of the vestibular community (Bisdorff et al, 2009). Terms such as "visual vertigo" have been used in the past, but have been suggested by the committee as being inappropriate, as these terms 
suggest a sensation of movement brought on by a visual stimulus. Although an agreement about nomenclature has not yet been agreed upon, it has been accepted that there is a set of symptoms that usually results from vestibular pathology, or the interplay between visual and vestibular systems (Bisdorff et al, 2009). This thesis will address patients' symptoms by their characteristic names and suggest how they might fit in with the new nomenclature suggested by this committee.

Although techniques and strategies for diagnosing, assessing and managing non-traditional complaints of dizziness are limited, it has been recognized for 2000 years that these complaints are legitimate. A more recent breakthrough (see Yates et al, 1998) has detailed them anatomically and physiologically as a valid entity. This has allowed for the development of theories as to the physiology underlying the generation of these complaints. Historical development of our present understanding is important in arriving at an accurate diagnosis of these patients.

The body of this thesis consists of a series of nine peer reviewed published studies. I am the lead author on six of the studies, and the second author on the other three. All the studies were designed to validate the theories and advance our understanding of atypical vestibular complaints. The papers show that many patients having nontraditional complaints are suffering from balance system pathology and that this pathology can be secondary to neck trauma, head trauma or iatrogenic intervention, but can sometimes be idiopathic.

In the studies that form the body of this thesis, new criteria for documenting these non-traditional complaints are described. The criteria have also been related to those disturbances of the balance system that are understood more fully. For example, astronauts in space, and also after return to earth often experience unwell feelings of "space motion sickness" that are thought to be similar to motion sickness. These symptoms are generated as a result of balance system disturbance in microgravity (Oman et al 1986). Similar balance system disturbances can be induced by a "night on the town". The hypothesis which this thesis evaluates is that partygoers, astronauts, and the patients with nontraditional balance system complaints have balance deficits which are sometimes temporary, sometimes persistent and possibly even permanent. Their 
symptoms are physiological rather than psychogenic or psychiatric and are recognized as arising from balance system deficits.

Chapter two is an introduction to my thesis and outlines the symptom set of visual vestibular mismatch (VVM), including historical perspectives. It includes an explanation of the symptom set, understanding of it through the ages, and our present day appreciation. It also examines why these patients are often difficult to diagnose, and how on occasion they have come to be erroneously categorized as psychiatric or neurotic.

Chapter three represents our "early work". In this study, we identified a population of patients who had suffered whiplash type injury, but had not hit their head. Some of the patients had "standard" vestibular complaints and standard posturography findings suggestive of a vestibular deficit. However many of the patients voiced vague "atypical" complaints of lightheadedness and dislike of environmental movement. In these patients, the same standard posturography abnormalities were found, and we formulated the idea that perhaps their vague complaints were also of vestibular origin.

Chapter four describes further work that was carried out after we recognized that the vague complaints of our patients might represent peripheral vestibular disease. We encountered a group of patients with such complaints who had suffered whiplash injuries and/or minor head injury. We recognized that patients with "standard" vestibular syndromes had the same complaints as our whiplash patients, and the similarity of symptoms in the two groups led us to believe that the symptoms in both groups were caused by underlying vestibular disease.

Chapter five addresses suggestions that the symptom set of VVM might be arising from central pathology. Previous authors had looked at dizziness after whiplash injury, and had regarded these symptoms as suggesting brainstem and/or cerebellar injury related to the whiplash mechanism. We delineated two groups of whiplash patients with vestibular symptoms; those who had also suffered head injuries and those who had not suffered any head trauma at all. We saw the need to investigate the similarities and differences in these two groups, as we thought that the symptoms might be arising not from central pathology, but from peripheral vestibular injury caused by the mechanics of the whiplash trauma. 
Chapter six looks at the development of VVM in patients with Meniere's disease. It must be emphasized that it is not the purpose of this thesis to embark on an investigation or discussion of the clinical entity of Meniere's disease. This chapter was a corollary of another study which investigated the efficacy of intratympanic gentamicin therapy (Longridge NS, Mallinson Al. Low-dose intratympanic gentamicin treatment for dizziness in Ménière's disease. J Otolaryngol 2000 Feb;29(1):35-9). Some patients in that study developed symptoms of VVM after the therapy itself (i.e. creation of a iatrogenic peripheral vestibular lesion) and voiced symptoms similar to those reported by our whiplash patients, and by our "traditional" vestibular patients. Our corollary study looked at these patients.

Chapter seven looks at the evidence that we had gathered to date suggesting that VVM, visual vertigo and space motion sickness likely had a common origin, and probably reflected a "motion sickness". Some people by their nature are motion sensitive, and we wondered if the development of these symptoms was due to a higher "autonomic sensitivity" or if motion sickness represented the upper end of caloric responses (i.e. vestibular sensitivity).

Chapter eight looks at the issue of age related decline in the vestibular system, as the clinical relevance of this to the development of VVM symptoms is unclear. The term "presbylibrium" has been used over the years by many authors (e.g. Furman and Cass (1996)) to refer to "disequilibrium of aging". This term is still in use in the present day. Goebel (2008) outlined it as being caused by "structural and physiological deterioration in the sensory systems which maintain balance". However this hypothesized deterioration is difficult to document. Furman and Redfern (2001) made the statement that the aging peripheral vestibular system remains functionally intact. They used off vertical axis rotation to show an age-related decline in otolith-ocular responses, but they hypothesized that this resulted from a decline in central vestibular processing, rather than from a loss of function of the otoliths themselves. We wondered if there was an age-related decline in caloric response (perhaps making older people more sensitive to the development of visual vestibular mismatch, as Paige (1992) had initially suggested).

Chapter nine examines symptoms of VVM after work related head injury. We had established that the development of VVM could occur after vestibular 
injury. We wondered if the symptoms in these patients were related to their head blow or were caused by peripheral vestibular injury.

Chapter ten looks at a subset of patients who had "atypical" Computerized Dynamic Posturography (CDP) results. The results in these patients suggested a nonspecific balance system deficit on all Sensory Organization Testing conditions, which were regarded in the literature as "aphysiologic" (Neurocom Equitest Data interpretation Manual, 1994; Furman, 1995). The literature suggested that these patients might have legitimate complaints, but the interpretation manual suggested (with no statistical support for the assumption) that vestibular system dysfunction was unlikely and these results were "suggestive of central nervous system pathology". Many of these patients described vestibular symptoms and also had histories of newly developed VVM, and we thought that perhaps the non-specific CDP abnormality we saw in these patients might represent peripheral vestibular injury.

Chapter eleven looks at the effects of ethanol on gait. Many of our patients with VVM would characterize their complaints during history taking as "like I had had a little bit too much to drink". We used a device which measures dynamic gait, to see if we could measure subtle balance deficits in subjects minimally impaired by ethanol. It has been suggested that the impairing effects of alcohol are related to reduced vestibular function (Tianwu et al, 1995), and that a sensitive method of measuring this deficit is using CDP conditions that exclude visual input (Ledin and Odkvist 1991). We thought it was important to try and show such subtle deficits, as perhaps these techniques could be transferred over to our patients with similar symptoms and signs.

Chapter twelve consists of a discussion of VVM and also details the historical development of our present understanding of the symptom set. In addition, it summarizes how the work in this thesis has helped to further our understanding of VVM. The discussion also examines the present, as well as the future direction of vestibular diagnostics, how our patients can be managed after they are finally supplied with an appropriate diagnosis, and how our understanding of the vestibular system, the autonomic nervous system, and the interaction between the two can better serve these patients. I will also try to incorporate the ideas advanced in this thesis into the new nomenclature that has recently been suggested and developed to standardize balance system disease (Bisdorff et al 
2009). The hope is that this will help to reduce the confusion surrounding the symptom set of VVM.

There is a caveat to be kept in mind. The writer is aware that patients seen through our clinic are largely referred by otolaryngologists, and neurologists referring have either excluded neurological disease or wish to know the extent to which peripheral vestibular disease may be contributing to their patients' complaints. We recognize that the complaints of VVM may arise as a result of neurological disease.

Chapter thirteen is a conclusion which presents ten relevant statements that must be kept in mind when trying to understand how complaints of VVM fit into the clinical picture in patients voicing these symptoms. 


\title{
CHAPTER TWO
}

\author{
Introduction
}

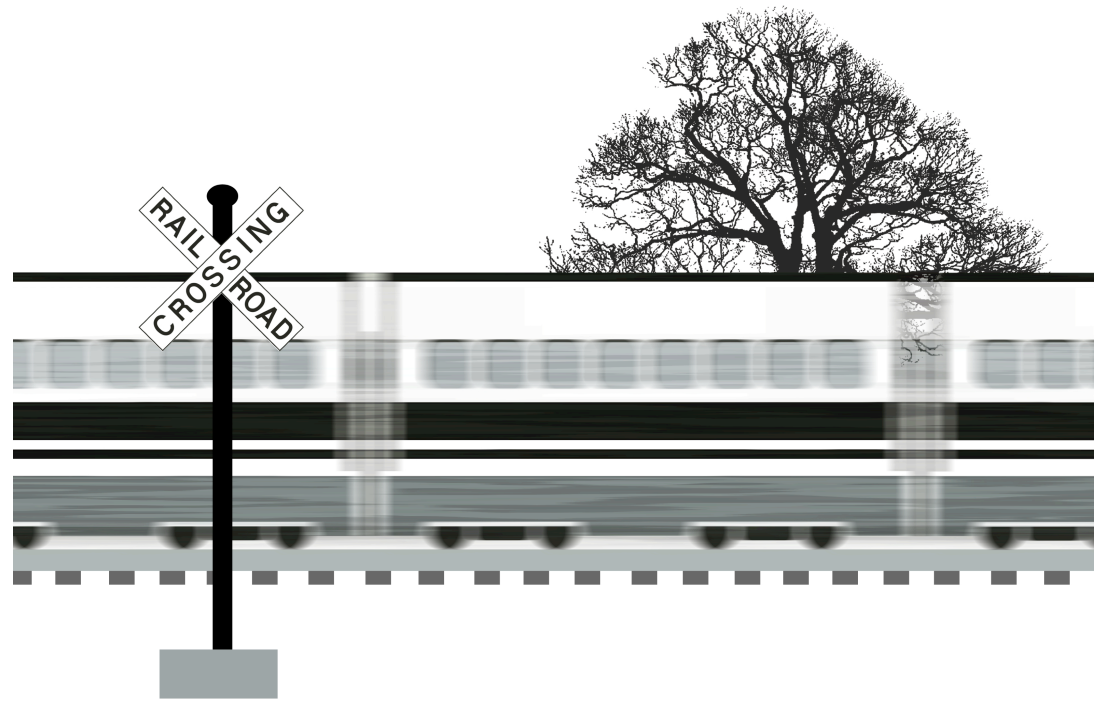




\section{AN EVOLVING UNDERSTANDING OF BALANCE SYSTEM DISEASE}

The symptom set of "visual vertigo" (VV) (Bronstein, 1995) or "visual vestibular mismatch" (VVM) (Longridge and Mallinson, 2002) has been recognized for some time, and it is one that can be debilitating to some patients. To the North American clinician, use of the term "vertigo" implies a spinning sensation and it is unfortunate that this condition has been defined using the term "visual vertigo", as this has resulted in the failure of its establishment in the literature as a physical entity, except in specialist clinics, where it is recognized as a valid symptom set. Patients with visual vertigo almost always deny a sense of spinning. To the European clinician, vertigo implies any hallucination of movement, hence the use of the term "non-vertiginous vertigo". As a result of this difference in definitions in papers written on opposite sides of the Atlantic Ocean, there is an inherent risk for misinterpretation of a patient's complaint during history taking.

The autonomic subset of symptoms relating to vestibular stimulation (e.g. seasickness) was studied by Maitland (1936). He stated that the "eminently seafaring British nation is conspicuous for its neglect of the study of seasickness". The understanding of seasickness up to that time reflected the idea that it was not generated by the vestibular system, because vestibular pathology as it was understood at the time (semicircular canal pathology) generated nystagmus, and no nystagmus had been observed in seasick individuals. However Maitland advanced the theory that the symptoms associated with seasickness were in fact generated within the vestibular system, because rotation of a subject could produce the same seasickness syndrome. He observed that there were some cases where the labyrinths were "unduly sensitive", so that there was a range of responses between subjects to a given stimulation. Interestingly, he noted that the group of people who were most susceptible was also affected by other vestibular stimuli, such as train sickness or car sickness, and that they "also disliked waltzing". Maitland wondered if the susceptibility in this subset of patients might be due to a conflict of stimuli, perhaps between vestibular impulses and visual signal. Supporting his theory was his observation that people with functionless labyrinths were not susceptible to seasickness, train sickness or any other motion stimulation. On the other hand he questioned his own theory, and wondered how visual stimulation could be playing a role, as he was aware 
that vertiginous symptoms "may still occur on shutting out the visual field by closure of the eyes".

Preber (1958) embarked on a large study of vegetative or autonomic correlates of vestibular stimulation, elicited either by physiological stimulation or by caloric tests. He attempted to quantify the autonomic responses by correlating the level of the vegetative response with nystagmus elicited during caloric testing. His work suggested an association between motion sickness susceptibility and speed of caloric induced nystagmus. In his detailed account, Preber discussed his findings but also alluded to the fact that labyrinthine stimulation using caloric irrigation may not play a major role in the generation of vegetative responses. He referenced earlier work by Hulk and Henkes (1950) who had studied vegetative reactions of labyrinthine origin by measuring retinal blood pressure. They had found that rotatory vestibular stimulation did not induce reactive changes in retinal blood pressure, but the phenomenon appeared consistently in $50 \%$ of patients after a slight otolithic stimulation using a "parallel balance test", (which was essentially a linear swing, producing a translational, rather than a rotational stimulus). The response was not seen in patients with loss of labyrinthine function, and did not appear after administration of tetraammonium bromide (which produces a transitory paralysis of the peripheral vegetative receptors in the labyrinth). Hulk and Henkes concluded that stimuli acting on the semicircular canals do not elicit any vegetative responses, but otolithic stimulation induced a specific and sensitive reaction from the "vegetative nervous system" as they called it, as measured by changes in retinal blood pressure.

Based largely on this work, Preber suggested that "overstimulation of the labyrinths" was the primary factor in the pathogenesis of motion sickness. It was also suggested by Guedry (1970) that while the concept of "overstimulation" of the labyrinths might be important in the generation of motion sickness, "conflicting data from the visual, vestibular and somatosensory systems may be the important aspect of the stimulus". 


\section{HISTORICAL PERSPECTIVES - DIZZINESS THROUGH THE AGES}

The awareness of an interface between vertigo and affective symptoms has been recognized since antiquity. Soranus of Ephesus (AD 98 - AD 138) was one of the most learned physicians of classical times, and his obstetrics and gynecology tests were still plagiarized 1500 years later, as they contained many valuable contributions that could have been written in modern times, including the forerunner of the Apgar score still used today. His extensive text about acute and chronic disease has been lost, but a fifth century translation, Tardarum Passionum (Caelius Aurelianus) describes "scotomia" (dizzy complaints), and includes both moving stimuli and gazing down from heights as provocative situations:

"The disease is aggravated if the patient watches the flow of a river from a high point, or gazes at a potter's wheel or does anything when bending forward".

Soranus also described vertigo "accompanied by sweating of the upper parts of the body". For those who do not have the Latin skills to digest the Tardarum Passionum, this understanding is outlined in delightful detail by Balaban and Jacob (2001).

In the $6^{\text {th }}$ century, the famous physician Galen recognized that vertigo could be brought on by being "whirled around in a circle" but could also be brought on in the absence of movement ("if they watch a turning wheel or look at the socalled whirls in a river"). He also recognized individual differences and inferred that there was a wide range of interindividual susceptibility or sensitivity, noting that "some people are affected even if they are not rotated, although others must be rotated several times in a circle".

This "understanding by observation" 1500 years ago of the vestibular system suggested two aspects of it which are still accepted today:

- There is a large interindividual variation in susceptibility to the symptoms.

- There are certain situations that will generate symptoms

The second point (the idea of a "situation specific" disorder) implies that there is a link between the organic symptoms and psychiatric disorders. This link was 
initially detailed in the $17^{\text {th }}$ century, when the symptoms of vertigo were regarded as a principal sign of "hypochondriacal melancholy". By the 19th century vertigo was defined as a neurological disorder. The related affective symptoms were recognized as well, but they had an ambiguous status as being either of neurologic or psychiatric origin.

As dizziness became more accepted as a brain disease, the accompanying signs were still regarded as a physical disorder that accompanied insanity. Westphal in 1871 developed an understanding of the situation specific interface and resulting symptoms of anxiety that were generated by vertigo. $\mathrm{He}$ developed the term "agoraphobia" (literally "fear of the marketplace") to describe his patients' fear of walking in an open square. As a treatment modality, he also suggested that a patient could overcome their fear by "fixating on a specific line or on an object that is moving away from them". Westphal was perplexed by the fact that his patients' symptom set never involved "vertigo" as he understood it (sensation of spinning) (Balaban and Jacob, 2001). Relevance of this observation to Bronstein's (1995) patients with visual vertigo (i.e. nonvertiginous vertigo) will be discussed later.

Cordes in 1870 wrote of his personal experiences with height phobia and that it generated "sensations of nonrotatory movement, like being on a boat". As these reports did not conform to the classic complaints of vertigo, they were dismissed as being caused by nervous exhaustion or muscle weakness.

At about the same time, there was also an accumulating body of evidence that symptoms of vertigo might be generated by the ear and the $\mathrm{VIII}{ }^{\text {th }} \mathrm{cranial}$ nerve. The physiologist Flourens in 1825 published his work in German outlining his experiments (Barany, 1916). Flourens thought it would be possible to get an insight into the workings of the semicircular canal structure in the pigeon by destroying the structure. His work with pigeons, rabbits and other animals demonstrated consistent results, showing for instance that destruction of a horizontal semicircular canal in a pigeon resulted in it turning in circles. Destruction of a vertical canal resulted in it turning somersaults (Barany and Ibershoff, 1910). Although his descriptions were excellent, Flourens did not recognize that the animal was probably suffering from vertigo. 
Unknown to Flourens, Purkinje was working in Prague and treating violent prisoners in a cage by inducing nausea, which helped to calm them down. He discovered nystagmus, described the effect of head position on vertigo, and showed that the symptom set arose in the head itself. He was aware of Flourens' work but failed to "put two and two together", because he thought that the vertigo in his prisoners arose not from the ear, but from the brain.

Understanding of the inner ear stood still for almost 40 more years. The work of Prosper Meniere, publicized in 1861 (the year he died) was driven by clinical observations in patients (Barany, 1916). Meniere had observed the frequent correlation of vertigo with tinnitus in patients who had normal middle ear function. The cochlea was known at the time to be the site of hearing but the semicircular canal attached to it was thought to have no function at all. Although vertigo was still accepted as a disease of the cerebellum, Meniere's vertiginous patients developed no signs of brain disease over the years and he had the idea that semicircular canal pathology was responsible for the production of vertigo in his patients.

Barany's work resulted in the source of vertigo being accepted as arising from the inner ear. It was still accepted that these symptoms had multiple manifestations, many affecting the mental senses. Hughlings Jackson stated that a patient with vertigo also has "horrible depression, he may say that he feels as if he were going to die". By the early $20^{\text {th }}$ century, the notion of a primal link between loss of a sense of balance and affective disorders became entrenched in psychology. Zwerling (1949) suggested a possibility between "neurotic tendency" and tendency to motion sickness.

There was also an increase in the number of reports of patients who displayed simultaneous symptoms of ear disease (true vertigo) and agoraphobia. The concept of differing susceptibilities was again raised, and it was suggested that there was a certain population of susceptible individuals who could develop agoraphobia in the face of vertigo. Through the $20^{\text {th }}$ century, further understanding of agoraphobia was gained. Panic anxiety became accepted as a diagnostic entity and initial studies reported that abnormalities of vestibular tests were seen in a large proportion of patients with panic disorder (Jacob et al, 1985) and specifically in patients with agoraphobia (Yardley et al, 1994). Furman et al (1998) also outlined a specific relationship between vestibular 
dysfunction and agoraphobic avoidance. They stated that "pseudoagoraphobic" syndromes in patients with vestibular disorders have long been recognized and that the psychiatric condition of height phobia is also related to vestibular dysfunction.

In 1935, Koffka in his "Principles of Gestalt Psychology" (cited in Balaban and Jacob, 2001) outlined the important role of vision in balance, stating that we "lean on our eyes as we do with our feet" and "as we do with our hands". However this phenomenon of sensory integration was largely ignored for the next 40 years until McCabe (1975) described "supermarket syndrome" in patients with Meniere's disease. He described that these patients had "an intolerance for looking back and forth along aisles and up and down shelves". He outlined that nausea could be caused by motion of a patient with dizziness, but also described "vestibulo-gastric illness", which included illness caused by movement of a visual field. In short, motion sickness could occur as a result of:

- Real motion

- Passive exposure to real motion

- Apparent motion ("cinerama sickness").

Although there was an acceptance of the interaction between visual and vestibular systems, it was unclear how this was postulated to cause symptoms in patients.

The term "visual vertigo" was initially used by Erasmus Darwin in 1797 (Balaban and Jacob, 2001) to designate a visually provoked form of vertigo that arose along with dizziness "when we lose the means of balancing ourselves, or preserving our perpendicularity, by vision". By the 1870's, "visual vertigo" referred specifically to vertigo associated with extraocular muscle pathology. Bronstein (1995) has broadened the term to designate any visually induced vertiginous syndrome (using the European definition of vertigo; any sensation of movement of self or surroundings). He has used the term to describe a set of symptoms similar to McCabe's "supermarket syndrome" (1975) (i.e. the symptom set generated by a visual vestibular disagreement). As discussed previously, Bronstein's term is a misnomer in North America, as North Americans understand "vertigo" as a spinning sensation. The term "visual vertigo" confuses the situation, as very rarely is there spinning with it. Bronstein initially suggested 
that visual vertigo resulted from the "dominant role of vision in the control of posture" (1986). He later outlined the problems with this dominant role, as it could result in a symptom complex that arose from a process of compensating for vestibular injury that is interfered with by unusually high visual reliance, leading to intolerance to situations of visual conflict.

The term "visual vestibular mismatch" was first used by Benson and King in 1979. They used the term to describe a "motion cue mismatch". They suggested that it was a part of the system complex known as neural mismatch. It was postulated that there was some kind of central memory which was linked to a "comparator" (anatomical location unknown and not suggested) where sensory information was correlated with the neural store. If the input signals from the receptors did not agree with the expected (i.e. stored) information, then a mismatch signal was generated. It was postulated that the newly developed signal served two purposes; to update the stored signal, and to initiate the neurovegetative and sensory responses colloquially referred to as motion sickness. The evolutionary role of the response was not addressed, although Longridge (1993) was the first to suggest a role for the autonomic aspects of vestibular response. He postulated that the anorexic part of the vegetative symptoms specifically occurring in vestibular disease may have been beneficial in preventing an unbalanced and vulnerable animal from foraging for food. In other words, the autonomic symptoms of vestibular disease may have evolved to make an animal unwell enough to stay home when vertiginous, keeping it in relative safety.

Paige (1992) introduced the term "visual vestibular mismatch" into the clinical literature, using it in a different sense from that used by Benson and King. $\mathrm{He}$ used the term to refer to the differing signals between two sensory inputs (rather than a differential between a sensory input and a stored template). Paige reviewed the literature showing that anatomical deterioration of all vestibular structures occurs with aging; this reaches $40 \%$ by the $9^{\text {th }}$ decade. He also showed that patients had visual problems which were not directly related to the vestibular senesence. Adaptive plastic mechanisms (which normally maintain VOR performance under conditions of head movement) also deteriorate with aging. If the senescence of these two systems did not occur in parallel, (which would prevent them from being effectively integrated), a resulting mismatch 
between the two signals would occur. Paige found that the performance in his elderly patients on vestibular assessment tests was the same as in younger patients with documented vestibular abnormalities, and he suggested that it was this mismatch in the older patients that had been created by the nonparallel senescence, that "mimicked" the vestibular loss in the younger patients. Paige made the point that there was definitely a senescence of vestibular function but made no guess as to whether it affected the semicircular canals, otolithic structures, or both. He did bring up the frequency of complaints of "imbalance", as opposed to "vertigo", in his elderly patients.

Paige's suggestions were that visual vestibular mismatch might develop as an inability in elderly people to recalibrate the VOR to an appropriate level (although he stated that evidence for this was scant). Alternatively, he suggested that the senescence-related reduction of vestibular input might directly impair adaptive capabilities. He did state that, regardless of the mechanism, the elderly were compromised in their abilities to "control eye movements that serve to maintain gaze, and therefore retinal image stability".

\section{PRESENT UNDERSTANDING}

In this thesis, the term "visual vestibular mismatch" is similar in some respects to the situation outlined by Paige, but the thesis suggests that this mismatch can occur at any age as a result of vestibular pathology. In other words, the development de novo of visual vestibular mismatch is suggestive of a balance system lesion (Mallinson and Longridge 1998[2]). The physiologic mechanisms involved in compensation for balance system damage have been investigated extensively, and can be used to explain why a vestibular lesion can create visual vestibular mismatch. Vision clearly plays a role in postural control in healthy subjects, but the role is secondary, in that vestibular information acts as the template. For example, a visual illusion of movement (e.g. watching a 3D movie) is disregarded by the vestibular system, as the vestibular signal suggests that the illusion of movement is artificial and does not need to be acted on. In the absence of perfectly reliable vestibular information, a dogmatic dependence on visual information is developed to maintain balance, so that patients with vestibular disorders become even more visually dependent for balance (Redfern et al, 2001). Under the 3D movie situation, the "visual 
preference strategy" can generate an "appropriate" response to the perceived movement, and generate concomitant autonomic responses.

In addition, an increased visual dependence might limit a patient's ability to compensate fully for a vestibular disorder, particularly where there is a sensory conflict due to excessive visual motion (Guerraz et al, 2001). As a result of this sensory conflict, many patients with vestibular disorders are not able to integrate visual and vestibular function in an appropriate manner. It seems that some patients have an intolerance for any discrepancy between visual and vestibular signals. Some individuals are exceedingly sensitive to any signal disagreement, in the same way that some individuals are exceedingly motion sick. This results in the development of posttraumatic motion sickness, visual vestibular mismatch, or both. These two attributes may be similar in nature, as individuals with other motion sensitivities, such as motion sickness, are unable to disregard erroneous visual cues (Redfern et al, 2001).

Visual vestibular mismatch is difficult to diagnose because of a severe lack of adequate investigation tools, a limited ability to measure degree of injury in these patients, and because there is a wide inter-individual variability between degree of injury and intensity of symptoms.

The exploration of space has vastly improved our understanding of the vestibular system, as microgravity is the only situation in which vestibular responses can be considered to be "off line". The symptom set of "space motion sickness" (SMS) was reported by Soviet cosmonauts, and also reported consistently by orbiting American astronauts. The "sensory conflict theory" to explain motion sickness was accepted at the time, and it predicted that motion sickness should occur in space (Oman et al, 1986).

The sensory conflict theory did not attempt to pinpoint the anatomic site of space motion sickness. The theory dictated that there was a "conflict between sensory input and a signal originating in centres responsible for processing body movement control and spatial orientation information".

As we know in patients, there is a wide interindividual variability with respect to symptoms. Oman et al commented on the wide range of interindividual susceptibility that they noted in their space motion sick patients. However they were confused by the fact that when they measured motion sickness 
susceptibility on earth, and then compared it to space sickness intensity rankings, the least and most susceptible subjects reversed position. They came to the conclusion that space sickness was fundamentally a motion sickness, and that head movements were a clearly identifiable stimulus. As will be seen, this closely parallels patients with symptoms of visual vestibular mismatch, and interestingly, it has been suggested (Mallinson and Longridge 1998[1], 1998[2]) that the new development of motion sickness in a patient is suggestive of a balance system deficit. Work presented in this thesis helps to form the hypothesis that this may result from disagreement between semicircular canal and otolith signals, similar to Oman's theory.

Black et al (1999) recognized that in addition to space motion sickness, disturbances in postural equilibrium and gait upon return from space were among the most consistently observed consequences of space flight. In their study of four astronauts, post flight performance variabilities were compared between astronauts, and it was found that that one of them performed balance tests very poorly post flight. This was totally unexpected, as he had not shown these deficits after his previous flights. However this astronaut had undergone an additional eccentric pitch axis rotation test after landing, and the theory was that this additional stimulation had interfered with the readaptation process post flight. They concluded that the stimuli to the otoliths in this one individual was what disrupted his recovery, and that post flight postural instability in astronauts resulted from disrupted processing of otolithic inputs.

Disturbances of postural equilibrium are also seen in patients, to the point where they have measurable abnormalities on Computerized Dynamic Posturography (Equitest ${ }^{\circledR}$ ), but these abnormalities are nonspecific, and patients often show below par performance on all six Sensory Organization Test conditions.

The two aspects of space motion sickness (i.e. symptoms of nausea and also signs of extreme imbalance) are well documented. Do they have a common origin? In microgravity, there is no reason to suspect that canal stimuli or canal function would be radically altered by microgravity (Parker, 1998). This suggests that the sensory conflict in space motion sickness and also on earth relates to a canal-otolith conflict. The conclusion was that this conflict was responsible for postural instability and disorientation in astronauts after landing (Black et al, 
1999), and it was suggested that the otoliths also play a major role in the development of space motion sickness (Parker, 1998). It is unclear whether the symptoms of space motion sickness precede or occur after the postural instability, but the understanding has developed to the point where the balance and autonomic/visceral control centres, traditionally viewed as separated, should now be considered as one functional entity (Oman 1998). This was originally proposed by Preber (1958) who stated that " ... the symptoms [of motion sickness] are the same whether they result from the movement of ships, aircraft or cars".

While the evidence presented suggests that these symptoms arise from (and are suggestive of the presence of) peripheral balance system disease, a clinician cannot rule out other causes, as it is possible that in neurological disease, this symptom complex can occur due to central dysfunction.

Why does the high visual reliance suggested by Bronstein (1995) develop and cause the symptom set known as visual vestibular mismatch? It is now clear that the symptoms of VVM (in some people at least) are not suggestive of "neurologic damage" or "psychiatric disease". Bronstein suggested that visual reliance was the natural compensation mechanism and that visual information would now automatically dominate a situation where previously reliable vestibular information had been compromised. The probable mechanism as outlined by Mallinson and Longridge (1998) related to the fact that even under normal environmental conditions, physiological flaws in sensory systems exist. Under normal environmental circumstances, visual and vestibular information often do not match, and physiological shortcomings of one system can be looked after by the other. In the normal individual, vestibular information is regarded as the most reliable frame of reference signal (always reliable because it is referenced to gravity) and the vestibular system is most capable of accurately detecting movement within this frame of reference. For example, if a passenger is sitting in a car at a stop sign on a hill and observes movement of a car in front, the visual signal alone is incapable of determining which car is moving (i.e. "them rolling back, or me creeping forward"), because the visual signal will be identical for either situation. The advantage of the vestibular system is that it can detect the presence or absence of acceleration. If an accurate vestibular signal is incorporated into the paradigm, then it can be 
determined whether it is the individual, or the surroundings that are moving. It has been suggested that detecting the presence or absence of self movement in this way is a role of the otoliths, because as discussed earlier, disrupted processing of otolith inputs upon return from orbital flight is probably the source of postural instability of astronauts post flight (Black et al, 1999).

It is important to reiterate that Paige (1992) suggests that creation of visual vestibular mismatch occurs due to an asymmetric senescence, but the use of the term by Mallinson et al (1995), and Mallinson and Longridge (1998 [1], 1998 [2]) refers to a certain clinical situation; one where a distorted, impaired or adulterated vestibular signal is generated. The signal distortion creates a mismatch between visual environmental information and the vestibular reference signal. Our initial work has suggested strongly that the deficit is otolithic, and this thesis postulates that in the presence of an otolithic deficit, there is a decreased ability of the vestibular system to calculate self movement in an accurate manner. Under these circumstances, the visual signal is "over relied" on and, as suggested by Bronstein, the hypothesis is that in many cases visual information becomes the new "template" for maintaining stability with respect to one's environment (Mallinson and Longridge, 1998).

In addition to the well known vegetative responses related to visual vestibular mismatch, there are also other factors at play and these have been recognized, albeit not understood for some time. The symptoms of visual vestibular mismatch can involve vegetative and also postural symptoms to varying degrees. I have wondered why some patients have predominantly postural, rather than vegetative signs and symptoms. Some patients are aware of only the postural features ("I feel like I'm on a boat all the time") while some are aware of only the vegetative features ("I feel sweaty and nauseated all the time"). Again, there is a complete lack of tests to document this malfunction. Any movement in one's visual environment can potentially be interpreted as self movement, and this can create symptoms of newly developed visual vestibular mismatch in subjects who are sensitive to such signal differences. The resulting over reliance or mismatch between vestibular and visual signals can create an unsafe environment at heights, on ladders, and in other situations where good balance is necessary. In addition, it can put people at risk recreationally. For example jogging through a sunny forest with the sunlight flickering through the 
trees, jogging along a beach watching the waves roll in, or even enjoying carnival rides are examples of recreational pursuits that could cause symptoms and/or create potentially injurious situations. Sports pursuits requiring exact knowledge of body position (golf, skiing, horseback riding, basketball, badminton, among many) are all pursuits that could potentially be injurious or much less enjoyable.

In summary, these patients sometimes have signs of imbalance, but sometimes only symptoms of imbalance (patients and their family/friends often deny any noticeable imbalance). Sometimes (but not always) autonomic symptoms (motion sickness and space motion sickness) can be present. It can be seen that the symptom set (whether autonomic or just a perception of imbalance) can generate distress which could result in avoidance behaviour (hence the labeling of these patients as agoraphobics), and ironically the best advice might be a reiteration of that offered by Borde in 1547: "Such men having this passion let them beware of climbing or going up upon high hills or round stairs" (cited in Balaban and Porter, 1998).

Identifying visual vestibular mismatch requires careful history taking. While obtaining the history, it is important to ask questions specific to visual vestibular mismatch in a roundabout, indirect, non-leading manner. A nine-question questionnaire was originally developed and then refined into a set of five questions related to visual vestibular mismatch (Longridge and Mallinson, 2005) (Appendix one). This questionnaire has been introduced into the literature for guidance during history taking. Modern day patients often volunteer complaints of nausea or instability in specific visual environments such as crowds or shopping malls, and are often bothered by escalators or traffic. Mallinson and Longridge (1998)(1)) suspected that visual vestibular mismatch was not an ingrained symptom that is seen in normal people, and regarded its development de novo as being representative of balance system disease. A set of five questions was developed to delineate a patient's sensitivity, and classify them as "VVM positive" ( 3,4 or 5 positive answers) or "VVM negative" $(0$, 1 or 2 positive answers). This question set is still used in the clinical setting.

Visual vestibular mismatch is often seen in patients with work related head trauma (Longridge and Mallinson, 2005) and after whiplash type injury (Mallinson and Longridge, 1998(2)), and can also be caused by intratympanic gentamicin 
treatment for Ménière's disease (Longridge, Mallinson and Denton, 2002). It can rarely occur spontaneously without other vestibular complaints. 


\section{HYPOTHESES}

It became apparent that visual vestibular mismatch could occur in many circumstances:

- After head trauma (McCabe, 1975)

- $\quad$ Resulting from recognized ear disease (e.g. diagnosed Meniere's disease) (Longridge et al, 2002)

- After intratympanic gentamicin therapy for Meniere's disease.

- Related to other vestibular disease (e.g. acute or recurrent vestibulopathy)

- $\quad$ Spontaneously (in very rare instances)

It was also suggested that in patients with vestibular disease arising from a wide variety of causes, a common thread in a subgroup of patients from each category was that they developed the symptom set outlined as visual vestibular mismatch. I wondered if it might be seen in the whiplash population, head injury population, or in the group of patients with more traditional complaints (spinning vertigo sometimes seen in patients who have traditional vestibular disease). If this could be answered, it might be easier to make inferences about the causes of VVM. It was possible that otolithic decline might be partly responsible for the development of imbalance. A hypothesis was developed that there might be a common mechanism of damage, as the symptoms caused were identical regardless of the category of patient (i.e. a given patient could not be categorized according to their history). It was further hypothesized that the common pathogenic process involved a lesion in the balance system, and if the cause of injury could be identified, it might be possible to allege a certain mechanism of injury. This was the initial intention of the experiments discussed in my thesis. 


\section{CHAPTER THREE}

\section{Dizziness, imbalance and whiplash}

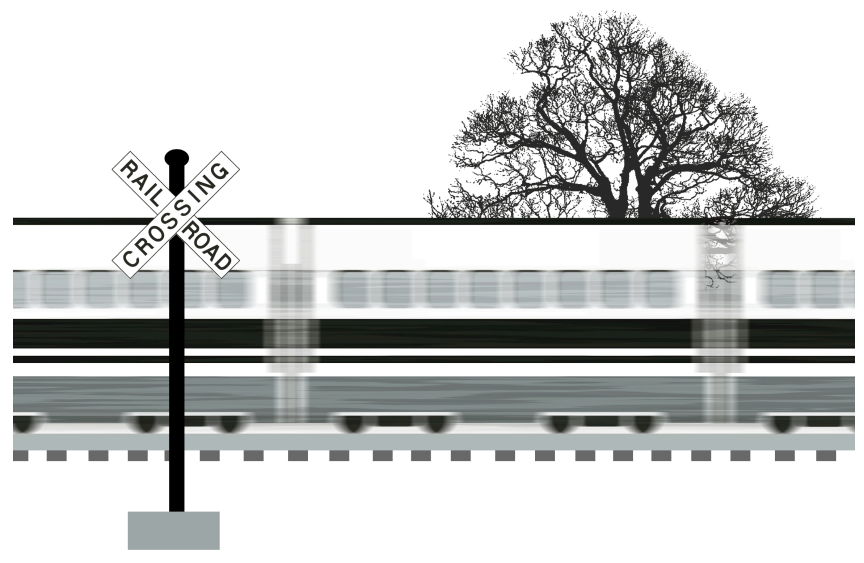

Mallinson Al, Longridge NS. Peacock C.

Journal of Musculoskeletal Pain 1996;4(4):105-112. 


\begin{abstract}
Eighteen patients were evaluated for dizziness and imbalance resulting from whiplash associated disorder. Assessment consisted of standard caloric testing and Computerized Dynamic Posturography (CDP). Although the standard vestibular tests showed no abnormalities in any of these patients, thirteen of them had abnormalities on CDP. The concept of dizziness is variously attributed to problems from the neck, brainstem or bloodflow to the brain and is ill defined in the literature. In our patients, efforts were made to delineate specifically the patient's complaints by careful history, which included anecdotal problems the patient reported that were recognized as possibly coming from the balance system of the inner ear. Dizziness may be attributable to a vestibular site of lesion, with the CDP results supporting a provisional diagnosis that somehow implicates the balance system of the inner ear.
\end{abstract}

KEYWORDS: whiplash, dizziness, imbalance, posturography 


\section{INTRODUCTION}

In a rear end collision, the body accelerates forward while the head's inertia causes it to lag behind. The resulting extension ends when the soft tissues reach their limit of tension or compression, or when the head is stopped by the headrest of the vehicle. The head then rebounds forward, resulting in a flexion process. This is the motion of so-called whiplash, and is probably associated with extension, flexion, shear, tension, compression, and possibly other features yet to be elucidated (1).

MacNab (2) showed that there was significant injury to the peri-vertebral musculature in serious whiplash injuries. Prognostic indicators appeared to be the severity of early symptoms including radicular symptomatology of the neck.

Dizziness is often mentioned as a symptom in whiplash associated disorder (WAD) $(1,3,4,5)$. The etiology of vertigo, dizziness and imbalance may be due to stretching of the ligaments in the cervical spine, irritation or damage to the vertebral arterial blood supply and damage to the autonomic nervous system in the cervical spine $(5,6)$. Damage to the inner ear is also a possibility $(1,7)$.

The incidence of dizziness in WAD has been quoted as $21 \%$ (4) to $85 \%$ (1). The aim of the present paper was to elicit from patients the specific dizzy-related complaints of which they suffer. Patients' complaints were compared to results of standardly recognized balance assessment techniques of electronystagmography (ENG) and Computerized Dynamic Posturography (CDP).

It has been observed that some patients have subjective vague complaints of lightheadedness, unsteadiness, and dislike of things moving rapidly past them, particularly in malls, supermarkets or at the edge of a busy road. Fluorescent lighting may be distressing and checkered floors may be bothersome. Visual vestibular mismatch is a recognized syndrome where it is assumed that vestibular input and ocular input do not mesh precisely, resulting in symptomatic awareness of particular difficulties. Excessive nausea and motion sickness are frequent complaints. Although dizziness often resolves, prolonged symptomatology sometimes persists. The current treatment for dizziness is 
vestibular rehabilitation exercises of the Cawthorne-Cooksey $(8,9)$ variety, but the rehabilitation process for dizziness is sometimes limited by concomitant neck pain. In more severe WAD, some patients may be incapacitated for a prolonged period and may not complain of vertiginous symptoms until several weeks after the accident, at a time when they move around enough to become aware of their difficulty. This might account for some of the short delays in apparent dizziness onset following whiplash trauma.

\section{PATIENTS AND METHODS}

This retrospective review was obtained by reviewing motor vehicle accident charts of patients seen by one investigator (NSL), including ENG and CDP data from the preceding three years. Only rear end accidents were included. Pedestrians and patients involved with side swipe or head on collisions were excluded. Patients who had a head injury were excluded. There was no random selection and no control group. Patient assessment consisted of history, otolaryngological and balance physical examination, ENG, audiometry and CDP assessment using EquiTest ${ }^{\mathrm{TM}}$ protocol. The ENG (10) protocol included assessment for spontaneous nystagmus with eyes open and eyes closed, gaze nystagmus, optokinetic nystagmus and smooth pursuit. Caloric-induced nystagmus was also assessed, including fixation suppression ratio. Postural testing as described by Barber (11) was not undertaken as it had not been found to be helpful in a study of non-traumatic vertiginous patients (12). The CDP protocol followed exactly the EquiTest ${ }^{\mathrm{TM}}$ interpretation manual (13). The Sensory Organization Test (SOT) sequence used in this protocol has been described elsewhere (14).

\section{RESULTS}

The charts of 77 patients who had sustained motor vehicle accident injuries were examined. Only 18 patients (Table 1) were pure rear end accidents. All but one were wearing a seat belt. All but one of them had sought medical attention from either their family doctor or a hospital Emergency Ward.

Computerized Dynamic Posturography was abnormal in 13 of 18 patients. In 11 of these 13 patients the abnormality was a specific pattern of abnormality which suggests impairment in the vestibular system. In particular there was poor 
performance on SOT conditions 5 and/or 6. Two patients had a more generalized abnormality pattern which we have come to assume indicates mild inability to integrate sensory information of balance.

Eight patients had characteristic vestibular syndromes (Table 1) (15): benign positional vertigo, acute vestibulopathy (vestibular neuronitis), recurrent vestibulopathy. Seven of these eight had abnormal posturography patterns, with five of the seven being specific vestibular abnormality patterns.

TABLE 1. Subject Profiles and Responses to Testing

\begin{tabular}{|c|c|c|c|}
\hline PATIENT & SUBJECTIVE COMPLAINTS & ONSET LATENCY & EQUITEST \\
\hline 1. (38F) & $\begin{array}{l}\text { spinning, lightheaded, } \\
\text { imbalance, blurred vision }\end{array}$ & $\begin{array}{l}\text { immediately after } \\
\text { \#2, signif. incr. with } \\
\text { \#3 }\end{array}$ & $\begin{array}{l}\text { abnormal } \\
\text { vestibular }\end{array}$ \\
\hline 2. $(54 \mathrm{M})$ & $\begin{array}{l}\text { feel drunk constantly, worse } \\
\text { with head movement }\end{array}$ & $<30$ days & $\begin{array}{l}\text { grossly } \\
\text { abnormal } \\
\text { nonspecific }\end{array}$ \\
\hline 3. $(33 M)$ & $\begin{array}{l}\text { nausea with head } \\
\text { movement,lightheaded }\end{array}$ & 30 minutes & $\begin{array}{l}\text { abnormal } \\
\text { vestibular }\end{array}$ \\
\hline 4. (18F) & Nausea, vague imbalance & 6 days & normal \\
\hline 5. (42F) & $\begin{array}{l}\text { unsteady, clumsy, might fall, } \\
\text { like being on a merry-go- } \\
\text { round }\end{array}$ & not known & $\begin{array}{l}\text { abnormal } \\
\text { vestibular }\end{array}$ \\
\hline 6. (60M) & $\begin{array}{l}\text { like a drunk, blurry vision, } \\
\text { feel funny in malls }\end{array}$ & 3 days & $\begin{array}{l}\text { abnormal } \\
\text { vestibular }\end{array}$ \\
\hline 7. (28F) & $\begin{array}{l}\text { spinning for a week, } \\
\text { trouble bike riding down hills }\end{array}$ & minutes & $\begin{array}{l}\text { abnormal } \\
\text { vestibular }\end{array}$ \\
\hline 8. $(46 \mathrm{M})$ & $\begin{array}{l}\text { feel seasick, } \\
\text { unsteady if I get up fast }\end{array}$ & 3 days & normal \\
\hline 9. (29F) & $\begin{array}{l}\text { "sea legs", nausea, woozy } \\
\text { imbalance, pull to left }\end{array}$ & 7-1 4 days & $\begin{array}{l}\text { abnormal } \\
\text { vestibular }\end{array}$ \\
\hline 10. (28F) & $\begin{array}{l}\text { must focus when I walk, } \\
\text { motion sickness }\end{array}$ & $<1$ day & $\begin{array}{l}\text { abnormal } \\
\text { vestibular }\end{array}$ \\
\hline
\end{tabular}




\begin{tabular}{|l|l|l|l|}
\hline 11. (45F) & $\begin{array}{l}\text { walks like a drunk, nausea } \\
\text { trouble in malls, not secure }\end{array}$ & 90 days & $\begin{array}{l}\text { abnormal } \\
\text { vestibular }\end{array}$ \\
\hline 12. (48M) & $\begin{array}{l}\text { like being on a merry-go- } \\
\text { round, nausea waves, } \\
\text { wobbly }\end{array}$ & $2-3$ days & $\begin{array}{l}\text { abnormal } \\
\text { vestibular }\end{array}$ \\
\hline 13. (39F) & $\begin{array}{l}\text { 2 one hour spells of } \\
\text { spinning, brief spins with } \\
\text { movement }\end{array}$ & $<1$ day & $\begin{array}{l}\text { abnormal } \\
\text { vestibular }\end{array}$ \\
\hline 14. (30F) & $\begin{array}{l}\text { "sea legs" } \\
\text { also lightheaded }\end{array}$ & $\begin{array}{l}\text { abnormal } \\
\text { imbalance, like looking at } \\
\text { trouble in malls and on stairs }\end{array}$ & immediate \\
\hline 15. (53F) & $\begin{array}{l}\text { whirling, eyes jiggle } \\
\text { imbalance, nausea }\end{array}$ & 1 day & normal \\
\hline 16. (49M) & $\begin{array}{l}\text { "like stepping off an } \\
\text { elevator" }\end{array}$ & $\begin{array}{l}\text { abnormal } \\
\text { spin when I look up }\end{array}$ & <estibular \\
\hline 17. (40M) & $\begin{array}{l}\text { lightheaded, nausea } \\
\text { veering, unsteady }\end{array}$ & normal \\
\hline
\end{tabular}

\section{DISCUSSION}

The concept of vestibular involvement in whiplash injury is poorly discussed in the literature pertaining to cervical spine injury. Although true vertigo is alluded to, we only heard the complaint in eight of our patients, allowing us to make a definitive diagnosis in all eight. We felt that ten patients who denied true vertigo had problems with the vestibular system as supported by the posturography results. A combination of posturography and a very careful history taking is crucial to delineate the problem as coming from the vestibular system.

Hinoki (5) found $87 \%$ of patients involved in a flexion extension injury had dizziness whereas it was a much smaller percentage in a study by Sturzenegger (4). Table 1 lists complaints voiced by patients in describing their symptoms. Previous papers, presumably for reasons of simplicity have grouped patients 
with these complaints as being dizzy, lightheaded or imbalanced. A main purpose of this paper is to draw attention to the fact that, if questioned, many patients with vestibular disease other than WAD also voice complaints mentioned in Table 1. The complaints therefore arise from an abnormality in the balance system.

Although poorly understood, it may be that the differing functions of the vestibular system are managed by discrete parts of the system. This is suggested by the fact that certain "unusual complaints" are described characteristically in a markedly similar fashion by some patients and denied by others. For instance, persistent imbalance (8/18 patients), inability to tolerate excessive optokinetic stimulation (7/18 patients), "feeling drunk" (6/18 patients), and "sea legs" (4/18 patients) are common complaints. However, attempts to delineate a common thread in these groups, or use the complaints as predictors of examination or test results have been unsuccessful.

Ten patients did not have classical vestibular syndromes but had complaints which suggested an abnormality in the balance system. Interestingly six of these patients had abnormal posturography suggestive of a vestibular abnormality pattern.

Sixteen of 18 patients showed no abnormality on ENG. There was no evidence of spontaneous nystagmus greater than $7^{\circ}$ per second, no gaze nystagmus, smooth pursuit abnormality, or optokinetic abnormality noted. There was no caloric abnormality detected in any of the patients. In two patients there was evidence of nystagmus characteristic for benign positional vertigo on position testing. These findings are in significant contradistinction to those of Oosterveld (1) who found significant ENG abnormalities in many patients who were tested after a whiplash.

Computerized Dynamic Posturography may detect abnormalities in patients with vestibular disease when ENG is normal (14). The most useful test was CDP which was abnormal in 13 of 18 patients, all but two of the 13 abnormalities showing a pattern characteristic for inner ear vestibular disease. As Chester (7) found from the legal investigative standpoint, CDP is more frequently abnormal than ENG. Computerized Dynamic Posturography shows a characteristic 
configuration for normal and abnormal. Normal CDP results occurred in our series despite symptoms of WAD.

Most dizzy patients show neutral or improved function by Cawthorne-Cooksey rehabilitation exercises. In some patients who have flexion extension injury, not only are they not improved, they may be distinctly worse. In our study two patients were symptomatically worse following these exercises. Some patients will demonstrate this in physical terms by stating that their symptoms are very severe the next day, following a day of activity.

Under normal circumstances, there are two main reflexes mediated by the vestibular system utilizing all the afferent information. The vestibulo-ocular reflex (VOR) serves to foveate an image on the back of the eye. Operation of this reflex can be indicated using a simple doll's eye maneuver. The efficiency of the reflex can be utilized using bedside testing (16) or by caloric tests. The vestibulospinal reflexes (VSR) or "righting" reflexes serve to orient a patient in space with respect to the surroundings and to earth vertical. Patients can often be separated by history as having an abnormality affecting one or the other reflex. For instance, a patient complaining solely of imbalance could be thought of having a VSR impairment, while a patient complaining of intolerance to a patterned rug or to excessive movement in the visual field could be delineated as having a VOR complaint. By this delineation, 9 of our series (50\%) had a VSR type of abnormality, 4 had a VOR problem, and 5 had features suggestive of both groups. No other differences could be found among the three groups.

While two patients had generalized abnormalities of balance on posturography, the observation of a specific abnormality pattern in SOT five and/or six in 11 of our patients with WAD allows us to speculate strongly that the inner ear may be the cause of the vestibular compromise in many of these patients, although the presence of visual vestibular mismatch could indicate the possibility of a more central component or a combination of inner ear and central disease.

If we assume that acute trauma has its clinical effects soon after application, then if the vestibular system was damaged in a whiplash event, then some dizzy type symptoms should have their presentation soon after the traumatic event. Among the 18 subjects in this study, 13 had onset within one week, five were 
delayed in onset by over seven days. Among the early onset subjects, eight had positive CDP and five negative. Among the delayed onset subjects, all five had positive CDP test results that might suggest some vestibular mechanisms for their symptoms. The delay in onset of dizziness is assumed, without proof, to be due to the fact that a patient who is markedly incapacitated becomes aware of symptoms as pain eases and mobility returns.

\section{CONCLUSIONS}

Eighteen post-whiplash patients with complaints of dizziness were retrospectively analyzed using sophisticated CDP which found a high incidence of positive findings suggestive of a vestibular disturbance. In the same patients, there was a low incidence of findings of vestibular disturbance using standard ENG. There was no correlation between positive CDP findings and early symptom onset, with many of the early onset patients having negative CDP, and all of the delayed onset having positive CDP. In most of the patients with CDP abnormalities, the pattern of abnormality suggested that the inner ear was the likely cause of the disorder. In those with a nonspecific pattern of abnormality and those with normal CDP, the site was unknown and could be central, from the inner ear, or from the neck. 


\section{REFERENCES}

1. Oosterveld WJ, Kortschot HW, Kingma GG, et al.: Electronystagmographic findings following cervical whiplash injuries. Acta Otolaryngologica Stockholm 11 1:201-205, 1991

2. MacNab I: Acceleration injuries of the cervical spine. J Bone Joint Surg 46-A:1797-1799, 1964.

3. Lee J, Giles K, Drummond P: Psychological disturbances and an exaggerated response to pain in patients with whiplash injury. J Psychosomatic Res 37(2):105-110, 1993.

4. Sturzenegger $M$, DiStefano $G$, Radanov BP, et al.: Presenting symptoms and signs after whiplash injury: the influence of accident mechanisms. Neurology 44:688-693, 1994.

5. Hinoki M. Vertigo due to whiplash injury: a neurotological approach. Acta Otolaryngologica Stockholm 419 (suppl):9-29, 1985.

6. Pfaltz CR: Vertigo in disorders of the neck. In Vertigo. Dix MR and Hood JD (Eds) 1984. John Wiley \& Sons Ltd. Chichester.

7. Chester JB: Whiplash, postural control and the inner ear. Spine 16(7): 716-720, 1991.

8. Cawthorne TE: Vestibular injuries. Proc R Soc Med (Lond) 39:270-273, 1945.

9. Cooksey FS: Rehabilitation in vestibular injuries. Proc R Soc Med (Lond) 39:273-275, 1945.

10. Barber HO, Stockwell CW: Manual of electronystagmography. $2^{\text {nd }}$ Ed.: C.V. Mosby Company. St. Louis, 1980.

11. Barber HO: Positional nystagmus especially after head injury. Laryngoscope 74:891-944, 1964.

12. Longridge NS, Barber HO: Bilateral paroxysmal positioning nystagmus. J. Otol. 7(5):395-400, 1978.

13. Neurocom International Inc. EquiTest Interpretation Manual 1992. Neurocom International, Clackamas, OR. 
14. Lipp M, Longridge NS: Computerized Dynamic Posturography: its place in evaluation of the patient with dizziness and imbalance. J Otolaryngology 23(3):177-183, 1994.

15. Longridge NS, Robinson RG: Approach to the patient with dizziness and vertigo. In Textbook of Internal Medicine, Kelley WN (ed). $2^{\text {nd }}$ edition, 1992: JB Lippincott, Philadelphia.

16. Longridge NS, Mallinson Al: A discussion of the Dynamic Illegible "E" Test. A new method of screening for aminoglycoside ototoxicity. Otol Head Neck Surg 92(6):671-677, 1984. 


\section{CHAPTER FOUR}

Specific vocalized complaints in whiplash and minor head injury patients

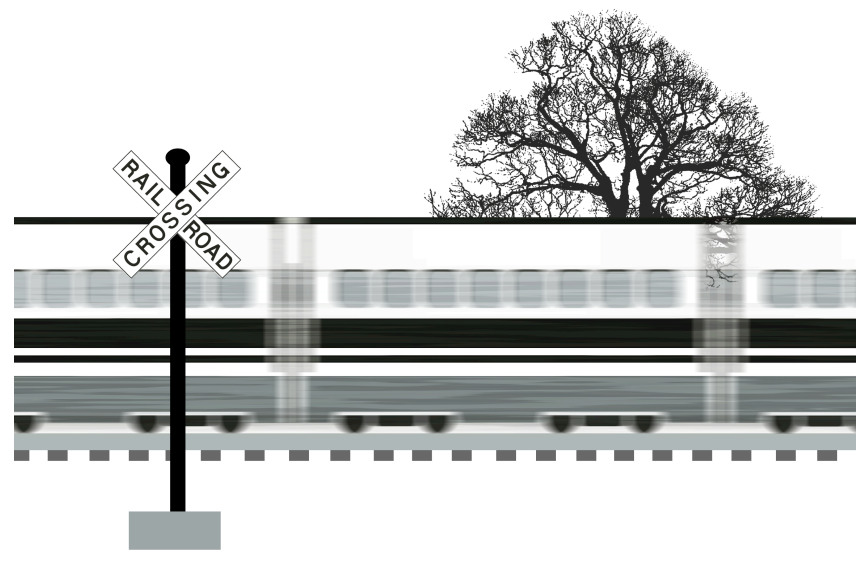

Mallinson, Al, Longridge NS.

Am J Otol 1998;20(4):809-813. 


\section{ABSTRACT}

Objective: Subtle complaints of visual-vestibular mismatch may not be elicited in an initial history-taking. Clinicians must be familiar with the nature of these complaints when assessing whiplash patients because other injuries may predominate and patients do not volunteer these more subtle complaints, which may be persisting and sometimes debilitating.

Study Design: A retrospective case review was performed.

Setting: The study was conducted at a tertiary/quaternary referral clinic.

Patients: Patients with whiplash, mild head injury, or both were referred for assessment of symptoms persisting for at least 2 years after their injury.

Interventions: A full history; otolaryngologic examination; including assessment of eye movements, corneal reflexes, and gait; investigation including electronystagmography and computerized dynamic posturography; and history-taking and detailed recording of related complaints were performed immediately before diagnostic workup.

Main Outcome Measures: Many patients had more subtle complaints, which we now recognize as indicative of vestibular pathology, that have not previously been described in detail in the literature and are often generalized using terms such as "dizziness" or "lightheadedness." It is important to take a detailed history from these patients to delineate their more subtle complaints, because their symptoms frequently do not "fit" into traditional syndromes.

Results: Complaints verbalized by patients were tabulated. On more careful analysis, they can be identified as arising from a mismatch between vestibular information and other sensory information used to maintain balance.

Conclusions: Many patients with the standard vestibular syndromes have the same subtle complaints (apart from the standard vertiginous complaints) that patients with whiplash and minor head injury verbalize. The similarity of the complaints in the two groups indicates that the subtle symptoms are caused by underlying vestibular disease.

KEYWORDS: whiplash, dizziness, imbalance, head injury 
Patients with either whiplash injury (correctly called "whiplash-associated disorder" or "WAD") or mild head injury (also referred to as "mild traumatic brain injury") often have dizziness. This report, the first of two, delineates complaints voiced by these patients and legitimizes them as being organic. Patients with known organic vestibular disease, such as Meniere's disease, vestibular neuronitis, or recurrent vestibulopathy voice standard complaints of vestibular dysfunction; however, on direct questioning, they will often report more subtle symptoms, similar to those described by our patients with whiplash. These complaints are described in this paper, and the patients are studied in detail in the second paper. The physical abnormalities in these patients and the consistency of our findings strongly suggest that their complaints have an underlying organic basis.

Although not analyzed separately in this paper, the patients in our second paper were grouped into 2 groups: those with "whiplash only" and those with "mild head injury." Patients with whiplash without a blow to the head, apart from contact with a headrest, represent a separate group from the patients who also had head injury that met the criteria of mild head injury as originally outlined by Jane (1) and defined precisely by Kay et al. (2). Mild head injury or mild traumatic brain injury is defined as injury with one or more of the following symptoms: loss of consciousness (LOC) for less than 30 minutes, posttraumatic amnesia measured at 24 hours or less, Glasgow Coma Score between 13 and 15 at the 30-minute mark after injury, change in mental state, and neurologic deficits on examination. Mild head injury has also been subcategorized by Jane (1) into 4 grades of severity: grade 0 , patients are struck in the head but not stunned (usually seen in athletes); grade 1, people who are momentarily stunned but report no LOC or amnesia; grade 2, concussion results in altered sensation for more than a minute and clouding but no LOC; grade 3, LOC for less than a minute; and grade 4, LOC for more than 1 minute but without coma.

The Quebec Task Force on flexion and extension injury (3) reviewed over 10,000 papers on the subject of whiplash-associated disorder. Many of the papers were classified by the task force as anecdotal case reports and only 294 had scientific data about whiplash. Of these, only 62 were deemed to be scientifically acceptable and clinically relevant. The task force encouraged 
evidence-based studies on whiplash-associated disorder and called for a collaborative effort in treatment and research.

We have assessed a number of patients who have had dizziness associated with either whiplash or minor head injury. After reviewing the literature (4-10), it was clear that when patients reported traumatic dizziness, this symptom was classified using limited terms, such as "dizziness," "lightheadedness," or "imbalance."

This introductory paper describes the types of complaints that patients with traumatic dizziness report. These complaints have not previously been described in detail, but are characteristic of dysfunction affecting the two reflexes subserved by the vestibular system: the vestibulo-ocular reflex (VOR) and the vestibulospinal reflex.

Complaints of dizziness are usually self-limiting. Pearce (10) found that $70 \%$ of patients with whiplash and dizziness had their symptoms settle within 6 months of the injury. The remaining patients with persistent symptoms were likely to have them on a long term basis.

The aim of this paper was to tabulate patients' complaints after WAD or mild head injury. Although the most common complaints were imbalance and vertigo, some patients reported difficulty identifying motion of self or surroundings. Other patients described feeling as if they are falling or increased susceptibility to motion sickness.

\section{PATIENTS AND METHODS}

Patients in this study were referred for assessment of symptoms of dizziness persisting for at least 2 years after a whiplash injury or minor head injury from a motor vehicle accident ("rear ending," lateral, or head-on accidents). None of the injuries in these patients were worse than a grade 3 mild head injury, defined as LOC for less than a minute.

During assessment, patients had a full history-taking and otolaryngological examination, including assessment of eye movements, corneal reflexes, and gait. They also underwent electronystagmography and Computerized Dynamic Posturography, and a careful vestibular history was taken. Patients were 
excluded if they had not completed clinical assessment, including electronystagmography and Computerized Dynamic Posturography.

\section{RESULTS}

Two patients were excluded because they had not completed clinical assessment. Thirty-six charts were retrospectively analyzed. Specific symptoms reported by the patients were tabulated (Table 1). Table 2 compares the complaints of patients who had only whiplash to those of patients who also had minor head injury. Complaints are very similar between groups; imbalance, nausea and vomiting, and a worsening of symptoms with head movement were reported equally by members of both groups. However, in the group with only whiplash, specific vertiginous complaints were much more common than in the group with whiplash and head injuries.

\section{DISCUSSION}

Patients who have dizziness after whiplash, mild head injury, or both frequently do not have acute vertiginous symptoms that specifically indicate any of the traditionally recognized vestibular syndromes. Their complaints are often more nonspecific and, in the literature, have been variously classified as lightheadedness, vertigo, or imbalance without any definition of these terms or any clear understanding of the pathophysiology. Our patients consistently report symptoms that are not ordinarily reported by patients with acute vertigo. Patients will describe subtle feelings of movement of self or surroundings, awareness of imbalance, and physical disorientation. These complaints represent the chronic manifestation of ongoing problems and are legitimate and organic, not anxiety-based or psychogenic, which are often the ascribed causes in patients with vague complaints that cannot clearly be categorized.

What is the relationship between whiplash injury, visual-vestibular mismatch, dizziness, and imbalance? The concept of visual-vestibular mismatch, or "visual vestibular conflict" (11), is particularly important to persons who have reduced tolerance to any such conflict, resulting in motion sickness. The VORs are responsible for producing compensatory eye movements in space. These reflexes are also responsible for the generation of the linear VOR (LVOR), including translational LVORs that act at higher frequencies in response to horizontal eye movements in response to movements of the head on the 
interaural axis. Vertical LVORs respond to dorsoventral movements, and horizontal and vertical LVORs respond to nasooccipital axis motion of the head (12). This LVOR behaves according to the kinematic requirements of compensatory eye movements during linear motion, and it augments visually driven ocular following information, sometimes referred to as "optic flow" (12).

The etiology of motion sickness is widely believed to be conflicting efforts of the visual and vestibular systems to stabilize images (13). The effects of this mismatch, initially proposed by Reason (14) to result from a neural mismatch, can be devastating in everyday life, as evidenced by patients with extreme motion sickness. It does not result from retinal slip generated by decreased VOR gain (because the blind can also become motion sick); rather, it appears that "motion-sickness provoking" environments may be generated by inadvertent egocentric motor activity (concentrating on a body frame of reference rather than the external world) (15). The symptoms may be provoked as a warning device resulting from an inadequate representation of this ego-spatial relationship in the brain (16).

A similar mismatch or visual-vestibular conflict may also be responsible for mal de debarquement syndrome, or illusion of motion after sailing ("sea legs") (11). However, why there is such a wide variation in susceptibility to motion sickness or an intolerance for visual-vestibular mismatch among persons is not known. Although there is some evidence that this is correlated with higher VOR gain (17), the only effective medication for treating the symptoms does not seen to affect VOR gain (13). Nevertheless, many people are not affected by visualvestibular mismatch, although others are unable to read a map or change a radio station in a moving car.

There are many other situations that lead directly to an acute change in vestibular response, and the resulting visual-vestibular mismatch can cause the same symptomatic reaction. These might include cases of vestibular pathology (15). Therefore, sensitive patients could be rendered markedly symptomatic by even minimal vestibular lesions, which is a situation we encounter repeatedly in our clinic. Although some studies have suggested a possible correlation between the level of caloric response and susceptibility to motion sickness (reviewed in 17), experience in our laboratory has not supported this hypothesis. 
Neck muscle activations are abnormal or absent in patients with vestibular loss, implying that the vestibulocollic system plays a large role in head stabilization. These neck reflexes can partially compensate for the vestibular system to provide head and trunk stabilization (18). Moreover, sensory information from the neck could substitute for vestibular information in patients with vestibular loss. Stabilization of head position during postural movements relies not exclusively on vestibular and neck reflexes, but on the entire action of the entire postural control system. Therefore, any injury to the neck also has the potential to cause a cervico-vestibular mismatch, and, in particularly sensitive patients, this could be a corollary of motion sickness. The symptoms would include sensations of drunkenness, "sea legs," or vague unsteadiness. Of note, almost half of our patients with only whiplash also reported true spinning, markedly similar to complaints of patients with classic ear disease. These "traditional" voiced complaints do not necessarily suggest true semicircular canal pathology.

Only one of our patients with head injury reported true spinning; the predominant complaint in this group was unsteadiness, perhaps indicating that the head injury caused a subtle central vestibular (as opposed to peripheral vestibular) lesion. Many physicians are unfamiliar with assessing patients with this type of disease and with recognizing the vague but genuine complaints these patients have. Visual-vestibular mismatch (or cervico-vestibular mismatch) is often difficult to recognize, even after a careful history is taken. In the patient with whiplash, other complaints, which may include acute vertigo or many other possible symptomatic complaints, are often so overwhelming that the minor complaints described in this paper are ignored by the patient unless his or her physician specifically inquires about them. 


\section{Table 1. Vocalized complaints in whiplash and minor head injury patients}

\begin{tabular}{|c|c|c|}
\hline Patient & Age/Sex & Voiced complaints \\
\hline 1 & $54 \mathrm{M}$ & $\begin{array}{l}\text { Like being on a boat pitching in the water } \\
\text { Balance poor, worse if he bends over }\end{array}$ \\
\hline 2 & $36 M$ & $\begin{array}{l}\text { Imbalance, out of focus, eyes jiggle, bad on } \\
\text { ladders } \\
\text { Can't ride bicycle or catch a ball }\end{array}$ \\
\hline 3 & $18 \mathrm{~F}$ & $\begin{array}{l}\text { Whirling, unsteady on feet } \\
\text { Vomiting }\end{array}$ \\
\hline 4 & $28 M$ & $\begin{array}{l}\text { Imbalance leaning forward } \\
\text { Feels like he is falling backwards when he jumps } \\
\text { up }\end{array}$ \\
\hline 5 & $25 \mathrm{~F}$ & $\begin{array}{l}\text { Maximum } 15 \text { minute tolerance in busy store } \\
\text { Spinning spells, nausea from walking around her } \\
\text { office }\end{array}$ \\
\hline 6 & $37 \mathrm{M}$ & $\begin{array}{l}\text { Severely unsteady for six weeks } \\
\text { Still improving gradually }\end{array}$ \\
\hline 7 & $15 \mathrm{~F}$ & $\begin{array}{l}\text { Two spinning spells per day } \\
\text { Unsteady, nauseated, now carsick }\end{array}$ \\
\hline 8 & $34 \mathrm{~F}$ & $\begin{array}{l}\text { Had spinning spells lasting hours for first month } \\
\text { Positional dizziness for } 4 \text { years }\end{array}$ \\
\hline 9 & $58 M$ & $\begin{array}{l}\text { Initial attacks for } 2 \text { to } 3 \text { hours } \\
\text { Off balance, rehab exercises made worse }\end{array}$ \\
\hline 10 & $19 \mathrm{~F}$ & $\begin{array}{l}\text { Spinning spells usually lasting seconds to minutes } \\
\text { Some as long as an hour }\end{array}$ \\
\hline 11 & $53 M$ & $\begin{array}{l}\text { Spinning spells lasting } 30 \text { seconds, three spells of } 1 \\
\text { to } 2 \text { days Balance not what it used to be }\end{array}$ \\
\hline 12 & $50 \mathrm{~F}$ & $\begin{array}{l}\text { Falls forward } \\
\text { Spells of positional spinning }\end{array}$ \\
\hline 13 & $33 \mathrm{~F}$ & $\begin{array}{l}\text { Unsteady on feet, can't carry coffee, escalators } \\
\text { bad } \\
\text { Sits in shower, thinks she is still when car moving }\end{array}$ \\
\hline
\end{tabular}




\begin{tabular}{|c|c|c|}
\hline 14 & $42 \mathrm{~F}$ & $\begin{array}{l}\text { Unsteady in the dark, also spinning lasting } \\
\text { seconds } \\
\text { Queasy after driving for } 1 \text { hour }\end{array}$ \\
\hline 15 & $42 \mathrm{~F}$ & $\begin{array}{l}\text { Vomiting with head movement for } 3 \text { days } \\
\text { Positional spinning recurred } 1 \text { year later }\end{array}$ \\
\hline 16 & $19 \mathrm{~F}$ & $\begin{array}{l}\text { Spells of imbalance for minutes } \\
\text { Made worse by stress }\end{array}$ \\
\hline 17 & $40 \mathrm{M}$ & $\begin{array}{l}30 \text { second spells of spinning after fast head } \\
\text { movements } \\
\text { Rehab exercises made worse }\end{array}$ \\
\hline 18 & $38 \mathrm{~F}$ & $\begin{array}{l}\text { Blurry vision, spinning with nausea and vomiting } \\
\text { Imbalance, also lightheaded }\end{array}$ \\
\hline 19 & $54 \mathrm{M}$ & $\begin{array}{l}\text { Feels drunk all the time } \\
\text { Any head movement worsens feeling }\end{array}$ \\
\hline 20 & $33 \mathrm{M}$ & $\begin{array}{l}\text { Nausea on head movement } \\
\text { Lightheaded, off balance with eyes closed }\end{array}$ \\
\hline 21 & $18 \mathrm{~F}$ & $\begin{array}{l}\text { Nausea } \\
\text { Off balance }\end{array}$ \\
\hline 22 & $42 \mathrm{~F}$ & $\begin{array}{l}\text { Unsteady, clumsy, feels like she might fall } \\
\text { Like being on a merry-go-round }\end{array}$ \\
\hline 23 & $60 \mathrm{M}$ & $\begin{array}{l}\text { Blurry vision, like being drunk } \\
\text { Feels funny in shopping malls }\end{array}$ \\
\hline 24 & $28 \mathrm{~F}$ & $\begin{array}{l}\text { Spinning for first week } \\
\text { Has trouble riding a bike down a hill }\end{array}$ \\
\hline 25 & $46 \mathrm{M}$ & $\begin{array}{l}\text { Seasick feeling } \\
\text { Unsteady if he gets up quickly }\end{array}$ \\
\hline 26 & $29 \mathrm{~F}$ & $\begin{array}{l}\text { Nausea, woozy, imbalance all the time } \\
\text { Like sea legs, pulls to the left }\end{array}$ \\
\hline 27 & $28 \mathrm{~F}$ & $\begin{array}{l}\text { Nausea, has to focus when she walks } \\
\text { Newly developed motion sickness }\end{array}$ \\
\hline 28 & $45 \mathrm{~F}$ & $\begin{array}{l}\text { Not secure on feet, made worse by exertion } \\
\text { Walks like a drunk }\end{array}$ \\
\hline 29 & $48 \mathrm{M}$ & $\begin{array}{l}\text { Wobbly, unsteady, like being on a merry-go- } \\
\text { round } \\
\text { Newly developed motion sickness, worse with } \\
\text { head movement }\end{array}$ \\
\hline
\end{tabular}




\begin{tabular}{|c|c|l|}
\hline 30 & $39 \mathrm{~F}$ & $\begin{array}{l}\text { Two spells of nausea and vomiting } \\
\text { Spinning from getting out of bed }\end{array}$ \\
\hline 31 & $30 \mathrm{~F}$ & $\begin{array}{l}\text { Like sea legs } \\
\text { Lightheadedness }\end{array}$ \\
\hline 32 & $53 \mathrm{~F}$ & $\begin{array}{l}\text { Imbalance, worse on stairs and in shopping malls } \\
\text { Feels like when you are watching water move }\end{array}$ \\
\hline 33 & $49 \mathrm{M}$ & $\begin{array}{l}\text { Whirling, nausea and vomiting, worse turning to } \\
\text { the right } \\
\text { Eyes jiggle, unsteady on feet all the time }\end{array}$ \\
\hline 34 & $40 \mathrm{M}$ & $\begin{array}{l}\text { Newly developed motion sickness, disoriented by } \\
\text { cycling } \\
\text { Unsteady with eyes closed }\end{array}$ \\
\hline 35 & $33 \mathrm{~F}$ & $\begin{array}{l}\text { Veering, unsteady } \\
\text { Like you just stepped off an elevator }\end{array}$ \\
\hline 36 & $37 \mathrm{M}$ & $\begin{array}{l}\text { Feels like his car is still moving when stopped } \\
\text { Can't judge distances, constant imbalance }\end{array}$ \\
\hline
\end{tabular}


Table 2. Frequency of patients' voiced complaints

\begin{tabular}{|l|l|l|}
\hline & \multicolumn{1}{|c|}{$\begin{array}{c}\text { WAD only } \\
(\mathbf{n = 1 9 )}\end{array}$} & $\begin{array}{c}\text { WAD and HI } \\
(\mathbf{n = 1 7 )}\end{array}$ \\
\hline Imbalanced/unsteady & $11(58 \%)$ & $11(65 \%)$ \\
\hline Nausea \pm vomiting & $6(32 \%)$ & $7(41 \%)$ \\
\hline Spinning (true vertigo) & $9(47 \%)$ & $1(6 \%)$ \\
\hline Increased symptoms with head movement & $5(26 \%)$ & $3(18 \%)$ \\
\hline Newly motion sick & $2(11 \%)$ & $3(18 \%)$ \\
\hline Benign positional vertigo & $3(16 \%)$ & $1(6 \%)$ \\
\hline Dislike of malls & $1(5 \%)$ & $2(12 \%)$ \\
\hline Lightheadedness & $1(5 \%)$ & $2(12 \%)$ \\
\hline Blurred vision & $2(11 \%)$ & $6(6 \%)$ \\
\hline Difficulty riding bike & $1(5 \%)$ & $2(12 \%)$ \\
\hline
\end{tabular}

WAD—whiplash-associated disorder; HI—head injury

\begin{tabular}{|l|c|}
\hline Other isolated complaints & Frequency \\
\hline Made worse by stress & 2 \\
\hline Like being drunk & 2 \\
\hline Like a merry-go-round & 2 \\
\hline Like sea legs & 2 \\
\hline Feels like falling & 2 \\
\hline Rehab made worse & 2 \\
\hline Eyes jiggle & 2 \\
\hline Still car feels like moving & 1 \\
\hline Like a boat pitching & 1 \\
\hline Dislike escalators & 1 \\
\hline Unsteady in dark & 1 \\
\hline Poor judge of distance & 1 \\
\hline Can't catch a ball & 1 \\
\hline Trouble on ladders & 1 \\
\hline Falls forward & 1 \\
\hline Can't carry coffee & 2 \\
\hline
\end{tabular}




\section{REFERENCES}

1. Jane JA. Mild to moderate head injury. Definitions. In: Hoff JT, Anderson TE, Cole TM, eds. Mild to moderate head injury. Contemporary issues in neurological surgery. Boston: Blackwell Scientific Publications. 1989:1-8.

2. Kay T, Harrington DE, Adams R, et al. Definition of mild traumatic brain injury. J Head Trauma Rehabil 1993;8:86-8.

3. Spitzer WO, Skovro ML, Salmi MR, et al: Scientific monograph of the Quebec Task Force on whiplash-associated disorders: redefining whiplash and its management. Spine 1995;20 (Suppl):1S-73S.

4. Oosterveld WJ, Kortschot HW, Kingma GG, et al. Electronystagmographic findings following cervical whiplash injuries. Acta Otolaryngol (Stockh) 1991;111:201-5.

5. Rubin W. Whiplash with vestibular involvement. Arch Otolaryngol 1973:97:85-7.

6. Sturzenegger M, DiStefano G, Radanov BP, et al. Presenting symptoms and signs after whiplash injury: the influence of accident mechanisms. Neurology 1994;44:688-93.

7. Hinoki M. Vertigo due to whiplash injury: a neurotological approach. Acta Otolaryngol (Stockh) 1985;419 (Suppl):9-29.

8. Pfaltz CR. Vertigo in disorders of the neck. In: Dix MR, Hood JD, eds. Vertigo. Chichester: John Wiley \& Sons, 1984:179-97.

9. Chester JB. Whiplash, postural control and the inner ear. Spine $1991 ; 16: 716-20$.

10. Pearce JMS. Whiplash injury: a reappraisal. J Neurol Neurosurg Psychiatry 1989;52:1329-31.

11. Cohen H. Vertigo after sailing a nineteenth century sailing ship. J Vestib Res 1996:6:35-5.

12. Tomko DL, Paige GD. Linear vestibuloocular reflex during motion along axes between nasooccipital and interaural. In: Cohen B, Tomko DL, 
Guedry F. eds. Sensing and controlling motion: vestibular and sensorimotor function. Ann N Y Acad Sci 1992;656:233-41.

13. Schultheis LW, Robinson DA. The effect of scopolamine on the vestibuloocular reflex, gain adaptation, and the optokinetic response. In: Cohen B, Tomko DL, Guedry F. eds. Sensing and controlling motion: vestibular and sensorimotor function. Ann N Y Acad Sci 1992;656:880-3.

14. Reason JT. Motion sickness adaptation: a neural mismatch model. J R Soc Med 1978;71:819-29.

15. Watt DGD, Bouyer LJG, Nevo IT, et al. What is motion sickness? In: Cohen B, Tomko DL, Guedry F. eds. Sensing and controlling motion: vestibular and sensorimotor function. Ann N Y Acad Sci 1992;656:660-7.

16. Takahashi M, Ogata M, Miura A. The significance of motion sickness in the vestibular system. J Vestib Res 1997:7:179-87.

17. Gordon CR, Spitzer O, Doweck I, et al. The vestibulo-ocular reflex and seasickness susceptibility. J Vestib Res 1996;6:229-33.

18. Shupert $\mathrm{CL}$, Horak FB. Effects of vestibular loss on head stabilization in response to head and body perturbations. J Vestib Res 1996;6:423-37 


\section{CHAPTER FIVE}

Dizziness from whiplash and head injury: differences between whiplash and head injury

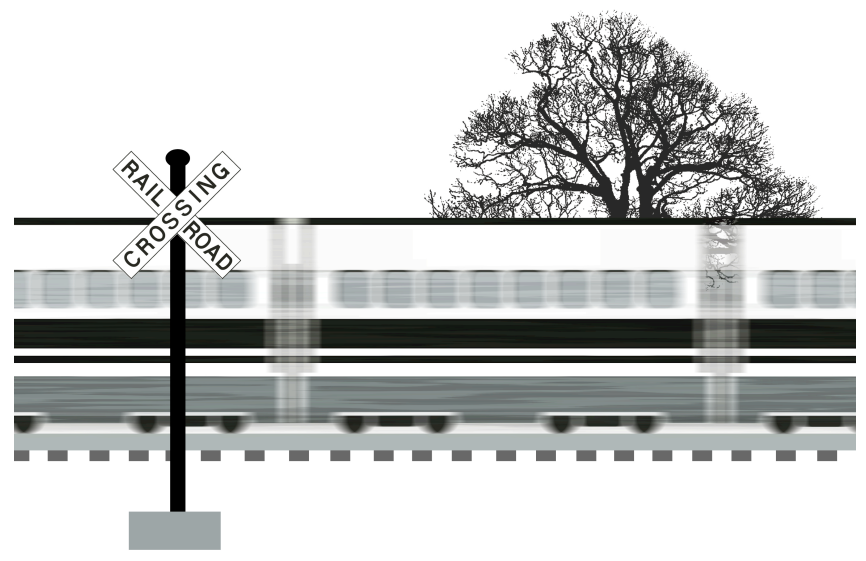

Mallinson, Al, Longridge NS.

Am J Otol 1998;20(4):814-818. 


\section{ABSTRACT}

Objective: Large discrepancies exist in the literature regarding incidence and types of symptomatology in whiplash. This is because of the evolution of whiplash injury over the years with the advent of head rests and seat belts. Previous authors have regarded symptoms of dizziness as a result of brainstem or cerebellar injury or both. It has been difficult in those studies to ascribe a mechanism of injury, as patients with whiplash injury only have been grouped with those who have incurred mild traumatic brain injury as a result of a significant blow to the head. The authors saw the need to delineate patients who had suffered whiplash injury from those who also had suffered mild head injury, as defined in the rehabilitation-neurosurgical literature, to attempt to define differences in symptoms, abnormalities, and mechanisms of recovery in these two groups.

Study Design: The study design was a retrospective case review.

Setting: The study was conducted at a tertiary-quaternary referral clinic.

Patients: The records of 36 patients were reviewed. Nineteen of these patients suffered a whiplash-associated disorder and 17 suffered a mild head injury as well. These patients were referred for assessment of symptoms persisting for at least 2 years after their injury. Patients were excluded if they had not completed clinical assessment, including electronystagmography (ENG) and Computerized Dynamic Posturography (CDP).

Interventions: A full history, otolaryngologic examination, including assessment of eye movements, corneal reflexes and gait, as well as an investigation, including ENG and CDP, and history taking and detailed recording of related complaints immediately before diagnostic work-up were performed.

Main Outcome Measures: Symptoms reported by patients who had received either whiplash alone or whiplash plus mild head trauma as defined in the literature were measured. Patients were classified according to type of accident, type of injury suffered, and degree and nature of posturographic abnormalities.

Results: Patients often have similar complaints regardless of whether or not they had suffered a brain injury. Although CDP showed abnormalities in both groups, 
standard ENG assessment, including caloric testing, showed abnormalities only in the head-injured group. The posturographic abnormalities also were analyzed in both groups, and it was found that there was a correlation between the type of posturographic abnormality and the type of injury suffered. Although ENG testing is done routinely, posturography is shown to be more sensitive in picking up abnormalities. In addition, the authors have shown that posturography can delineate the type of injury suffered by exhibiting the compensation strategy used as well as the efficacy of that compensation strategy.

Conclusions: Because ENG abnormalities are limited to patients who have suffered a head injury, the inference is that these two groups of patients have suffered damage at different sites along the balance system pathways, but both of these lesions can lead to similar symptoms. Although the mechanisms of whiplash injury and how they affect the vestibular system are poorly understood, posturography testing is essential in inferring how a patient is recovering by measuring how and how well the patient is overcoming his or her deficit. This has important medical legal implications regarding legitimizing a patient's problem, prognostic factors, as well as rehabilitation plans, measures, and outcomes.

KEYWORDS: posturography, compensation, whiplash, head injury, dizziness 
Dizziness as a whiplash-associated disorder due to flexion-extension injury is common. Numerous articles have described this disorder. These go back to the classic article by MacNab (1), whose interpretation of the term "whiplash" differed from that of the current day. Patients in his study suffered gross movement of the neck to the point at which the head could touch the thoracic spine during the hyperextension process. In his study (published in 1964), symptoms resulting from a lateral collision appeared to be milder than most of those occurring after a rear-end collision. Modern-day whiplash results from hyperextension of the neck, which is arrested by the impact of the head on the head restraint, followed by a flexion process, which is altered by the seat belt that serves to restrain the body. As a result, lateral accidents, in which the head movement is not damped by a restraint, may now inflict more severe injury than rear-ending collisions.

It is not surprising that over the years, there have been large discrepancies in the incidence and types of symptomatology related to whiplash injury. Hinoki (2) describes the T-bone accident, in addition to the rear-ending accident, and classified symptoms suffered in both types of accidents as having the same pathologic origin. However, it is unclear whether his patients had head rests. He reported that $85 \%$ of the patients suffered "dizzy" symptoms, without defining his use of this term. No mention is made of direct head trauma in this study. The reader is left to assume that none of the patients suffered a head blow in the accident other than from the head rest. Oosterveld et al. (3) describe $85 \%$ of the patients with whiplash as reporting "some type of vertigo." These symptoms included floating feelings and lightheadedness, but they did not ascribe a site to the lesion causing these symptoms. Oosterveld et al. inferred pathology to the cervical muscular system in $64 \%$ of the patients studied and "proved the presence of both brainstem and cerebellar pathology" in $43 \%$ of the patients. Sturzenegger et al. (4) indicated that a short latency before onset of symptoms was prognostically bad and regarded vertigo and imbalance as caused by brainstem injury. Although Oosterveld offered pursuit abnormalities as evidence of both brainstem and cerebellar pathology, Sturzenegger gave no clear evidence as to how he reached his conclusion. Sturzenegger also noted that head restraints might reduce neck symptomatology somewhat but not 
dramatically and also commented that the speed of the cars at the time of the accident appeared to bear little relevance to the patient's symptoms.

Probably another reason for the discrepancies in symptomatology seen in the literature is that patients with whiplash and those who incur a significant blow to the head are lumped together. Rubin et al. (5) studied a group of patients who had suffered a closed head injury or a whiplash injury. They did not delineate between these two seemingly differing traumas. No study that we have found has particularly delineated patients suffering from whiplash only and those suffering head injury at the same time.

As discussed in our companion article, both groups of patients often report similar symptoms, and the characteristic symptoms they describe are attributable to disruption of one or more of the vestibular reflexes. However, despite the striking similarities in their stories, it still follows that they have suffered injuries to different structures and, in addition, it seems that they might use different mechanisms of compensation or recovery from their injuries.

Compensation for balance system damage has been investigated extensively both from the point of view of the physiologic mechanisms involved as well as from the point of view of the practical aspects of vestibular rehabilitation. A basic tenet of compensation developed by Bronstein (6) is that there is a dominant role of vision in the maintenance of posture. In the absence of the vestibular "template" proposed by Nashner and McCollum (7) (against which all other sensory information is compared and either used or disregarded), there is a dogmatic dependence on visual information to keep balance. This "visual preference strategy" can be delineated with Computerized Dynamic Posturography (CDP). Unfortunately, in everyday life, there are some patients in whom this preference has its drawbacks. Some patients have an intolerance for any discongruency between visual and vestibular signals. This "visual-vestibular mismatch" (VVM) was originally described by Paige (8), and Mallinson et al. (9) regard the development of VVM as indicative of vestibular pathology. Patients who have VVM have symptoms develop that are annoying in everyday life. Compensation for vestibular injury classically entails enlisting visual information, which usually is given hierarchical preference over proprioceptive input unless the visual information is deficient or unreliable or is seen to have been compromised in some way (6). This study set out to determine whether patients 
with whiplash-associated disorder only had findings different from those who had mild head injury.

\section{METHODS}

A retrospective study of our 36 patients with dizziness after a motor vehicle accident (MVA) was undertaken. This included analysis of CDP and standard electronystagmography (ENG) assessment. These patients were long-term sufferers (>2 years) of complaints characteristic of a disorder of the balance system. During patient assessment, it was determined whether, in addition to the whiplash injury, the patient had incurred a blow to the head apart from impact with the head rest. Patients were excluded if their head injury was too severe to meet the definition of mild traumatic brain injury $(10,11)$.

\section{RESULTS}

Dizziness developed in one patient 2 years after his MVA. It came on after temporomandibular joint surgery for jaw pain induced by his whiplash injury. He was excluded from the study.

Our study divided accidents into six types (Table 1). The type of accident (rear end, T-bone, or head-on) made little difference to the patient's presenting complaints, but the presence or absence of mild head injury (criteria for mild head injury are outlined in our companion article) was discovered to be important with respect to abnormalities found on standard investigation. As a result, patients were separated into "head injured" and "whiplash only" groups. Twenty-seven patients in all had abnormal CDP patterns. The CDP abnormality patterns in the two groups were examined (Table 2).

Of 21 patients who did not suffer a head injury in their MVA, 19 suffered whiplash only (Type A). In none of the 19 was a standard, recognized ENG abnormality detected, and none had a caloric reduction. However, CDP testing showed abnormalities in 15 (79\%) of 19 patients. 


\section{TABLE 1. Legend of motor vehicle accident types}
A. Rear end accident with whiplash and no head injury (19)
B. Rear-end accident with whiplash and head injury (5)
C. T-Bone or sideswipe accident with whiplash and no head injury (-)
D. T-bone or sideswipe accident with whiplash and head injury (7)
E. Head-on accident with whiplash and no head injury (2)
F. Head-on accident with whiplash and head injury (3)

In 10 of the 15 patients, the abnormality was a standard, recognized vestibular pattern, whereas in 5 patients, there were nonspecific abnormalities (12).

Twelve patients had a T-bone or head-on MVA, and only 2 of these patients did not suffer a head injury. Both of these had normal ENG and CDP results. Fifteen patients studied suffered a mild head injury. Five (33\%) of the 15 patients had a caloric abnormality and $3(20 \%)$ had central ENG findings. Twelve (80\%) of the 15 patients had CDP abnormalities. Nine of these abnormalities were characteristically vestibular. To study the nature of the CDP abnormalities, these abnormalities were broken down into four groups, all of which are delineated by Nashner in the interpretation manual (12):

- Group 1: Classic vestibular abnormalities (sensory organization test 5 or 6 down pattern or both). Ten of the patients fell into this group, 6 of whom were in the head-injured group. This CDP pattern suggests the presence of some type of vestibular deficiency.

- Group 2: Somatosensory-preferenced abnormalities (sensory organization tests 4,5 , and 6 down patterns). Six patients fell into this group, all of whom had whiplash only. These patients exhibit a strong somatosensory dependence and cannot make effective use of either vestibular or visual inputs in the absence of a stable surface (12).

- Group 3: Visually preferenced abnormalities (sensory organization tests 3, 5, and 6 down patterns). Three patients fell into this group, all of whom had had head injuries. These patients are destabilized by orientationally inaccurate visual stimuli. 
- Group 4: Nonspecific abnormalities (none of the above patterns but abnormal CDP performance). Eight of our patients fell into this group, three of whom had had head injuries.

Table 2. Computerized dynamic posturography (CDP) abnormality patterns

\begin{tabular}{|c|c|c|c|}
\hline Patient & Age/Sex & CDP Abnormality & $\begin{array}{c}\text { Abnormality } \\
\text { Group }\end{array}$ \\
\hline 1 & $54 \mathrm{M}$ & Condition 6 down & 1 \\
\hline 2 & $36 M$ & Condition 6 down & 1 \\
\hline 3 & $18 \mathrm{~F}$ & Normal & \\
\hline 4 & $28 M$ & Condition 3 and 6 down & 3 \\
\hline 5 & $25 \mathrm{~F}$ & Normal & \\
\hline 6 & $37 \mathrm{M}$ & Condition 3 and 6 down & 3 \\
\hline 7 & $15 \mathrm{~F}$ & Condition 5 and 6 down & 1 \\
\hline 8 & $34 \mathrm{~F}$ & Normal & \\
\hline 9 & $58 \mathrm{M}$ & Normal & \\
\hline 10 & $19 \mathrm{~F}$ & Condition 3,5 and 6 down & 3 \\
\hline 11 & $53 \mathrm{M}$ & Condition 5 and 6 down & 1 \\
\hline 12 & $50 \mathrm{~F}$ & Condition 5 and 6 down & 1 \\
\hline 13 & $33 \mathrm{~F}$ & Condition 1,2 and 4 down & 4 \\
\hline 14 & $42 \mathrm{~F}$ & Condition 5 and 6 down & 1 \\
\hline 15 & $42 \mathrm{~F}$ & Normal & \\
\hline 16 & $19 \mathrm{~F}$ & Condition 1-6 down & 4 \\
\hline 17 & $40 M$ & Condition 3 down & 4 \\
\hline 18 & $38 \mathrm{~F}$ & Condition 5 and 6 down & 1 \\
\hline 19 & $54 \mathrm{M}$ & Condition 1-6 down & 4 \\
\hline 20 & $33 \mathrm{M}$ & Condition 2,3 and 5 down & 4 \\
\hline 21 & $18 \mathrm{~F}$ & Normal & \\
\hline 22 & $42 \mathrm{~F}$ & Condition 4-6 down & 2 \\
\hline 23 & $60 M$ & Condition 4-6 down & 2 \\
\hline 24 & $28 \mathrm{~F}$ & Condition 6 down & 1 \\
\hline 25 & $46 \mathrm{M}$ & Normal & \\
\hline 26 & $29 \mathrm{~F}$ & Condition 4-6 down & 2 \\
\hline 27 & $28 \mathrm{~F}$ & Condition 4-6 down & 2 \\
\hline
\end{tabular}




\begin{tabular}{|c|c|l|c|}
\hline 28 & $45 \mathrm{~F}$ & Condition 5 and 6 down & 1 \\
\hline 29 & $48 \mathrm{M}$ & Condition 5 and 6 down & 1 \\
\hline 30 & $39 \mathrm{~F}$ & Condition 5 and 6 down & 1 \\
\hline 31 & $30 \mathrm{~F}$ & Condition 2-6 down & 4 \\
\hline 32 & $53 \mathrm{~F}$ & Normal & 2 \\
\hline 33 & $49 \mathrm{M}$ & Condition 4-6 down & 4 \\
\hline 34 & $40 \mathrm{M}$ & Condition 2 down & \\
\hline 35 & $33 \mathrm{~F}$ & Normal & 4 \\
\hline 36 & $37 \mathrm{M}$ & Condition 3 and 5 down & \\
\hline
\end{tabular}

\section{DISCUSSION}

Although closed head injury can occur as a result of whiplash (13), there is a marked difference in the threshold of force required to injure the brain and to injure the neck. The lowest threshold to cause brain trauma in animals is recognized to be approximately $60 \mathrm{~g}$ of force (13) (and the threshold for humans is suspected to be at least $70-80 \mathrm{~g}$ ) (14), but the limitation of tolerance to whiplash is a gravitational acceleration of approximately $14 \mathrm{~g}$ (15). That is, a whiplash-type motion resulting in injury causes the head to be exposed to accelerating forces far below those required to be injurious to the brain. The whiplash motion in itself does not necessarily cause traumatic brain injury, and it is extremely important in any study to delineate patients who have suffered whiplash only from those who also have incurred a blow to the head.

In patients suffering a rear-end accident in a modern motor vehicle, head injury apart from minor head rest contact is unusual. In our group of nonhead-injured patients, no caloric reduction and no central abnormality on ENG were detected. However, $79 \%$ of these patients showed a CDP abnormality. Computerized dynamic posturography is the most effective investigation in patients who have not suffered head injury, although it is ENG that routinely is done.

The ENG abnormalities are limited to patients who have suffered a head injury, suggesting the presence of both peripheral as well as central disturbance. The inference is that despite their similar symptoms, patients who have suffered pure 
whiplash versus those with a mild head injury may have a different etiology and mechanism of damage.

The small number of patients in accident types B through $F$ limits statistically significant conclusions. However, it generally is accepted that CDP abnormalities with reductions on conditions 5 and 6 indicate a disturbance in the vestibular system (12).

In patients who suffered a head injury, a significant number had abnormalities detectable on ENG. However, the CDP results were abnormal in approximately the same percentage of patients as in those who did not suffer head injury. It was not possible to differentiate between the head-injured and the nonheadinjured groups using only the criterion of normal or abnormal CDP results.

Both of these groups have to compensate for their damage. It is expected in the presence of normal visual input and intact cerebellar function that our patients would have a visual preference develop, the "regular" mechanism of compensation as outlined by Bronstein (6). However, we have identified a group of patients suffering whiplash only who show a preference for somatosensory input. We postulate that these patients represent a separate group with a different lesion site and that both groups require a specifically tailored mechanism of compensation.

It is difficult to compare our findings with those of other investigators because they have not grouped the patients as we have. There are other reports that support our findings showing that patients suffering from head injury and whiplash use a visually preferenced method of compensation (5). Chester (16) also found different groups of CDP abnormalities in his 43 patients. He did not delineate head-injured from nonhead-injured patients. We believe that the differing CDP findings in our groups of patients can be broken down with respect to site of lesion and mechanism of injury and that our head-injured and nonhead-injured patients represent two distinct groups of patients having "picked" different methods of compensation for their injuries.

The "vision preference" pattern of abnormality occurs in patients with balance disorders secondary to traumatic head injury. Patients with a vision preference are more likely to show either normal ENG results or subtle losses of peripheral vestibular function (12). This supports the premise that the visual system is the 
primary choice of compensation for subtle vestibular losses. Clinical evidence for this premise is advanced by the many patients with vestibular disorders or caloric reductions or both who show a newly developed failure to integrate visual and vestibular function as a result of their newly developed dogmatic reliance on visual information for balance maintenance. This results in development of post-traumatic motion sickness or VVM or both. This is confirmed by Bronstein (17). He has shown that the efficiency of the visuopostural loop increases when there is a conflict between the visual and proprioceptive cues. Perhaps evidence is provided to support this by two of our patients who reported a worsening of symptoms after being prescribed standard visual rehabilitation exercises.

The vestibular system, as outlined by Nashner, serves as a template against which other conflicting information is suppressed. Thus, a person with normal vestibular function can ignore the ordinarily powerful visual-optokinetic input in everyday life, because if unable to do so, he or she would be destabilized by any conflict such as watching a bus pull away from the curb.

Our group of head-injured patients had developed a strategy of compensation with visual preference abnormality patterns showing on CDP, suggesting that they had compensated in a fashion in keeping with Nashner's explanation. In these patients, visual input dominates in the maintenance of balance.

We postulate that the concept of "compensation" (i.e., recovery from permanent vestibular damage) involves development of the ability to suppress actively an inappropriate response. In patients who initially develop visually preferenced CDP abnormalities, eventual compensation-conditioning allows them to suppress appropriately visual stimuli that are inappropriate, so that they eventually "learn" (i.e., condition to) which visual stimuli are appropriate to balance maintenance and which visual stimuli are inappropriate. The compensation process in this situation is not the development of new pathways but the development of appropriate suppression mechanisms.

All six patients who showed a somatosensory-referenced abnormality were whiplash-only patients. They had had rear-end MVAs, which are the most likely to cause neck injury at very low velocities because of the design of seats, head rests, and seat belts. 
The central nervous system may achieve head stability in different ways, depending on the nature of the movement task. Both vestibulocollic and cervicocollic reflexes may contribute to stabilization of the head, depending on the goal of the subject performing the task (18). Patients with cervical root compression also manifest impaired CDP performance before surgical treatment of their spinal cord compression, which again returns to normal postsurgically, along with diminished complaints of balance difficulties (19). These findings were confirmed by Persson et al. (20) in 1996. They suggest that such surgery may reduce cervical muscle tension and subsequent "normalization" of the proprioceptive signals from the neck and a reduction of the sensory mismatch when proprioceptive signals converge with vestibular information in the central nervous system.

We believe that this belief supports evidence advanced by Persson et al. (20) that the CDP abnormalities are the result of disruption of tonic neck input into the linear vestibulo-ocular reflexes and are not caused by vestibular system damage. We postulate that in the same way that the vestibular system acts as a template to suppress inappropriate visual information (which takes over in the presence of vestibular system damage), the tonic neck reflexes serve to suppress inappropriate proprioceptive information. Loss or damage to these reflexes causes a loss of this suppression inability, with resultant "taking over" by the proprioceptive information. In the same way that the vestibular system works hand in hand with vision to suppress inappropriate visual information, the vestibulocollic and cervicocollic systems work hand in hand with the proprioceptive system, suppressing inappropriate somatosensory information. The resulting somatosensory-preferenced CDP abnormality arises as a result of loss of this suppression and not as a result of vestibular damage. This explains the observation in the Equitest manual that "this pattern (i.e., somatosensory dependence) is not commonly observed in patients with pathology limited to the vestibular system" (12).

We have speculated that compensation for vestibular damage involves a relearning of the suppression techniques for inappropriate information. We also hypothesize that in the same way, somatosensory-dependent individuals can do the same. Once patients are well on the way to compensating, they are better trained at suppressing the inappropriate information, although they still 
do not perform as well in the absence of that information. This gives rise to the "nonspecific" patterns of CDP abnormalities. Patients with these CDP abnormalities arise from both groups of patients (whiplash-only and head injured), and we propose that they represent patients who, for want of a better term, have "compensated" as far as they can for their difficulties. This does not mean to infer that these patients are symptomatic or even that they are functioning well. Of 10 patients who had 5 or 6 down patterns or both, 6 had head injuries and 4 had no head injuries. The 5 or 6 down patterns or both can be exhibited by a compensated patient from either group. The same holds true in our group with nonspecific CDP abnormalities. Three of the eight had had head injuries and five of the eight had had whiplash only.

We have identified a group of patients on CDP investigation suffering from vestibular symptoms who have a somatosensory rather than a visual preference. The group of patients we have identified also seems to be delineated by the type of injury suffered.

\section{CONCLUSIONS}

We have long wondered what influences the central nervous system when it "picks a strategy of compensation" as shown on CDP assessment in recovering patients. Perhaps it is not a matter of picking a strategy to compensate for a common lesion, but the CDP abnormality reflects the pathway that has been least injured and also shows the stage of recovery that the patient has attained at the time of assessment.

Continued follow-up may show strategy changes if the compensation process is evolving or lack of change if it has been completed. Ongoing accumulation of more patients should allow us to confirm or refute the postulate that we have delineated a group using a somatosensory rather than a visual template in the compensation process. 


\section{REFERENCES}

1. MacNab I. Acceleration injuries of the cervical spine. J Bone Joint Surg 1964;46A:1797-9.

2. Hinoki M. Vertigo due to whiplash injury: a neurotological approach. Acta Otolaryngol (Stockh) 1985;419 (Suppl):9-29.

3. Oosterveld WJ, Kortschot HW, Kingma GG, et al. Electronystagmographic findings following cervical whiplash injuries. Acta Otolaryngol (Stockh) 1991;111:201-5.

4. Sturzenegger M, DiStefano G, Radanov BP, et al. Presenting symptoms and signs after whiplash injury: the influence of accident mechanisms. Neurology 1994:44:688-93.

5. Rubin AM, Woolley SM, Dailey VM, et al. Postural stability following mild head or whiplash injuries. Am J Otol 1995;16:216-21.

6. Bronstein AM. Suppression of visually evoked postural responses. Exp Brain Res 1986;63:655-8.

7. Nashner LM, McCollum G. The organization of human postural movements: a formal basis and experimental synthesis. Behav Brain Sci 1985:8:135-72.

8. Paige GD. Senescence of human visual-vestibular interactions. J Vestib Res 1992;2:133-51.

9. Mallinson Al, Longridge NS, Peacock C. Dizziness, imbalance and whiplash associated disorder. J Musculoskeletal Pain 1996:4:105-12.

10. Jane JA. Mild to moderate head injury. Definitions. In: Hoff JT, Anderson TE, Cole TM, eds. Mild to moderate head injury. Contemporary issues in neurological surgery. Boston: Blackwell Scientific Publications. 1989:1-8.

11. Kay T, Harrington DE, Adams R, et al. Definition of mild traumatic brain injury. J Head Trauma Rehabil 1993;8:86-8.

12. Neurocom International Inc. EquiTest Interpretation Manual. Clackamas, OR: Neurocom International, 1992.

13. Ommaya AK. Biomechanics of head injury. In: Nahum AM, Melvin J, eds. The biomechanics of trauma. Norwalk: Appelton Century Croft, 1985:245-69.

14. Reid SE. Radio-telemetry studies of head impacts on the football field. In: Head and neck injuries in sports. C. Thomas, 1984:24-79. 
15. Mertz HJ, Patrick LM. Investigation of the kinematics and kinetics of whiplash. SAE Transactions 1967;76:Paper \#670919:2952-80.

16. Chester JB. Whiplash, postural control and the inner ear. Spine $1991 ; 16: 716-20$.

17. Bronstein AM. Visual control of balance in cerebellar and Parkinsons syndromes. Brain 1990;113:767-79.

18. Shupert CL, Horak FB. Effects of vestibular loss on head stabilization in response to head and body perturbations. J Vestib Res 1996;6:423-37.

19. Vitte E, Lazennec JY, Pharaboz C, et al. Induced perturbations of Equitest in cervical spine pathologies. In: Woollacott $M$, Horak $F$, eds. Posture and gait: control mechanisms (Vol 2). Eugene, OR: University of Oregon Books, 1992:176-9.

20. Persson L, Karlberg M, Magnusson M. Effects of different treatment on postural performance in patients with cervical root compression. J Vestib Res 1996;6:439-53. 


\section{CHAPTER SIX}

\section{Visual vestibular mismatch in patients treated with intratympanic gentamicin for Ménière's disease}

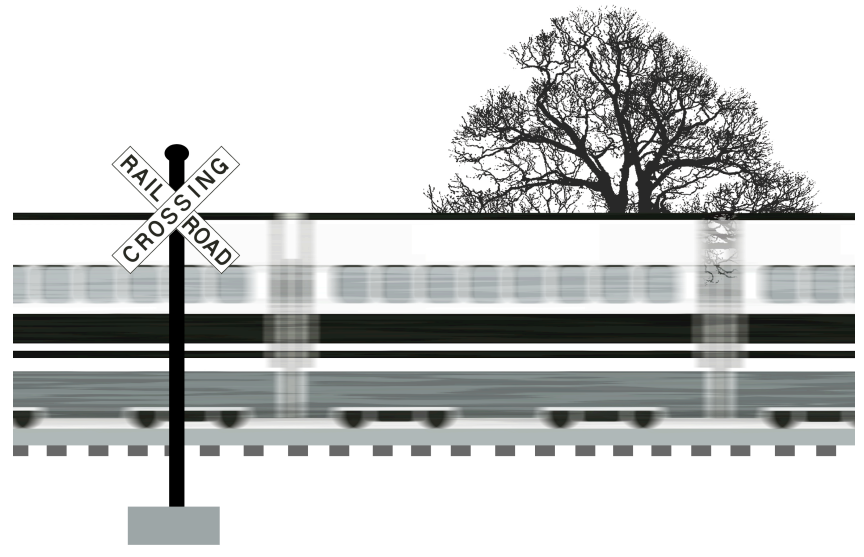

Longridge, NS, Mallinson AI, Denton A

J. Otolaryngol 2002 Feb;31 (1):5-8. 


\section{ABSTRACT}

Objective: To support the hypothesis that the symptom complex known as visual vestibular mismatch (VVM) can be induced by peripheral vestibular disease.

Design: Retrospective chart review; prospective questionnaire.

Setting: A tertiary/quaternary care hospital clinic.

Methods: The charts of 28 patients who were treated for Meniere's disease were studied. Their responses to a pretreatment VVM questionnaire were scored and compared with their answers in a telephone follow-up to the same questions post-treatment. These questionnaires were compared with those filled in by 100 control patients without ear disease.

Main Outcome Measures: Patients' responses to a VVM-specific questionnaire.

Results: Seventeen of 28 patients had VVM. Gentamicin therapy increased the number of positive answers. There was no correlation between the development of VVM complaints, caloric scores, and posturography performance. No control patients had symptoms of VVM.

Conclusion: We conclude that the development of VVM indicates the onset or worsening of vestibular disease as it can be induced or exacerbated by gentamicin therapy. As there is no correlation between VVM and caloric scores, we suggest that otolithic damage may be responsible for this symptom set developing.

KEYWORDS: gentamicin, Meniere's disease, motion sickness, posturography 
The well-known vestibular symptoms in Meniere's disease can often be disruptive to a patient's lifestyle. Patients suffering such recurrent attacks can now be offered the simple but effective therapy of intratympanic gentamicin instillation. After ablation therapy, they no longer suffer the consequences of dramatic fluctuation of labyrinthine function, thus ending the recurrent and unpredictable dizzy spells accompanied by nausea and vomiting. They are then left with the challenge of compensating for their newly created labyrinthine deficit. This is usually successful, with a return to a satisfactory lifestyle.

Patients with classic Meniere's disease usually do not present a diagnostic challenge. Vertigo, nausea, and imbalance are easily definable as being of vestibular origin, with caloric testing often being able to lateralize the lesion. In recent years, more subtle symptoms of vestibular disease have been recognized and are now understood to a larger extent. This subtle symptom set was described as "visual vertigo" by Bronstein (1) and referred to as "visual vestibular mismatch" (VVM) by Longridge and Mallinson (2-4). These symptoms, which were often previously ascribed to a neurologic, histrionic, or psychiatric origin, are now accepted as arising from the vestibular system $(1,2)$. They often present in a subtle fashion, sometimes only during a careful history taking. Recent literature supports the fact that the symptoms are genuine and not at all suggestive of malingering or psychiatric behaviour $(1,5-7)$.

Visual vestibular mismatch is a syndrome in which visual and vestibular information does not mesh satisfactorily in the brain, often resulting in general malaise and complaints that are often vocalized as "dizziness." This discongruency between the normal environmental signals results in a subset of symptomatology, for example, feeling unwell when walking down the aisle of a supermarket, standing at a busy crosswalk with many cars going by, or in a busy shopping mall. This results from over-reliance on visual signals, which can cause the illusion of movement. Patients can also be bothered by elevator rides, escalator rides, walking across checkered floors, and awareness of dislike of fluorescent lights. Frequently, there is an awareness of new onset of motion sickness not present prior to the instigating event, and this is also accepted as a symptom of newly developed vestibular pathology (2). Other complaints attributable to VVM are described occasionally. Symptomatology can be 
invoked by leafed boughs of trees waving up and down, Venetian blinds swaying, or moving water (such as rippling on the water of the seashore or even in a hand basin). Symptoms very often also include nausea. These symptoms have been described previously as being related to mismatch between visual and vestibular signals $(4,5,8,9)$.

Visual vestibular mismatch is a clinical diagnosis. Often it coincides with an abnormality involving the balance system that can be detected by Computerized Dynamic Posturography (CDP). In one study, CDP results were abnormal in approximately two-thirds of patients with VVM caused by trauma, although in about one-third of patients, the symptoms were present without abnormality on posturography (4).

In a study to assess the effectiveness of intratympanic gentamicin treatment on unilateral Meniere's disease (10), patients were assessed by telephone followup. During this follow-up, several patients spontaneously voiced complaints of VVM. This was followed up in more detail by a repeat telephone call to clarify VVM symptoms pre and post intratympanic gentamicin. Patients treated with gentamicin for Meniere's disease over a period of 4 years were assessed for VVM, and these findings are the basis of this article. The objective of the investigation was to determine whether a purely peripheral vestibular disorder could produce VVM and whether alteration of peripheral function resulted in the development of or a change in VVM symptoms.

\section{PATIENTS AND METHODS}

A retrospective chart review of patients treated with intratympanic gentamicin was undertaken (10). During telephone follow-up to determine the success or failure of intratympanic gentamicin, a questionnaire (Table 1) was given to each patient to determine whether he or she had experienced dizziness induced by eight situations and whether he or she had motion sickness. These complaints were separate from the dizziness occurring during the acute vertiginous episodes of their Meniere's disease. Patients were asked whether these symptoms had been present before or after intratympanic gentamicin therapy and, if present before, whether they were changed by the therapy for better or worse. One hundred patients with no audiovestibular abnormalities, referred for nose and throat disease, were used as controls. 


\section{RESULTS}

All of the 28 patients completed our questionnaire (see Table 1), both prior to and after their intratympanic gentamicin therapy. Eleven were not bothered by any of the stimuli inquired about and gave "no" answers to all nine questions both pre- and post-treatment.

In Table 2, it can be seen that 27 answers suggested a worsening of symptoms (i.e., induced or brought on) and 16 answers suggested an improvement of symptoms. But of these 16 symptom improvements, 10 still suggested lingering symptoms (i.e., answers were still positive but less so). This suggests that intratympanic gentamicin therapy is not a good modality for resolving the symptoms of VVM. On the other hand, for 26 of the 27 worsening of symptoms answers, the symptoms arose de nouveau, suggesting that intratympanic gentamicin therapy is, in fact, an agent highly suspicious of inducing symptoms of VVM.

\section{Table 1. Dizziness Questionnaire}

1. Does walking down a supermarket aisle increase your dizziness?

2. Because of your dizziness do you have difficulty reading?

3. Do you have motion sickness?

4. Do fluorescent lights make your dizziness worse?

5. Does standing at the edge of a busy crosswalk make your dizziness worse?

6. Does your dizziness get worse in a shopping mall?

7. Does your dizziness get worse on an escalator?

8. Does your dizziness get worse in an elevator?

9. Do checkered floors make your dizziness worse?

(Four visual vestibular mismatch questions bolded for this article only.) 
Table 2. Effects of Intratympanic Gentamicin on

\section{Visual Vestibular Mismatch*}

\begin{tabular}{|c|c|c|c|c|c|c|c|c|c|c|}
\hline \multicolumn{11}{|c|}{ Question Number ${ }^{\dagger}$} \\
\hline & $\overline{1}$ & 2 & 3 & 4 & 5 & 6 & 7 & 8 & 9 & Total \\
\hline Improved & 1 & 1 & 1 & 2 & 1 & 1 & & 2 & 1 & 10 \\
\hline Worsened & & & 1 & & & & & & & 1 \\
\hline Cured & 2 & 0 & 0 & 0 & 1 & 1 & 0 & 1 & 1 & 6 \\
\hline Induced & 6 & 0 & 2 & 3 & 1 & 7 & 3 & 0 & 4 & 26 \\
\hline $\begin{array}{l}\text { Good outcome } \\
\text { (cured/improved) }\end{array}$ & 3 & 1 & 1 & 2 & 2 & 2 & 0 & 3 & 2 & 16 \\
\hline Poor outcome & 6 & 0 & 3 & 3 & 1 & 7 & 3 & 0 & 4 & 27 \\
\hline $\begin{array}{l}\text { (induced/worsened) } \\
\text { Total in which change }\end{array}$ & 9 & 1 & 3 & 5 & 3 & 9 & 3 & 3 & 6 & 43 \\
\hline occurred & & & & & & & & & & \\
\hline
\end{tabular}

* Number of changed responses to questionnaire pre- and post-treatment.

† See Table 1.

Improved = symptoms present but more tolerable after treatment

Worsened $=$ symptoms present but less tolerable after treatment

Induced = symptoms developed after treatment

Cured = symptoms disappeared after treatment.

Table 3. Number of Patients with Positive Answers to Each Question Pre and Post Intratympanic Gentamicin Therapy (N = 28)

Question Number*

\begin{tabular}{ccccccccc}
\hline $\mathbf{1}^{\dagger}$ & 2 & 3 & $\mathbf{4}^{\dagger}$ & 5 & $\mathbf{6}^{\dagger}$ & 7 & 8 & $\mathbf{9}^{\dagger}$ \\
\hline Pre ITG $\mathbf{8}$ & 5 & 6 & $\mathbf{5}$ & 7 & $\mathbf{6}$ & 4 & 3 & $\mathbf{7}$ \\
Post ITG $\mathbf{1 2}$ & 5 & 8 & $\mathbf{8}$ & 7 & $\mathbf{1 2}$ & 7 & 2 & $\mathbf{1 0}$ \\
\hline
\end{tabular}

\footnotetext{
*See Table 1.
}

† Visual vestibular mismatch-specific questions.

ITG = intratympanic gentamicin 
All of the patients underwent our standard protocol (discussed elsewhere (10)) with pre and post CDP and caloric assessment. The caloric changes, CDP changes, and treatment outcomes are not reported here as they are not related to this study, but there was no correlation in any of these parameters between the results of the 11 negative responders and the 17 others with one or more positive complaints.

In the 17 patients who had any positive answers at all, supermarket aisles, shopping malls, and checkered floors were the most common inducers of these complaints (questions 1, 6, and 9). Surprisingly, fluorescent lights were also complained of commonly. We also regard these four questions (1, 4, 6, and 9) as being the most indicative of VVM as they all assess similar circumstances; they all ask about maintenance of balance in the presence of an active disorienting visual stimulus. As a result, we examined these four VVM-specific questions (bolded in the questionnaire by us for the purpose of this article) more closely, hypothesizing that difficulties with VVM would be reflected when a patient was placed in such circumstances.

Of the 17 patients who responded positively to any of the questions in the questionnaire, 10 of them had an answer change to at least one of the four VVM-specific questions post therapy. This is summarized in Table 3. There were a total of 24 "changed" answers (i.e., "yes" to "no" or "no" to "yes"). Table 4 examines the VVM-specific questions. In this category, there were 20 posttreatment answers suggesting development of symptoms and 4 indicating resolution of symptoms. Control patients did not answer the questionnaire positively.

\section{DISCUSSION}

The complaints of patients with VVM have been described by us previously (24). The exact anatomic location causing the symptoms is unclear (11). The association with head injury may suggest origins in the neck, brainstem, cerebellum, or inner ear (4).

Our patients with Meniere's disease stand as a model of specific inner ear damage as a result of their gentamicin injections. The development and 
alteration of symptoms of VVM with therapy for Meniere's disease indicate that pure inner ear disease can induce symptoms characteristic of VVM in the absence of any other factors. We realize that although it is possible that patients' symptoms may have developed because of the passage of time and not because of their intratympanic gentamicin therapy, the patients who did note changes specifically felt that the changes coincided with the gentamicin treatments. We consider this to be proof that the gentamicin induced these complaints. It is not known whether these symptoms would be totally or even partially relieved by complete ablation of the inner ear. To date, no patient has had symptoms severe enough to justify surgical ablation. This procedure would result in complete destruction of inner ear function, which would then allow determination of whether the symptoms of VVM are relieved. At some point, this information may become available.

The absence of a close correlation between caloric response and relief of symptoms of vertigo suggests that damage to the lateral semicircular canal may not be the sole cause of the change. The initial and most extensive hair cell damage in aminoglycoside ototoxicity occurs in the apex of the cristae and striolar regions of the maculae, and gentamicin has also been implicated in otoconial membrane damage (12). We hypothesize that some patients also suffer some decreased function of the otoliths resulting from therapy for their Meniere's disease and that the otolithic damage may be responsible for the development of VVM. The amount of damage caused by the gentamicin to the inner ear structures already damaged by Meniere's disease may explain why some of our patients have improvement in and others have worsening of their symptoms.

As none of the control patients had dizziness in the first place, a direct comparison of responses to the questions cannot be made. The questions to the control group had to be phrased differently, that is, "Do you get dizzy in a shopping mall?" This presented a different situation than the questions asked of the patients with Meniere's disease, which took the form of "Does your dizziness change in a shopping mall?" In the control group, $15 \%$ suffered from motion sickness and always had. 
We are unaware of any effective method ofimproving the symptoms of VVM once they are present. Generally, patients are instructed to undertake the maximum activity they can tolerate to try and suppress their symptoms as effectively as possible. By challenging the balance and visual systems, it is felt that this may improve the integration of signals so that the symptoms of this syndrome are relieved. Unfortunately, in our experience, this is frequently not the case, and some patients find that their symptoms are worsened by this mobilizing approach. Some patients have these symptoms on a long-term basis, and we are concerned that they may be present permanently.

\section{Table 4. Visual Vestibular Mismatch Specific Question Changes Post Therapy}

\begin{tabular}{|c|c|c|c|c|}
\hline Question Number & 1 & 4 & 6 & 9 \\
\hline Patients in whom symptoms developed & 6 & 3 & 7 & 4 \\
\hline Patients in whom symptoms resolved 2 & 0 & 1 & 1 & \\
\hline Total change & 8 & 3 & 8 & 5 \\
\hline
\end{tabular}




\section{REFERENCES}

1. Bronstein AM. The visual vertigo syndrome. Acta Otolaryngol Suppl (Stockh) 1995;520:45-48.

2. Longridge NS, Mallinson Al. Visual vestibular mismatch in whiplash and Meniere's disease. In: Claussen CF, Haid C-T, Hofferberth B, eds. Equilibrium research, clinical equilibriometry and modern treatment. Amsterdam: Elsevier Science BV, 2000:397-402.

3. Mallinson Al, Longridge NS, Peacock C. Dizziness, imbalance, and whiplash. J Musculoskeletal Pain 1996; 4:105-112.

4. Mallinson Al, Longridge NS. Dizziness from whiplash and head injury. Am J Otol 1998;19:814-818.

5. Furman JM, Jacob RG. Psychiatric dizziness. Neurology 1997;48:1161-1166.

6. Yardley L, Luxon L, Bird J, et al. Vestibular and posturographic test results in people with symptoms of panic and agoraphobia. J Audiol Med 1994:3:48-65.

7. Furman JM, Jacob RG, Redfern MS. Clinical evidence that the vestibular system participates in autonomic control. J Vestib Res 1998;8(1):27-34.

8. Benson AJ, King PF. The ears and nasal sinuses in the aerospace environment: Scott-Browne's diseases of the ears, nose and throat. Vol. 1. Basic science. London: Butterworth's, 1979:205-243.

9. Grimm RJ, Hemenway WG, LeBray PR, et al. The perilymph fistula syndrome defined in mild head trauma. Acta Otolaryngol Suppl (Stockh) 1989;464:1-40.

10. Longridge NS, Mallinson Al. Low dose intratympanic gentamicin treatment for dizziness in Meniere's disease. J Otol 2000;29:35-39.

11. Bronstein AM. Visual vertigo syndrome: clinical and posturography findings. J Neurol Neurosurg Psychiatry 1995;59:472-476.

12. Black FO, Peznecker SC. Vestibular ototoxicity—clinical considerations. Otolaryngol Clin North Am 1993;26:713-736. 


\section{CHAPTER SEVEN}

\section{Motion sickness and vestibular hypersensitivity}

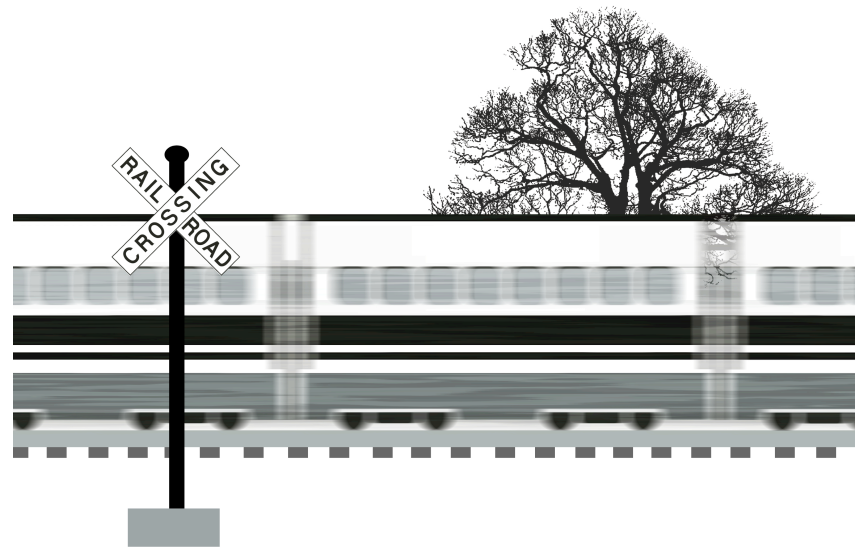

Mallinson Al, Longridge NS.

J. Otolaryngol 2002 Dec;31 (6):381-385. 


\section{ABSTRACT}

Objective: Motion sickness is poorly understood, although it has been recognized for years as debilitating. Vestibular function is required for motion sickness to occur, but motion sickness can also be brought on without body motion. The aim of this study was to see if there was a correlation between caloric response and motion sickness susceptibility.

Design: One experiment was a prospective study carried out on 200 patients. A second prospective study was carried out on 121 patients.

Setting: Patients referred to our tertiary/quaternary care dizziness clinic.

Methods: In experiment 1, caloric scores in patients were correlated with symptoms of motion sickness as established by responses to a simple question. In experiment 2, caloric scores were correlated with symptomatic responses to caloric testing itself.

Main Outcome Measures: Caloric responses of the best ear were measured according to standardized caloric evaluation methods.

Results: There was no correlation between motion sickness and caloric scores. There was a significant difference in caloric scores between patients made symptomatic by calorics and those who were not.

Conclusions: The autonomic response seen in some patients is not triggered by a specific level of semicircular canal response (as measured by caloric testing). We hypothesize that (similar to space motion sickness) the trigger is a signal differential that arises between semicircular canals and otoliths and that some patients are unable to suppress this response. These patients often suffer motion sickness on a long-term basis.

KEYWORDS: calorics, electronystagmography, motion sickness, nausea, otoliths 
The set of unpleasant symptoms referred to as motion sickness has been recognized as a significant problem for hundreds of years, and yet the problem remains an enigma. Maitland, in 1931, commented that the "eminently seafaring British nation is conspicuous for its neglect of the study of seasickness." (1) Different aspects of motion sickness, such as seasickness, train sickness, or carsickness, are not abnormal and are all related. However, the de novo development or worsening of motion sickness, either as carsickness or as a symptomatic response to visual vestibular mismatch (VVM), is strongly suggestive of the development of vestibular pathology.(2) Space sickness is also a motion sickness, although, interestingly, when ranking subjects susceptible to space sickness and those susceptible to motion sickness, the least and most sensitive subjects switch positions.(3)

Motion sickness is related to vestibular function; individuals with total bilateral vestibular loss do not suffer from motion sickness. (4) However, the vestibular system influences autonomic function in several ways that have clinical implications. The control mechanisms of this influence are poorly understood, and the huge variation in individual susceptibility remains unresolved.(5) Today's understanding of motion sickness is as poor as it was at the end of the Second World War.(6)

Unfortunately, the lack of understanding is closely paralleled by the lack of effective treatment of the symptoms. Some medications, largely based on antihistamines, can suppress the symptoms of nausea, but their mode of action is not well understood.

Flack, in 1931, stated that seasickness was predominantly of vestibular origin. He observed that certain individuals were "unduly sensitive" to symptoms of nausea and vomiting, and, with these symptoms, these individuals also had a related rise in pulse and blood pressure. (7) He attributed these changes to reflex vagal stimulation and ocular muscle imbalance. Pappas et al., in 1986, also correlated autonomic sensitivity with dizziness; in a group of dizzy patients with "no demonstrable reason for dizziness," he found a high percentage of autonomic dysfunction on Valsalva and postural tests.(8) It is now presumed that the purpose of the autonomic response influence is to 
help restore homeostasis.(5) This is supported by animal studies that show direct vestibular input to important centres of autoregulation (6). The clinical importance of the generalized autonomic malaise is that, in some patients, it can dominate or even override the acute vestibular disturbance and can persist long after the traditional vestibular symptoms have resolved.

Various theories have emerged over the years to try to explain the enormous variability in individual susceptibility and the widely differing symptom intensity between people. The reader is referred to reviews such as that by Oman (9) to follow the developmental progression of these theories. The contemporary view is the sensorimotor conflict theory, which states that a conflict of signals, rather than excessive vestibular stimulation, is the symptom generator. The main purpose of the conflict is to invoke either a short-term response, in the form of a postural adjustment, or a long-term adaptive process in the form of "sea legs." Although these conflicts serve a physiologic purpose, they can still be triggered inappropriately. For instance, excessive vestibular stimulation (e.g., dancing, twirling, etc.) does not ordinarily generate symptoms, but passive exposure to real motion or even to apparent, perceived motion (e.g., in a giant-screen theatre) can generate motion sickness. (3) It has been suggested that the conflict between motor outflow and sensory return triggers conflict neurons,(9) perhaps in the vestibular system (primary vestibular afferents?), and the result is abnormal stimulation of the autonomic response, which, in some individuals, is inappropriately strong.

Do the lingering complaints seen in certain patients represent vestibular hypersensitivity or autonomic hypersensitivity? The minimal circuitry responsible for the emetic response is present in the brainstem (decorticate humans can get emesis), but we wondered why this response is triggered so violently by vestibular stimulation in some individuals and not at all in others. One of the earliest attempts to address this question was by Preber, who, in 1958, using the new technique of electronystagmographic recordings of caloric irrigation responses, found that motion sick individuals had both greater maximum eyespeed and also significantly different changes in skin 
resistance.(10) Lidvall, in 1962, using measurement of the slow-phase velocity of calorically induced nystagmus, concluded that the tendency to motion sickness is in direct proportion to the sensitivity of the balance organs.(11)

We wondered if motion sick patients did, in fact, have higher caloric responses than their non-motion sick counterparts or if they just had a higher "autonomic sensitivity." The purpose of the described experiments was to address this issue.

\section{METHODS}

In a prospective study, we examined the results of 200 patients referred sequentially to our tertiary/quaternary care dizzy clinic. The caloric results of these patients were scored according to the method delineated by Barber and Stockwell.(12) Although these patients were referred for complaints of dizziness, patients with true vertigo are, by definition, suffering from unilateral pathology, and we felt justified in using the caloric score of their better ear (i.e., the nonpathologic ear) as a valid measure of "maximum caloric response." We excluded any patient with possible bilateral disease using the exclusion criteria as set out in Table 1.

\section{Table 1. Patient Exclusion Criteria}

Any patient meeting any of the following factors, which may have influenced maximum caloric response, were excluded from the study:

- Any history of aminoglycoside exposure

- History suspicious of vestibular pathology affecting both sides. (A typical history that might suggest this would be two sequential attacks of acute vertigo and persistent imbalance following the second one, coupled with calorics that were bilaterally hypoactive.)

- Any sedative medication in the previous 48 hours

- Previous electronystagmography (as caloric scores can habituate)

- Any spontaneous nystagmus with eyes closed (making calculation of one caloric response less accurate) 


\section{Table 2. Groupings of Patients According to}

\section{Motion Sickness Susceptibility}

Group 0

Group 2

Group 1 no complaints of motion sickness in a moving car

extreme motion sickness (many patients actually said they were unable to read in a car for more than one or two minutes before becoming sick, so we accepted two minutes as the upper time limit for this group)

"a little motion sick". This group included all other patients not in the first two groups

\section{Table 3. Groupings of Patients According to}

\section{Subjective Caloric Response}

Calorics 0

Calorics 1

Calorics 2 either denied sensation from calorics or found them pleasurable

calorics tolerable, but not pleasant, but they denied nausea. (a typical sensation in this group would be the sensation of true vertigo, classically induced by caloric testing)

nausea and extreme discomfort from calorics 
Patients were divided into three groups based on their answer to a simple standardized question always asked by the same investigator during history taking: "How long can you read in a moving car?" The groups were delineated as outlined in Table 2. We delineated three groups: a group who was not bothered by reading in a car at all (0), a group who could not tolerate even looking at a map in a car (2), and a group in between who could read for a period of time (1). (We accepted up to 2 minutes.) Patients who could not understand our very simple question owing to a language barrier or dementia were excluded. Rare patients who had no experience as a passenger in any moving vehicle were also excluded. We compared the caloric scores of the three groups.

In our second experiment, also a prospective study, we gathered sequential data on a further 122 patients. These patients were subjected to the same inclusion/exclusion criteria, but this time we asked them after caloric testing what subjective sensation they experienced from calorics. Again, there was a wide range of subjective sensation, ranging from no feeling at all to excessive nausea and vomiting. We once again delineated three groups of patients based on their answers (Table 3). A group we called "calorics 0" either denied sensation from calorics or found them pleasurable. A group called "calorics 1" found them to be tolerable but not pleasant, but they denied nausea. (A typical sensation in this group would be the sensation of true vertigo classically induced by caloric testing.) A group called "calorics 2" reported nausea and extreme discomfort from calorics. We compared average caloric scores between groups.

\section{RESULTS}

Our first study was of 200 patients. Table 4 compares the average caloric score in each of the three groups of motion sensitivity. Caloric scores were not significantly different between the three groups of patients, although there was a suggestion of a subtle relationship between motion sickness and caloric score, with slightly higher caloric scores in more sensitive groups. 


\title{
Table 4. Maximum Caloric Responses of Differing Car-sickness Groups
}

\author{
No. Patients \\ Maximum Caloric Score \\ $(n=200)$ \\ (Slow Phase Vel. in deg/sec)
}

Group 1

(not carsick)

Group 2

18

42.0

(a little carsick)

Group 3

59

44.0

(very carsick)

\section{Table 5. Maximum Caloric Responses of}

\section{Differing Caloric Sensitivities}

$$
\begin{aligned}
& \text { No. Patients } \\
& (n=122)
\end{aligned}
$$$$
25
$$

Calorics 0

(avg. age 53.1)

Calorics 1

(avg. age 44.7)

Calorics 2

46

46.1

(avg. age 42.3)

Maximum Caloric Score (Slow Phase Vel. in deg/sec)

* Significant at .05

Our second study was of 122 patients. Table 5 compares the average caloric score in each of these three groups. These results did show significant differences. Caloric scores in the group reporting little or no sensation from calorics were significantly lower $(p<.05)$ than in the other two groups. We looked for age-related effects but found none as there was no significant difference in age among the three groups. 


\section{DISCUSSION}

It has been postulated by Oman(9) that the symptoms of motion sickness, which can be referred to as the vestibuloautonomic response, have appeared only very recently on the evolutionary scale, since the advent and use of moving vehicles, and may represent a flaw in the developing vestibuloautonomic network. Symptoms of motion sickness can also be generated without any direct stimulus to the vestibular system, for instance, from many "old-fashioned" pursuits, such as watching clouds in the sky, water flowing in a stream, or leaves fluttering on a windy day. Today we have modern-day activities such as video games and cinemas.

In some people, motion sickness and the clinical symptom set known as VVM (2) seem to be an abnormal hypersensitivity invoked by a stimulus that is perceived as potentially destabilizing from the postural point of view. Motion sickness results predominantly from otolithic stimulation. The crucial otolithic role in the production of motion sickness was originally outlined by Preber.(10) More recently, it has been suggested that the otolith organs may be responsible for the vestibulosympathetic response,(13) and space motion sickness seems to be partly attributable to otolith asymmetry(14) or to a canal/otolith conflict.(15,16) Our data showed no correlation between caloric scores (i.e., semicircular canal [SCC] response) and motion sensitivity.

In both experiments, we took the liberty of delineating three groups of patients based on their subjective sensations to a given stimulus. We realize that we were probably dividing up a "continuum of response" rather than identifying specific groups. However, our clinical practice for some time has been to ask about motion sickness, and we have formed the impression that there is a group of patients with no complaints whatsoever from reading in a car for prolonged periods of time. Other patients state voluntarily that consulting a map or even looking down at their car radio is impossible when the car is moving. Time estimation in a patient suffering from the malaise of motion sickness seems to be extremely distorted, just as it is when a patient estimates the length of dizzy spells. As a result, when dividing our groups, 
we decided to divide them into "motion sick" and "not motion sick" and not to press patients to estimate how long they could read in a moving car. The only time estimate we did use was to delineate a "very sensitive group." Many patients reported being able to "read for a minute or two," as discussed earlier, and this was the only time quantification used. In a similar fashion, our three groups of caloric sensitivities also likely represent three segments of a continuum.

We also looked at any relationship between motion sensitivity (i.e., in everyday life) and caloric experience (i.e., vestibular sensitivity in our clinic).

We postulate that sensitivity to motion sickness (or to caloric stimulation) is a result of a signal differential at the conflict neuron level and that a vestibular counterbalance mechanism exists. Its task is to "balance" vestibular activity between vestibular structures, otolithic and SCCs. For example, a caloric (SCC) stimulus generates a corollary signal to the otoliths under ideal circumstances so that similar signals are seen from both structures at the conflict neuron level.

Many patients seem not to be sensitive to the autonomic symptoms generated by either type (calorics or motion) of vestibular stimulation. Twenty-five of the 122 patients were not bothered at all by the calorics. This group of patients had significantly lower caloric scores. Twenty of these 25 (80\%) were also not carsick.

Forty-six of the 122 patients were extremely nauseated by the calorics. But of these 46 patients, 19 (41\%) were not motion sick. We postulate that in this group of 19, only one arm of the counterbalance system may be functioning properly; these patients can successfully suppress the stimulus invoked by automobile rides, but stimulation of the SCC with calorics does not invoke the postulated mechanism.

The opposite limb of the pathway could potentially also be abnormal, but only 1 of our 25 patients (4\%) who was not bothered by calorics was a motion sick patient.

It seems that motion sickness is closely related to caloric sensitivity, as might be expected. Twenty-two of the 122 patients were very motion sensitive, and 21 
of these $(95 \%)$ were also bothered by calorics. These patients seem to be unable to suppress autonomic symptoms, perhaps owing to a lack of an effective counter-balancing mechanism. Therefore, vestibular stimulation of any kind will result in a net signal at the conflict neuron level, thus invoking resultant autonomic symptoms.

Our hypothesis supports Oman's (9) theory that the "inappropriate" autonomic response seen in some patients represents a flaw in evolutionary development. In the same way, newly developed symptoms in our patients may also have the potential to create such a flaw.

\section{CONCLUSIONS}

The "functionally appropriate" autonomic response to vestibular stimulation known as motion sickness can sometimes be excessive in man. Our two experiments suggest that the autonomic trigger for these symptoms may lie in a signal differential at the conflict neuron level. We postulate the existence of a mechanism that controls this differential and hence suppresses excessive symptomatology under ideal circumstances, with the result that many patients are not bothered by motion sickness. However, in some patients, the mechanism we propose to exist may be less efficient or even absent. We describe these patients clinically as "vestibular hypersensitives," and their vestibuloautonomicresponses can sometimes be debilitating.

From an evolutionary point of view, it has been suggested that the vestibular system is vital to survival in even a tired animal as sedative medications causing drowsiness do not affect performance on posturography.(17) An animal, even though drowsy, needs a functioning balance system to find a safe refuge. Perhaps this conflict mechanism may be helpful for the animal to "phase lock" vestibulo-ocular reflex and vestibulospinal reflex responses to maintain equilibrium when hunting, swimming, foraging, or escaping capture. 


\section{REFERENCES}

1. Maitland TG. General observations on sea-sickness and the labyrinthine theory. BMJ 1931;1:171-176.

2. Longridge NS, Mallinson AI. Visual vestibular mismatch in whiplash and Meniere's disease. In: Claussen C-F, Haid C-T, Hofferberth B, eds. Equilibrium research, clinical equilibriometry and modern treatment. Amsterdam: Elsevier Science BV, 2000:397-402.

3. Oman CM, Lichtenberg BK, Money KE, et al. M.I.T./Canadian vestibular experiments on the Spacelab-1 mission. 4. Space motion sickness: symptoms, stimuli and predictability. Exp Br Res 1986;64:316-334.

4. Yates BJ, Miller AD, Lucot JB. Physiological basis and pharmacology of motion sickness: an update. Br Res Bull 1998;47:395-406.

5. Furman JM, Jacob RM, Redfern MS. Clinical evidence that the vestibular system participates in autonomic control. J Vestib Res 1998; 8:27-34.

6. de Graaf B, Gresty MA. Foreword. Br Res Bull 1998; 47:393.

7. Flack M. Note on seasickness. Br Med J 1931; 1:176-177.

8. Pappas DG, Crawford W, Coghlan C. Dizziness and the autonomic disfunction syndrome. Otolaryngol Head Neck Surg 1986; 94:186-194.

9. Oman CM. Sensory conflict theory and space sickness: our changing perspective. J Vestib Res 1998; 8:51-56.

10. Preber L. Vegetative reactions in caloric and rotatory tests. A clinical study with special reference to motion sickness. Acta Otolaryngol Suppl (Stockh) 1958; 144:1-1 19.

11. Lidvall $\mathrm{H}$. Mechanisms of motion sickness as reflected in the vertigo and nystagmus responses to repeated caloric stimuli. Acta Otolaryngol (Stockh) 1962; 55:527-536.

12. Barber HO, Stockwell CW. Manual of electro-nystagmography. 2nd Ed. St. Louis: CV Mosby and Co, 1980.

13. Longridge NS, Mallinson Al, Denton A. Visual vestibular mismatch in patients treated with intratympanic gentamicin for Meniere's disease. J Otolaryngol 2002; 31:5-8. 
14. Yates BJ, Miller AD. Physiological evidence that the vestibular system participates in autonomic and respiratory control. J Vestib Res 1998; 8:17-25.

15. Coats AC, Norfleet WT. Immersed false vertical room. A new motion sickness model. J Vestib Res 1998; 8:135-149.

16. Thornton WE, Biggers WP, Pool SL, et al. Electronystagmography and audio potentials in space flight. Laryngoscope 1985; 95:924-932.

17. Gill C, Mallinson Al, Longridge NS. Effects of dimenhydrinate on computerized dynamic posturography. J Otolaryngol 2000; 29:337339. 


\section{CHAPTER EIGHT}

\section{Caloric response does not decline with age}

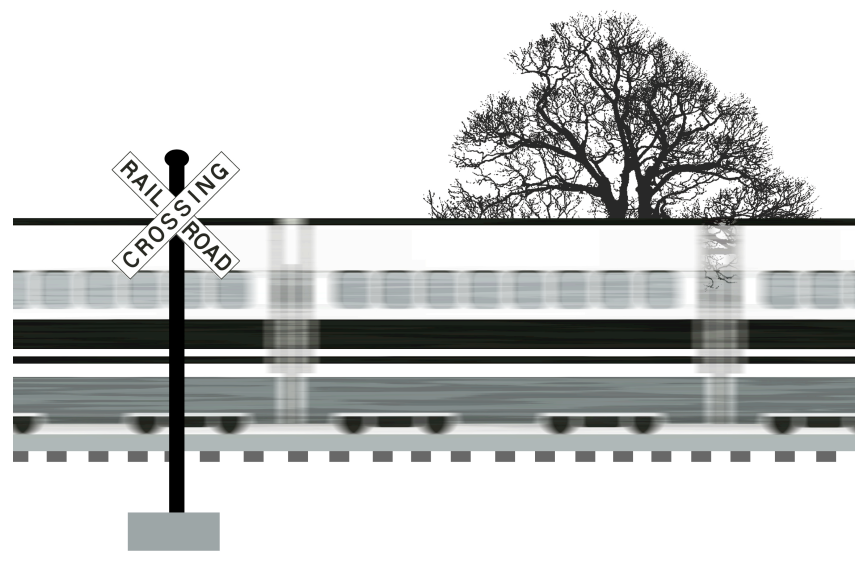

Mallinson Al, Longridge NS.

J Vest Res 2004;14(5):393-396. 


\section{ABSTRACT}

Complaints of imbalance in the elderly are commonly heard by clinicians, and pathology of the vestibular system may play an important role in these complaints. While there is solid anatomical evidence for age-related decline of some vestibular structures, a corresponding deterioration in physiologic function has not been convincingly demonstrated.

Vestibular function is traditionally measured with caloric irrigations. Although there has been some age dependent change in caloric response shown, there is no good parallel between caloric response and imbalance in the elderly patient.

Our experiment confirms that slow phase velocity of caloric responses does not decline with age. Calorics measure only one part of the vestibular system, and so should not be regarded as representative of balance system function. As a result, measured caloric response does not parallel documented anatomic age-related decline of the vestibular system.

KEYWORDS: calorics, aging, imbalance, otoliths, vestibular 


\section{INTRODUCTION}

Instability in the elderly is a well documented and widely researched problem. Instability is the result of some dysfunction of balance, and several studies have shown that stability decreases and postural sway increases with age $(10,15)$. However the reasons why aging adversely affects balance are not fully understood (4). Although Lord states (7) that there are no reports of an association between impaired vestibular function and instability in older people, Kristinsdottir et al. (5) state that vestibular dysfunction is fairly common in elderly individuals.

Vestibular deterioration with aging is known to occur in vestibular hair cells (13) and also nerve cells (2). Ross et al in 1976 (14) specifically showed degeneration of the otolith structures themselves. However despite the evidence provided to support anatomical deterioration of these structures, it has been difficult to illustrate a corresponding deterioration in physiologic function (for instance, utilizing the vestibulo-ocular reflex (VOR)) (11). Peterka et al. (12) did show a small decline, on average, in caloric responses with age based on a linear regression analysis, but called the results "ambiguous".

It has been suggested in the past that perhaps the lack of a correlation between anatomy and physiology may relate to the absence of clinical manifestations of the aging vestibular apparatus (16). Paige has suggested that our measurement techniques may not have "stressed" the VOR sufficiently to overcome the adaptive phenomena that are available to correct VOR performance deficits (11). He has also suggested that progressive anatomical deterioration with age can be viewed as a partial bilateral vestibulopathy (i.e. an age related "lesion"), which suggests that this "deficit" could potentially be measurable.

Later studies have been carried out to show that vestibular function is in fact related to instability and falling. One study (6) showed a very high correlation between fall related hip fractures and unilateral vestibular disease. In that study, patients who had suffered fall related hip fractures had a significantly higher incidence of head shake nystagmus compared to controls (indicating vestibular disease) and $75 \%$ of the patients with head shake nystagmus had fallen towards the slow phase of the nystagmus (which is what would be expected if the fall 
was vestibular related). It has also been suggested that vestibular disease may contribute to general instability in the elderly (5).

The "gold standard" of vestibular measurement is the caloric test as outlined by Barber (1). A caveat is that caloric testing measures only the function of the lateral semicircular canal (SCC). It does not assess the superior SCC, the posterior SCC, or the maculae, and so it is reasonable to question whether caloric testing can be used to quantify the physiologic decrease in function we assume should parallel anatomic age-related deterioration of the vestibular system.

Mulch et al. (8) addressed the question of age-related caloric response and provided an extensive review of work done in this regard. Their only definitive conclusion was that certain parameters of caloric response showed varying age dependent behaviour. However it has been suggested that decline in normal caloric response does not parallel the progressive course and level of deterioration shown in anatomical studies (12). One of the very few studies that measured caloric responses according to the accepted methods outlined by Barber (1) (analyzing maximum slow phase velocity) was conducted by van der Laan and Oosterveld (16). They showed that responses increased in intensity up to the age of 40 , and then progressively decreased with increasing age. Similar results were shown by Mulch and Petermann (8).

As mentioned previously, caloric testing is a measurement of lateral SCC function only, and perhaps should not serve as a valid measurement of agerelated balance system dysfunction. In addition, studies reporting SCC deficits related to age are not well detailed in experimental procedure, or subject selection. A previous study to investigate change in caloric response with age was carried out by Peterka et al. (12). In their analysis they used an "average response" (mean of all four calorics). As patients age, there is a greater chance that they may have suffered from unilateral vestibular pathology (i.e. past history of acute vestibulopathy) which could reduce the response on one side, and hence also reduce the "total response" in any subsequent bithermal caloric test. We were concerned that this may have been a confound in studies which do report senescence of SCC function over the age of 40 , and that calorics may in fact not be a true reflection of age-related vestibular decline. We proposed an experiment to see whether or not lateral SCC response to caloric 
testing does decline over age, designing the experiment to minimize any effect of previous vestibular insult.

\section{METHODS}

The charts of 185 patients referred sequentially to our clinic for dizziness were examined. This included 88 males and 97 females ranging in age from 9 to 89 years of age. Although our study would now require ethical approval from both the University and the Hospital, approval at the time of this study was not required, as the study fell into the category of a retrospective chart review of patients who had been exposed to only standard clinical assessment in our unit.

In our laboratory, we utilize the protocol outlined by Barber (1) that is used to obtain maximum vestibular response. All caloric testing was performed and analyzed by a single assessor, to eliminate the possibility of assessor variability. We calculated the mean of the hot and cold caloric responses (slow phase velocities) on the better responding side of all 185 charts.

All results of patients with previous history of vestibular complaints prior to their presenting troubles were excluded, as it is possible that a patient with more than one acute vestibular event could have suffered one lesion on each side. Also excluded were patients with any previous exposure to aminoglycosides or other ototoxic medications, and patients who had taken sedative medication in the last 48 hours. To address the concern that we were studying maximum caloric response in patients who had vestibular disease, we took the position that patients with true vertigo by definition have unilateral dysfunction, so by using the higher responding side, we were obtaining data from their nondiseased ear.

When scoring calorics, nystagmus seen in the first 15 seconds of an irrigation is by definition a spontaneous nystagmus (1), and any such record was discarded from the study. Any repeat ENG was also excluded, as repeat calorics can habituate response.

In analyzing one ear only, we felt that we were also cutting by $50 \%$ the chance that a patient had suffered a previous asymptomatic vestibular insult to the measured ear, and so a "maximal" response to calorics could be obtained. Although not made entirely clear in the literature, calorics have never to our knowledge been reported in this fashion before. 
AVERAGE RESPONSE OF BIGGEST SIDE
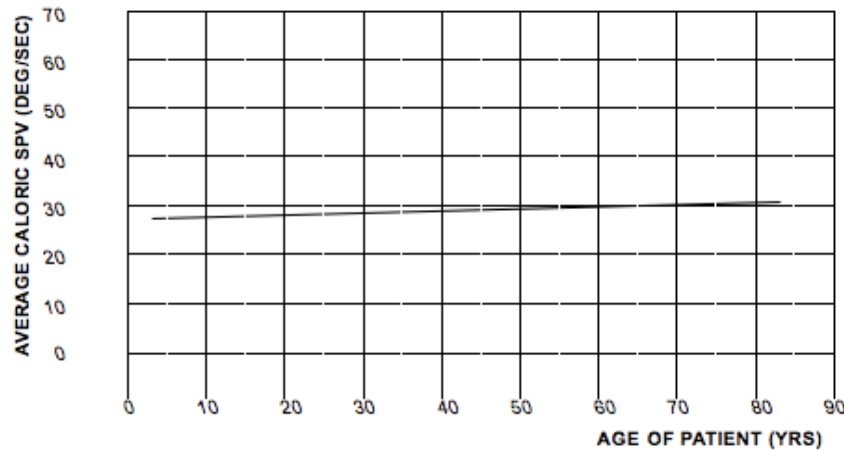

Fig. 1. "Best side average" caloric slow phase velocity plotted against age in 185 patients. $\left(\mathbf{R}^{2}=0.0043\right)(P=0.37)$.

\section{RESULTS}

We plotted caloric scores against age. We followed the lead of Peterka et al. (12) and looked at "average response" (the mean of the two calorics on the strongest side) and plotted this value against age (Fig. 1). A linear regression was performed to see if a relationship was suggested.

The $r^{2}$ value for the average of the calorics plotted against age was 0.0043 , with a p-value of 0.37 . The $r^{2}$ value suggests that only $0.43 \%$ of the variation in caloric score can be explained by age. The very high $\mathrm{p}$-value prevents us from suggesting there is any slope to the line.

\section{DISCUSSION}

Regardless of the actual mechanism, one of the abilities that is compromised in the elderly is the ability to control eye movements and foveate images. This is suggested by Paige [1 1] and also by Peterka et al. (12), both of whom measured VOR deficits related to age. Mulder et al. (9) have also shown that subjects over 70 years of age are impaired in their ability to adapt rapidly to disturbed peripheral conditions, both external and also internal. Perhaps the combination of a slight change in VOR coupled with senescence of the 
adaptive plasticity mechanisms (i.e. loss of ability of these mechanisms to compensate) plays an important role in the development of age related imbalance.

It has also been suggested that the reason the semicircular canal-ocular responses decline with age is related to a degradation of velocity storage, a hypothesized circuit that reduces phase lead and lengthens the dominant VOR time constant (4). This is probably a multineural signal processing that involves both the vestibular nuclei and also central processing. However, degradation of this hypothesized circuit will result in loss of ability to foveate an image effectively, precluding the ability to maintain balance (or the ability to compensate for a vestibular deficiency).

In summary, our findings suggest that caloric responses (i.e. measured semicircular canal-ocular responses) do not reflect anatomically documented age related senescence of the vestibular system. While caloric response remains a crucial (and one of the only) measures of vestibular function, our data and our method of analysis supports the findings of Peterka et al. (12) that age related effects on caloric results were ambiguous. In their analysis, Peterka et al. did find an average decrease with increasing age, but our method of using the highest side in each patient in an attempt to minimize the effects of previously suffered vestibular events may help to minimize the influence of acute attacks on a labyrinth over time (the possibility of which increases with advancing age). In short, caloric testing is clinically important in delineating the presence of a recent or remote unilateral lesion, but should not be regarded as a measure of true equilibrium and stability in the elderly. Aging does adversely affect equilibrium, and for upright balance to be maintained, the otolith organs may provide a critical signal concerning an impending perturbation of that equilibrium (9). Despite the maintenance of the semicircular canal signal, dysfunction of the vestibular system is common in elderly individuals (5). The only method presently described as being capable of measuring age-related otolithic decline is OVAR testing. Furman and Redfern (4) have used OVAR to show an age-related decline in otolith-ocular responses, which is hypothesized to result from a decline in central vestibular processing, rather than from a loss of function of the otoliths themselves. In summary, the caloric responses in our patients do not show an age related decline, and this agrees with Furman and 
Redfern's statement (4) that the aging peripheral vestibular system remains functionally intact. Perhaps the low stimulus amplitude signal supplied by the caloric test does not challenge the semicircular canal system sufficiently to reveal its defects, and we feel the caloric test should not be used as an indicator of age-related decline of balance system function. 


\section{REFERENCES}

1. H.O. Barber and C.W. Stockwell, Manual of Electronystagmography, (2nd ed.), C.V. Mosby. St. Louis, 1980.

2. B. Bergstrom, Morphology of the vestibular nerve; 2 : the number of myelinated vestibular nerve fibers in man at various ages, Acta Otolaryngol 76 (1973), 173-179.

3. F.O. Black, W.H. Paloski, M.F. Reschke, M. Igarashi, F. Guedry and D.J. Anderson, Disruption of postural readaptation by inertial stimuli following spaceflight, J. Vest. Res. 9(1999), 369-378.

4. J.M. Furman and M.S. Redfern, Effect of aging on the otolith-ocular reflex, J. Vest. Res. 11 (2001), 91-103.

5. E.K. Kristinsdottir, P.A. Fransson and M. Magnusson, Changes in postural control in healthy elderly subjects are related to vibration sensation, vision and vestibular asymmetry, Acta otolaryngol 121 (2001), 700-706.

6. E.K. Kristinsdottir, G.B. Jarnlo and M. Magnusson, Asymmetrical vestibular function in the elderly might be a significant contributor to hip fractures, Scand. J. Rehab. Med. 32 (2000), 56-60.

7. S.R. Lord, Physiological factors associated with falls, Plenary Presentation ISPGR 2003, Sydney Australia.

8. G. Mulch and W. Petermann, Influence of age on results of vestibular function tests, Review of literature and presentation of caloric test results, Ann. Otol. Rhinol. Laryngol. 88(Suppl 56) (1979), 1-17.

9. T.H. Mulder, W. Zijlstra and A. Geurts, Assessment of motor recovery and decline, Gait and Posture 16 (2002), 198-210.

10. M.E. Norre, G. Forrez and A. Beckers, Vestibular dysfunction causing instability in aged patients, Acta Otolaryngol 104 (1987), 50-55.

11. G.D. Paige, Senescence of human visual-vestibular interactions: vestibulo-ocular reflex and adaptive plasticity with aging, J. Vest. Res. 2 (1992), 133-151.

12. R.J. Peterka, F.O. Black and M.B. Schoenhoff, Age-related changes in human vestibulo-ocular reflexes: sinusoidal rotation and caloric tests, J. Vestib. Res. 1 (1990-1991), 49-59.

13. U. Rosenhall, Degenerative patterns in the aging human vestibular neuro-epithelia, Acta Otolaryngol 67 (1973), 208-220. 
14. M.D. Ross, D. Peacor, L.G. Johnsson and L.F. Allard, Observations on normal and degenerating human otoconia, Ann. Otol. Rhinol. Laryngol. 85 (1976), 310-326.

15. J.H. Sheldon, The effect of age on the control of the sway, Gerontol. Clin. 5 (1963), 129-138.

16. F.L. Van der Laan and W.J. Oosterveld, Age and vestibular function, Aerospace medicine 45 (1974), 540-547. 


\section{CHAPTER NINE}

\section{Visual vestibular mismatch in work-related vestibular injury}

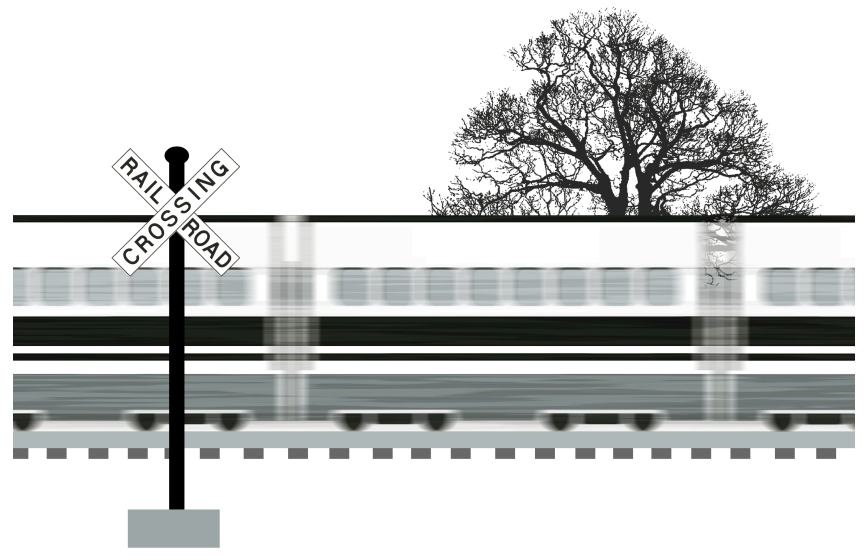

Mallinson Al, Longridge NS.

Otol Neurotol 2005 July;26(4):691-4. 


\section{ABSTRACT}

Objective: To define and investigate the symptom set known as visualvestibular mismatch and analyze its nature and occurrence in two groups of patients referred for dizziness.

Study Design: Prospective study of two groups of sequentially referred patients complaining of dizziness, imbalance, or both.

Setting: A tertiary and quaternary care ambulatory referral center.

Patients: Two groups of patients were studied. One was a group of patients who had suffered work-related head trauma and had subsequent complaints of dizziness and/or imbalance. The other was a group of patients referred for dizziness and/or imbalance who had no history of head trauma, work-related injury, or litigation procedures.

Interventions: Standard vestibular assessment including computerized dynamic posturography was carried out on all patients. A series of questions was designed to quantify patients' complaints of symptoms of visual-vestibular mismatch, and patients were scored according to their yes/no answers to the five questions.

Main Outcome Measures: Results of traditional vestibular tests were correlated with the answers to the questions. Computerized Dynamic Posturography and electronystagmography results were compared between both symptomatic and nonsymptomatic patients and also between patients who had traumatic and nontraumatic causes of their symptoms.

Results: We found no correlation between test results and the presence of visual-vestibular mismatch symptomatology. There does seem to be a connection between the presence of motion sickness symptomatology and the development of visual-vestibular mismatch symptoms.

Conclusion: Although visual-vestibular mismatch is of vestibular origin, it is discernible only after obtaining a careful history. It is a genuine symptom set of vestibular origin, and there is a certain group of patients who are more sensitive to this symptom set and who are often debilitated by its presence.

KEYWORDS: carsickness, dizziness, nausea, posturography, vestibular 
Visual stimulation alone can provoke vertiginous symptoms, and this was clearly outlined in some of the earliest medical writings. Soranus of Ephesus in the first century included moving visual stimuli (e.g., watching water flow or a potter's wheel rotating) as being provocative situations for vertigo. Galen observed that some people "could be affected even if they are not rotated." For a delightful account of the history of this phenomenon, the reader is referred to Balaban and Jacob (1).

The term "visual vertigo" (VV) was originally used by Erasmus Darwin in 1797 (cited in Balaban and Jacob [1]). The first connection between vertigo and seasickness was made by Hughlings Jackson in 1872 (1). More recently, Dichgans and Brandt (2) described the normal phenomenon of "motion perception," in which visual stimuli induce transient sensations of movement and also symptoms of motion sickness.

Bronstein (3) suggested that the clinical symptoms of $V V$ arise when the process of compensation from vestibular injury is disrupted by unusually high reliance on visual cues, leading to abnormal visually induced sway. Guerraz et al. (4) suggested that the development of $\mathrm{V} V$ was probably related to some idiosyncratic perceptual style.

The term "visual vestibular mismatch" (VVM) was originally used in the literature by Benson and King (5). Paige (6) redefined the term in reference to imbalance in the elderly, which he suggested could be the result of a difference in the rates of senescence in visual and vestibular function. However, the term has been redefined (7-9) as a symptom set generated by a discongruency between visual and vestibular signals. One-third of patients develop VVM complaints after intratympanic gentamicin therapy (8). We suspect that the development of VVM may indicate the presence of damage to the balance system. Our findings in treated Meniere's patients supports the statement by Furman and Jacob that these "...situational symptoms appear to be associated specifically with vestibular dysfunction" (10). Although patients are often markedly symptomatic, this dysfunction is often undetectable using standardized methods of vestibular measurement, such as electronystagmography (ENG) and computerized dynamic posturography (CDP). McCabe in 1975 (11) described a similar set of symptoms and coined the term "supermarket syndrome," defined as "an intolerance for looking back 
and forth... up and down aisles." Furman et al. (12) referred to the symptom set as "space motion discomfort" in 1997 and advanced solid clinical and anatomic evidence that the vestibular system participates in autonomic control, perhaps via vestibular nuclear and cerebellar regions that appear to integrate vestibular and autonomic information (13). Whiplash-related damage to some site in the balance system, either peripheral or central, also results in the generation of VVM (7), and $30 \%$ of patients undergoing intratympanic gentamicin therapy for intractable dizziness (i.e., iatrogenic vestibular damage) have been reported to develop VVM (9). VVM has come to be regarded by us as a symptom set that develops in some patients after suffering vestibular injury.

The importance of a mismatch between vestibular and visual input was alluded to by Brandt et al. (14) in describing "physiological height vertigo," in which the distance between observer and visible stationary contrasts is very large. We postulate that this mismatch is analogous to VVM and can also be created by vestibular injury, and we have come to regard the new development of fear of heights as indicative of a vestibular insult. Where is VVM generated? We have had the opportunity to examine the occurrence of VVM in two groups of patients: quaternary care referrals to our clinic from otolaryngologists and neurologists with various complaints of nontraumatic dizziness, and workers' compensation patients suffering dizziness and imbalance after work-related head injury. We felt this provided us with an ideal setting in which to examine the genesis of VVM. Did it result from peripheral end-organ symptoms or from perhaps more central damage suffered in a head blow? We also wished to determine whether VVM symptoms could be diagnosed by the "traditional" vestibular assessment techniques of CDP and ENG.

\section{PATIENTS AND METHODS}

In a prospective study, 61 patients referred to our clinic for assessment of nontraumatic dizziness were analyzed. All patients underwent an extensive otoneurologic history, completed a dizziness questionnaire, and underwent laboratory balance assessment with ENG according to Barber and Stockwell (15) and CDP using the Equitest (Neurocom, Inc., Clackamas, OR, U.S.A.). 
Included in the history-taking was the questioning in a non-leading fashion about VVM symptoms, using five VVM-specific questions (Table 1). We have purposely avoided putting the five questions into our questionnaire, which might serve to cue a patient in advance. Our history-taking is structured so that the five VVM questions are asked in a more roundabout manner, rather than being posed directly.

We excluded certain patients from the group of 61, as follows:

- Patients who had been involved in motor vehicle accidents.

- Patients who had developed symptoms after any type of head blow.

- Patients who did not have the language skills to answer our five VVM questions.

- Patients who were physically unable to complete posturography.

One hundred nine patients referred to us by the Workers' Compensation Board (WCB) were assessed in an identical manner. All patients had complaints of dizziness that came on after some type of work-related head trauma. All patents had had a neurologic examination, and it was felt that their complaints were not of neurologic origin.

All medical examinations were carried out by one of us (N.S.L.) and all diagnostic assessments and interpretations were carried out by the other (A.I.M.). Each assessor was blinded for the duration of the assessment with regard to impressions that might have been formed by the other. Three patients of the original WCB referrals were excluded, as follows:

- A patient with a sole complaint of tinnitus.

- A patient with a sole complaint of anosmia.

- A patient who had suffered recent gentamicin toxicity related to infection of orthopedic injuries from his accident. 


\title{
TABLE 1. VVM questions asked during history-taking
}

Are you made unwell by any of the following stimuli?

\author{
- Going on an escalator \\ - Watching traffic at an intersection \\ - Being in a supermarket \\ - Walking in a mall \\ - $\quad$ Seeing checkerboard floor patterns
}

\section{RESULTS}

Of the two groups we studied, our trauma patients (the WCB-referred patients) were slightly younger and much more male-dominated, likely because most "dangerous" occupations (e.g., forestry workers, construction, longshoremen) are traditionally dominated by younger men. One WCB patient was unable to complete posturography because of extreme nausea. Two patients in this group were unable to answer our VVM questions, as they had had no exposure to any of the offending stimuli.

Table 1 outlines our VVM-specific questions asked during history-taking in a nonleading fashion. We identified them as being VVM specific (i.e., the most common indicators of complaints of VVM) in a previous study (9). For the purposes of this study, we regarded a VVM-positive patient as one having a positive response to at least three of the five aggravating factors. Patients reporting a positive response to zero, one, or two of the five questions were categorized as VVM-negatives. We felt that positive answers to one or even two of the questions could represent suggestion or perhaps coincidence. We consider that sensitivity to three different aggravating factors suggests the presence of VVM. Table 2 outlines our data in the two groups of patients. All data were analyzed using a $\mathrm{X}^{2}$ analysis to determine significance. The only significant differences seen between the trauma and nontrauma groups were in the VVM-negative patients. Posturography results were significantly different in the VVM-negatives between the trauma and nontrauma groups. It was abnormal in $87 \%$ of the trauma group but in only $56 \%$ of the non-trauma group. 
Table 2. Comparison of nontrauma and trauma patients

\begin{tabular}{|c|c|c|}
\hline & $\begin{array}{l}\text { Trauma } \\
(n=109)(\%)\end{array}$ & $\begin{array}{l}\text { Nontrauma } \\
(n=61)(\%)\end{array}$ \\
\hline Male/female ratio & $\begin{array}{l}100 / 9 \\
(92 \% \text { male) }\end{array}$ & $\begin{array}{l}23 / 38 \\
(38 \% \text { male) }\end{array}$ \\
\hline Age (yr) & 40.5 & 47.6 \\
\hline Negative VVM $(0,1$, or 2 VVM score) & $76(71)$ & $43(70)$ \\
\hline Positive VVM $(3,4$, or 5 VVM score) & $31(29)$ & $18(30)$ \\
\hline Abnormal posturography & $94(88)$ & $38(62)^{a}$ \\
\hline Abnormal calorics & $16(15)$ & $14(23)$ \\
\hline \multicolumn{3}{|l|}{ ANALYSIS OF POSITIVE VVM POPULATION } \\
\hline Number of patients & 31 & 18 \\
\hline Abnormal posturography & $28(90)$ & $14(78)$ \\
\hline Abnormal calorics & $3(10)$ & $3(18)$ \\
\hline \multicolumn{3}{|l|}{ ANALYSIS OF NEGATIVE VVM POPULATION } \\
\hline Number of patients & 76 & 43 \\
\hline Abnormal posturography & $66(87)$ & $24(56)^{a}$ \\
\hline Abnormal calorics & $13(17)$ & $11(26)$ \\
\hline
\end{tabular}

$a_{p}<0.001$

\section{Table 3. Comparison of VVM groups}

VVM-positive (\%) VVM-negative (\%)

No. of patients

Abnormal posturography

Abnormal calorics

Motion sickness
49

42 (86)

$6(12)$

37 (76)
119

$90(76)$

24 (20)

$32(27)^{a}$

$a_{p}<0.001$ 


\section{DISCUSSION}

The concept of VVM has only recently come to be accepted as a physiologic rather than a psychological phenomenon and to perhaps be of balance system origin. Our patients with VVM differ from the patients described by Bronstein (3) in that some of them are not physically destabilized by orientationally inaccurate visual stimuli. This is evidenced by the fact that there was no difference in CDP performance between our VVM-positives and our VVMnegatives. However, our VVM patients characteristically develop autonomic symptoms (e.g., nausea, sweating, pallor, and panic), which are all components of the space motion discomfort symptoms outlined by Furman et al. (12). Certain patients are rendered totally incapacitated by the severity of this symptom set, and it can become a chronic condition.

Where is the VVM-causing abnormality located? It does not seem to be caused by head injury; $30 \%$ of our nontrauma group fell into the VVM-positive category, and $29 \%$ of our trauma group was VVM-positive. The trauma group's complaints were felt not to be neurologic, and both groups of patients voiced markedly similar complaints that were characteristically vestibular, in addition to their complaints of VVM. From this, it seems to us that VVM has arisen from damage that has occurred somewhere in the balance system. If VVM were brought on by head injury itself, we would expect to see a very high percentage of VVM-positives in our head-injured group.

Table 3 shows that measurement of VVM is difficult from an objective point of view, which can pose a challenge to the assessment of such patients. There was no difference in CDP performance between VVM-positive and VVM-negative patients. Calorics also were of no use in differentiating VVM-positives from VVMnegatives. The only distinguishing feature between the two groups was the significant difference in motion sickness, with only $27 \%$ of the VVM-negatives being motion sick, as opposed to $76 \%$ of the VVM-positives. Although it is possible that there is a psychological aspect to the complaints of some of our patients, "psychiatric dizziness" has recently been redefined as "dizziness occurring exclusively in combination with other symptoms as part of a recognized psychiatric symptom cluster" (10). This was not evident in any of our patients. 
The histories of our VVM patients are virtually identical to patients we have seen who have developed symptoms after suffering whiplash-associated injuries but no head injury and patients who developed symptoms after intratympanic gentamicin therapy.

\section{CONCLUSION}

VVM is not physically destabilizing, but we repeatedly encountered patients in whom the unpleasant symptom set can be severe. It can only be elucidated by obtaining a very careful history. VVM does not seem to be brought on by head injury as such, and it cannot be delineated using standard vestibular investigations. We have delineated a category of "susceptible" patients in whom the vestibular disruption is not necessarily destabilizing but rather invokes an autonomic motion sickness-like cascade of symptoms. These symptoms are physiologic rather than psychogenic, and we recognize them in patients with a variety of vestibular disorders. They encompass a wide variety of symptoms, and standard vestibular assessments are often not helpful in measuring their deficits. Nevertheless, we regard the development of VVM symptoms (which sometimes can be debilitating) as arising from the inner ear. 


\section{REFERENCES}

1. Balaban CD, Jacob RG. Background and history of the interface between anxiety and vertigo. Anxiety Dis 2001;15:27-51.

2. Dichgans J, Brandt TH. Visual vestibular interaction: effects on selfmotion perception and postural control. In: Held R, Liebowitz $H$, Teuber HL, eds. Handbook of Sensory Physiology. Berlin: SpringerVerlag, 1978:755-804.

3. Bronstein AM. The visual vertigo syndrome. Acta Otolaryngol 1995;520(Suppl):45-8.

4. Guerraz M, Yardley L, Bertholon P, et al. Visual vertigo: symptom assessment, spatial orientation, and postural control. Brain 2001;124:1646-5.

5. Benson AJ, King PF. The ears and nasal sinuses in the aerospace environment. In: Scott-Browne's Diseases of the Ears, Nose and Throat. Vol. 1. Basic Science. London: Butterworth's, 1979:205-43.

6. Paige GD. Senescence of human visual-vestibular interactions: smooth pursuit, optokinetic and vestibular control of eye movements with aging. Exp Br Res 1994;98: 355-72.

7. Mallinson Al, Longridge NS. Dizziness from whiplash and head injury. Am J Otol 1998;19:814-8.

8. Longridge NS, Mallinson Al. Visual vestibular mismatch in whiplash and Meniere's disease. In: Equilibrium Research, Clinical Equilibriometry and Modern Treatment. In: Claussen C- F, Haid C-T, Hofferberth B, eds. Amsterdam: Elsevier Science, 2000:397-402.

9. Longridge NS, Mallinson Al, Denton A. Visual vestibular mismatch in patients treated with intratympanic gentamicin for Meniere's disease. J Otolaryngol 2002;31:5-8.

10. Furman JM, Jacob RG. Psychiatric dizziness. Neurology 1997:48:11616.

11. McCabe BF. Diseases of the end organ and vestibular nerve. In: Naunton RF, ed. The Vestibular System. New York: Academic Press, 1975:299-302.

12. Furman JM, Jacob RG, Redfern MS. Clinical evidence that the vestibular system participates in autonomic control. J Vestib Res 
1998;8:27-34.

13. Balaban CD, Porter JD. Neuroanatomic substrates for vestibuloautonomic interactions. J Vestib Res 1998;8:7-16.

14. Brandt T, Arnold F, Bles W et al. The mechanism of physiological height vertigo. Acta Otolaryngol 1980;89:513-22.

15. Barber HO, Stockwell CW. Manual of Electronystagmography. 2nd ed. St. Louis: CV Mosby, 1980 


\section{CHAPTER TEN}

\section{"Across the board" posturography abnormalities in vestibular injury}

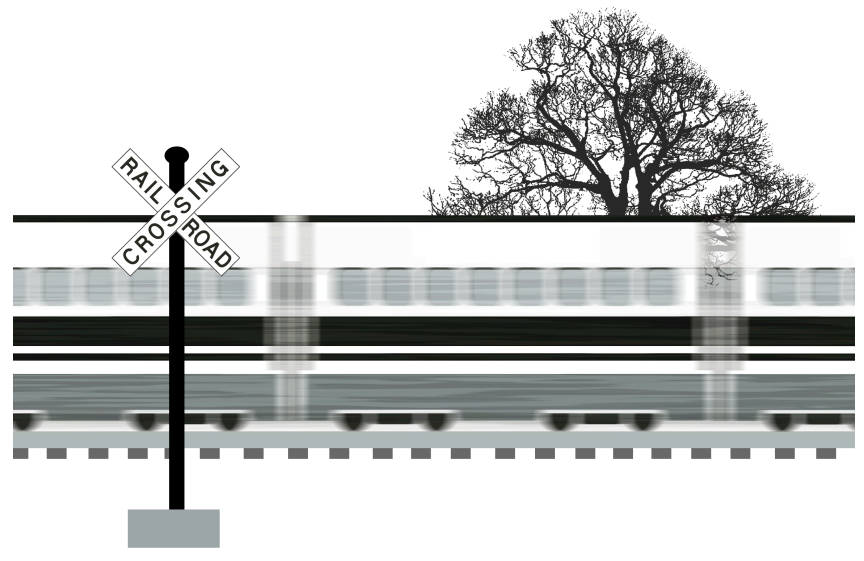

Mallinson Al, Longridge NS.

Otol Neurotol 2005 July;26(4):695-8. 


\section{ABSTRACT}

Objective: To analyze a newly defined group of Computerized Dynamic Posturography abnormalities and to determine if these patients' abnormalities are of vestibular origin.

Study Design: Analysis of results drawn from our larger study of two groups of sequentially referred patients complaining of dizziness and/or imbalance.

Setting: A tertiary and quaternary care ambulatory referral centre.

Patients: Two groups of patients were studied. One was a group of patients who had suffered work-related head trauma and had subsequent complaints of dizziness and/or imbalance. The other was a group of patients referred for dizziness and/or imbalance who had no history of head trauma, work related injury or litigation procedures.

Interventions: Standard vestibular assessment including Computerized Dynamic Posturography was carried out on all patients.

Main Outcome Measures: CDP results of all patients were reanalyzed and all results were pulled which were abnormal on at least 5 of 6 sensory conditions. All results were analyzed using a quantitative method of detecting malingering and also using our newly developed nine point subjective/objective criteria scale.

Results: While the standardized formulae categorized most of these results as "aphysiologic," our nine-point protocol showed most of the patients to be legitimate.

Conclusions: These results represent a legitimate subgroup of vestibular patients that we feel have been more or less unrecognized, many of whom are incapacitated by imbalance and disorientation. These results also are helpful in measuring safety of these patients in the workplace.

KEYWORDS: dizziness, imbalance, posturography, vestibular. 


\section{INTRODUCTION}

Traditional vestibular assessment with electronystagmography (ENG) is frequently unhelpful in localizing or even delineating a vestibular lesion, as ENG findings are often normal. Computerized Dynamic Posturography (CDP) does not provide localizing or lateralizing information, but it is a more sensitive test at detecting the presence of a vestibular system abnormality (1). It also is useful in assessing the safety of a patient at home or in the workplace, and is an appropriate technique for measuring functional ability (2).

Many patients that we see do not voice traditional complaints of vertigo, but report symptoms of vague imbalance and unsteadiness, which is very important to document and quantify especially with respect to workplace safety and also for safety in everyday activity. Occupations such as roofing, bridge building, crane operating, or even waitressing can be hazardous to the patient or surrounding people. Posturography frequently is helpful in assessing these patients, as it is very often abnormal.

Patients who have vestibular complaints frequently have abnormal CDP Sensory Organization Test (SOT) assessments, and often exhibit "typical" vestibular dysfunction patterns (e.g., "5,6 down"; "6 down") (3), or abnormality patterns that are suggestive of a specific preference or dependence on visual or somatosensory information (e.g., "4, 5, 6 down"; "3, 5, 6 down") (2). Many patients that we assess have CDP SOT deficits, which do not fit a traditionally recognized pattern. Not infrequently, they have deficits on 4, 5, or even all 6 of the SOT conditions. Although they relate vestibular sounding stories after careful history taking, and often have no known ulterior motives such as litigation, etc., these nonspecific SOT abnormality patterns are regarded in the literature as "aphysiologic" (2). In fact it is suggested in the CDP interpretation manual that during SOT assessment, if a generalized increase in sway is seen resulting in a patient's performance being impaired to an equal extent on all six conditions, vestibular system dysfunction as the primary cause of imbalance is unlikely.(3)

We see nonspecific CDP SOT abnormalities on a recurring basis in all three of the populations we encounter clinically; standard referrals to our tertiary care Dizzy clinic, work-injured patients who are looked after by a government- 
funded Worker's Compensation system, and medical-legal patients (often postMVA) who are involved in a litigation process. We refer to these abnormality patterns as "across the board" abnormalities. We use this term when at least 5 of 6 SOT conditions are subpar. In a companion study, we assessed two groups of patients. From these two groups, we extracted a subgroup of patients, all with similar "across the board" CDP deficits. These patients had histories of unsteadiness and imbalance, and neurological assessment of them did not identify a lesion to account for their complaints. We wondered if this group of "nonspecifics" did, in fact, represent a group of patients with legitimate pathology. We felt that they warranted closer study, and we undertook to analyze their results using standardized methods of evaluating aphysiologic performance, and also by using our criteria for detecting aphysiologic behaviour reported in our companion study (4).

\section{TABLE 1. Patients with nonspecific CDP abnormalities.}

"Across the board" pathologies

(at least 5/6 posturography conditions abnormal)

\begin{tabular}{lcc} 
& Trauma (WCB) & Nontrauma \\
\hline No. of patients ( $p<0.01$ ) & $33 / 109$ (30\%) & $6 / 61$ (10\%) \\
$\begin{array}{l}\text { No. of malingerers (using } \\
\begin{array}{l}\text { Mallinson/Longridge } \\
\text { criteria) }\end{array}\end{array}$ & 3 & 0
\end{tabular}

\section{CEVETTE CLASSIFICATION}




\section{METHODS}

The CDP SOT results of the 61 patients reported in our companion paper (4) were analyzed. A similar analysis was carried out on the results of the 109 patients referred to us by the Workers' Compensation Board. All of these patients had complaints of dizziness, which came on after some type of work-related head injury. All had an assessment by a neurologist, and it was felt that their complaints were not of neurological origin.

From those two groups of patients (nontrauma and trauma), a subgroup of 39 patients with CDP SOT deficits on at least $5 / 6$ conditions (for which we have coined the term "across the board" abnormalities) was selected. There were 33/109 patients from our traumatic group (30\%), and 6/61 (10\%) from our nontrauma group (Table 1). All CDP results were assessed using the Goebel criteria (5), Cevette formulae (6) and our nine-point malingering criteria outlined in our companion paper (4).

We also assessed the COG alignment of our 33 "across the board" patients in our traumatic injury group recorded during CDP assessment. If a patient maintains COG near the limits of stability, only small additional displacements are required to lose balance, and we thought that perhaps this may be contributing to the generalized instability shown by these patients.

\section{RESULTS}

Three patients of the trauma group who had across the board deficits were classified as flagrant malingerers using the Goebel criteria (5) and our nine-point scale (4). All three of those patients were also classified as "aphysiological" by the Cevette formulae (6). There were no patients in our nontrauma group judged by us to be malingering (none of these patients, as far as we are aware, had any ulterior motives, and they had waited three months to be assessed in our clinic).

Of the 30 remaining patients in the trauma group, 24 were classified by the Cevette formulae as "aphysiologic," 1 was classified as "normal," and 5 were classified as "vestibular" (Table 1). All six patients in our nontrauma group were classified as aphysiologic. (In addition to the fact that none of these 6 patients 
had any ulterior motives of which we were aware, 4 of them had caloric reductions, which strongly suggests vestibular pathology.)

When we examined the COG alignment of the 30 legitimate WCB trauma "across the board" patients, there was a significant difference; 16 of them (53\%) had their COG behind the center of foot support, while only 9 of the other 76 patients (12\%) exhibited this tendency.

\section{DISCUSSION}

We have come to recognize a group of "inherently unstable" patients with "across the board" posturography abnormalities (at least 5/6 conditions subpar). In our nontrauma group, $10 \%$ of patients fell into this category, but this figure was $30 \%$ in our trauma group. While one might conclude that this suggests the "across the board" pattern is aphysiologic, we were struck by the fact that patients with identical abnormalities were seen in the non workinjured group, and that most patients with these abnormalities had no other signs of malingering behaviour using either the Goebel criteria or our nine-point criteria. We postulate that this particular abnormality may suggest an impairment somewhere in the balance system (either peripheral or central) not necessarily reflected as a caloric abnormality (i.e., not impairing lateral semicircular canal function). In our nontrauma group, 4 of the 6 patients with these results had a unilateral reduction, but in our head injured group, only 5 of $30(17 \%)$ had a caloric abnormality.

Does this subset of CDP results represent a legitimate group of pathology that has gone unrecognized up until now? Our group of nontraumatic dizzy patients shows results similar to those in head injured patients, although Kisilevsky et al. (7) have inferred central pathology in people showing this combination of findings. However, they do not suggest the nature of the pathology any more specifically. They draw attention to the fact that, after a head injury, most patients do not show an acute "vestibular pattern" of CDP abnormality, but indeed show a multi-sensory deficit pattern (across the board) possibly suggestive of central pathology. The assumption of a central origin for this finding is based on information in the CDP manual (3), which suggests a central origin but makes no statistical support for this assumption. We see little, if any, central pathology in our groups of patients (and our trauma 
patients had all been examined by a neurologist). We wondered if in addition to "across the board" CDP abnormalities, they also had seen other standardly accepted CDP abnormalities (e.g., "4, 5, 6 down"; "3, 5, 6 down" patterns). These patterns also are said in the CDP assessment manual to be "suggestive of central nervous system pathology" (3) although it is generally accepted that these CDP abnormality patterns are standardly recognized patterns of peripheral vestibular deficits $(2,8)$.

We speculate that the "across the board" abnormality pattern is due to a disturbance of the balance system, perhaps involving parts that are as yet clinically unmeasurable (8). Even though it is not yet possible to measure vestibular activity in the utricular macula, the saccular macula, and two of the semicircular canals, we are aware that myogenic evoked potentials do measure an acoustic response from the macula of the saccule. We assume that these structures are still capable of producing significant disease. It should be remembered that otoconia weigh substantially more than their surrounding milieu, and in a situation of acute trauma, their inertia is likely to result in trauma to the macular organs.

Several studies have examined postflight instability in returning American astronauts. Paloski et al. (9) reported "substantial decrease in postural stability on landing day" in astronauts when measured on CDP. While they didn't report SOT scores for individual conditions, their discussion referring to "disrupted postural stability" seems to suggest a non-specific performance deficit.

A study by Black et al. (10) reports further results about instability of returning astronauts and shows a subtle "across the board" deficit in two of the astronauts. Interestingly, these same two astronauts had taken part in another experiment in which they had been exposed to a post flight eccentric rotation experiment. In one of these two astronauts, ataxia was so severe that posturography could not be completed initially, and when it was, the results showed a vestibular type of deficit (5,6 down) superimposed on a subtle drop in performance on all conditions. The explanation offered in this study was that, in these two astronauts, the post flight eccentric rotation had a disruptive effect on otolithic inputs. This was in agreement with Parker et al. (11) who in 1985 stated that post flight disorientation of astronauts may be related to an 
"otolith reinterpretation hypothesis," in which otolithic signals in $O G$ conditions suggesting falls (i.e., sudden movement of the body towards the feet) are reinterpreted as linear translations, as there is no such thing in space as a "fall". Fries et al. (12) in 1993 also suggested that although the combination of otolithic signals to postural control is controversial, it seems that otolithic information plays an important role.

More than half of the patients in the trauma arm of our study exhibited a misalignment of weight distribution, placing their weight inappropriately behind their center of foot support on a consistent basis, and the number of malaligned patients in the across the board group was significantly higher than the rest of our group. Perhaps this malalignment contributes to the generalized destabilization seen in our "across the boards." This rearward malalignment also has been observed by Kohen-Raz (13) in patients reporting imbalance after whiplash-type injuries, and we feel this may be another feature of otolithic disruption, perhaps leaving a patient unable to calculate earth vertical in an appropriate manner. Often these patients deny any symptoms of vertigo at all, even after direct questioning, but rather they voice complaints of "being off balance" or "feeling intoxicated."

Davies and Luxon looked at dizziness after head injury and felt that "the variety of audiovestibular abnormalities found in head injured patients would suggest that the sensory organs of the inner ear are vulnerable" (14). They also state that, based on the high incidence of benign positional vertigo (BPV) in head injury, the otoliths are the most frequently affected structure. Otolithic debris results in the well-known symptoms of canalolithiasis, and otolithic damage in our patients could account for the CDP abnormalities seen in our patients whether or not the calorics are normal.

We postulate that our group of patients (and also the returning astronauts with similar nonspecific CDP deficits) are exhibiting the vestibulospinal correlates of otolithic deficits. Our patients may represent the "other side" of BPV, and their symptoms and CDP results may have resulted from damage to the otoliths, either traumatically or nontraumatically.

We concur with Black et al. (10) that their astronauts' CDP abnormalities are physiologic and do suggest pathology of the balance system. However, most 
of the patients we saw in both our study groups with this pattern of abnormality were classified by the Cevette formula as "aphysiologic." We feel that the Cevette formulae neglect to recognize the "across the board" pathology group, a legitimate group of patients demonstrating an impairment, which can be extremely compromising to a patient's employability as well as disruptive to recreational activities. 


\section{REFERENCES}

1. Lipp M, Longridge NS. Computerized dynamic posturography: its place in evaluation of the patients with dizziness and imbalance. J Otolaryngol 1994:23:177-83.

2. Furman JM. Role of posturography in the management of vestibular patients. Otolaryngol Head Neck Surg 1995;112:8-15.

3. Equitest System Version 4.0 Data Interpretation Manual. Neurocom International, Clackamas, OR. 1994.

4. Mallinson Al, Longridge NS. A new set of criteria for evaluating malingering in work related vestibular injury. Otol Neurotol 2005;26:686 $-91$.

5. Goebel JA, Sataloff RT, Hanson JM, et al. Posturographic evidence of nonorganic sway patterns in normal subjects, patients and suspected malingerers. Otolaryngol Head Neck Surg 1997;1 17:293-302.

6. Cevette MJ, Puetz B, Marion MS, et al. Aphysiologic performance on dynamic posturography. Otolaryngol Head Neck Surg 1995;112:67688.

7. Kisilevski V, Podoshin L, Ben-David J, et al. Results of otovestibular tests in mild head injuries. Int Tinnitus J 2001;7:118-21.

8. Mallinson Al, Longridge NS. Dizziness from whiplash and head injury: differences between whiplash and head injury. Am J Otology 1998;19:814-8.

9. Paloski $W H$, Reschke M F, Black F O, et al. Recovery of postural equilibrium control following spaceflight. In: Cohen B, Tomko D L,Guedry F, eds. Sensing and Controlling Motion. New York, NY: Annals of the New York Academy of Science: 1992;656747-54.

10. Black FO, Paloski WH, Reschke MF, et al. Disruption of postural readaptation by inertial stimuli following spaceflight. J Vest Res 1999:9:369-78.

11. Parker DE, Reschke MF, Arrott AP, et al. Otolith tilt-translations reinterpretation following prolonged weightlessness: implications for preflight training. Aviat Space Environ Med 1985;56:601-6.

12. Fries $\mathrm{W}$, Dieterich $\mathrm{M}$, Brandt T. Otolithic contributions to postural control in man: short latency motor responses following sound stimulation in 
a case of otolithic Tullio phenomenon. Gait and Posture 1993;1:14553.

13. Kohen-Raz R, Roth V. Posturographic characteristics of whiplash patients. In: Claussen CF, Haid CT, Hofferberth B, eds. Equilibrium research, clinical equilibriometry and modern treatment. Amsterdam: Elsevier Science BV; 2000:647-60.

14. Davies RA, Luxon LM. Dizziness following head injury: a neurootological study. J Neur 1995;242:222-30. 


\section{CHAPTER ELEVEN}

\section{Evaluation of the effects of ethanol on static and dynamic gait}

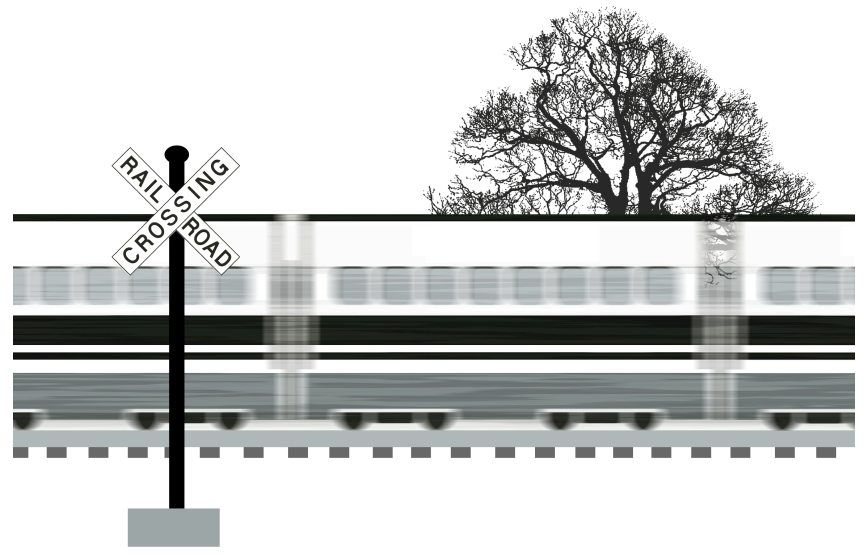

Mallinson AI, Longridge NS, Morley RE J Otolaryngol Head Neck Surg 2008 Dec;37(6):856-9. 


\section{ABSTRACT}

Objective: We used two balance assessment devices, Computerized Dynamic Posturography (CDP) and Swaystar transducers to detect subtle balance system deficits in nine subjects who had ingested minimal amounts of alcohol.

Design: Nine subjects were evaluated with both modalities before, and repetitively after, ingesting a small amount of alcohol.

Methods: We measured condition 5 (sway referenced platform; eyes closed) on CDP and tandem walking with eyes closed while wearing Swaystar to see if either test could detect a balance deficit.

Main Outcome Measures: We measured total sway amplitude with eyes closed in pitch and roll planes during tandem walking with Swaystar, and static balance scores of CDP sensory organization testing condition 5 before and after alcohol ingestion at 20 min intervals.

Results: Although there was no detectable deficit measurable by CDP, eight of our nine subjects showed increased dynamic sway as measured by Swaystar, after alcohol ingestion. Total sway was significantly greater $(p=.05)$ after alcohol ingestion.

Conclusion: It is important to assess dynamic, rather than static, equilibrium as it may have potential in detecting very subtle balance deficits.

KEYWORDS: ethanol, gait, imbalance, posturography, Swaystar 
The complexities of human balance make it difficult to assess subtle balance and gait disorders in an accurate and efficient manner in the clinical setting. Subjective evaluation using rombergism is useful as a gross screening test, but many patients with minimal but still legitimate complaints (or who have compensated well for a vestibular lesion) can pass quick office assessments such as tandem Romberg or tandem walking tests.(1)

Computerized Dynamic Posturography (CDP) is a modern method of measuring static balance by quantifying sway. Office evaluation techniques of dynamic sway (e.g., assessment of tandem walking) usually consist of observation of sway amplitude by standing behind a patient and observing sway in the roll plane (side-to-side sway). It is difficult in the clinical setting to make simultaneous observations about dynamic gait in both pitch and roll planes.

Swaystar (Balance International Innovations, Basel, Switzerland) is a lightweight, easy-to-use, belt-mounted set of transducers that enables quantification not only of sway amplitude but also of trunk angular velocities during dynamic gait in both pitch anterior-posterior (A-P) and roll (side-to-side) planes. Information at the trunk is important since the first response to a perturbation of balance occurs laterally in the trunk.(2)

Many people are familiar with the impairing effects of small doses of ethanol on dynamic gait and the general postural stability that such doses can cause.(3) The direct effects of ethanol on the vestibular system serve to reduce the sensitivity of the peripheral end-organ.(4) However, ethanol also reduces the gain of the vestibulo-ocular reflex (VOR) and causes central inhibition.(5) These effects on the VOR result in a sensation of apparent concomitant motion (ACM) of stationary visual stimuli correlated with head movement. This symptom is suggestive of a reduced gain of the VOR. (6)

Even minimal alcohol-induced deficits may potentially result in loss of balance under crucial conditions (e.g., on a roof, on a ladder, on a precipice). Ledin and Odkvist measured these deficits and found that the most sensitive measurement techniques were test conditions that excluded visual input.(3) It may be that, under conditions of alcohol impairment, visual input is used as a compensation device (similar to compensation mechanisms developed by patients with vestibular lesions). 
As ethanol suppresses the VOR, we wondered if it might also suppress the vestibulospinal reflexes (VSRs). The imbalance observed during intoxication is well documented. Fregly showed that the balance capabilities of patients with bilateral vestibular loss are degraded very little, if at all, by ethanol intoxication. (7) His interpretation of this finding was that ethanol-related ataxia results from a direct suppressive effect on the VSR and not on the central nervous system. It has also been suggested by Tianwu and colleagues that one of the reasons for postural instability after acute ethanol intoxication may be reduced vestibular function. (8)

Patients referred to our tertiary/quaternary care balance clinic often voice complaints of vague imbalance, which they sometimes characterize as "like I've had a couple of drinks." Because we often hear this volunteered during history taking, and because of the apparent suppressive effects that ethanol has on both the VOR and the VSR, we postulated that even minimal (in some cases, asymptomatic) amounts of ethanol might induce postural instability, resulting in some detectable alteration of dynamic gait. Often our patients' assessments show only slight (if any) abnormalities, and we wondered if it might be possible with CDP and/or Swaystar to detect these slight balance deficits in healthy subjects under the influence of a minimal dose of ethanol.

It has been shown that, with eyes closed, body sway is most pronounced under the influence of ethanol in men aged 40 to 49 years, but there were no other differences between individuals under the age of 40 years.(9) Because we wanted to eliminate any age effects, we studied healthy individuals under the age of 35 years.

\section{METHODS}

Both Vancouver General Hospital and University of British Columbia ethics committee approvals were obtained for this study. Five males and four females between the ages of 25 and 34 years were recruited. All were healthy and free of previous orthopedic trauma to the pelvis or lower extremities. Of note (and known before the experiment was begun) is the fact that one subject had a past history of mild head injury 3 years previously. 
All subjects underwent CDP sensory organization testing (SOT) using CDP (Equitest). The details of the principles(10) and techniques,(11) of balance measurement using CDP are well outlined in these cited references for the interested reader.

Assessment in all subjects also consisted of tandem walking 10 steps, with eyes closed, while wearing Swaystar. In this test, no guidance was given to any subject about cadence, except to "take 10 tandem steps with your eyes closed, and do as well as you can." The time taken to complete 10 steps was recorded.

Both CDP and tandem walking with eyes closed while wearing Swaystar was carried out prior to alcohol consumption (time 0). Immediately after baseline assessment, each subject consumed "three drinks" (89 $\mathrm{ml}$ or 3 oz.) of $40 \%$ alcohol on an empty stomach within a 5-minute period. Assessment was repeated at 20,40, and 60 minutes, measured from when ethanol consumption began. At each time interval, we extracted the median of the three CDP SOT condition 5 (sway referenced platform; eyes closed) scores. We also extracted two Swaystar measurements for analysis:

- maximum sway amplitude of tandem walking with eyes closed in roll plane

- maximum sway amplitude of tandem walking with eyes closed in pitch plane

Swaystar computes maximal angular trunk sway in degrees, and we summed the total sway in each plane (pitch and roll) to compute a total sway amplitude measurement for each subject.

We estimated blood alcohol levels attained in each subject. The total amount of pure alcohol was calculated by using the amount and strength of alcohol consumed and multiplying by the specific gravity of ethanol. Estimated blood alcohol level was derived using the weight of the patient and the known constant of amount of body water per kilogram. Projected estimates for blood alcohol concentration (BAC) in our subjects are reported in Table 1.

The greatest effect of ethanol appears at about 50 minutes when one examines ACM.(3) (This is caused by a direct effect of ethanol on the VOR.) We 
examined our data at both 40 and 60 minutes post-alcohol ingestion and used the larger of the 40-minute and 60-minute condition 5 CDP median scores and the larger of the Swaystar total sway amplitude scores in each subject.

\section{Table 1. Sway Amplitudes and CDP Condition 5 Scores}

\section{Before and After Alcohol Ingestion}

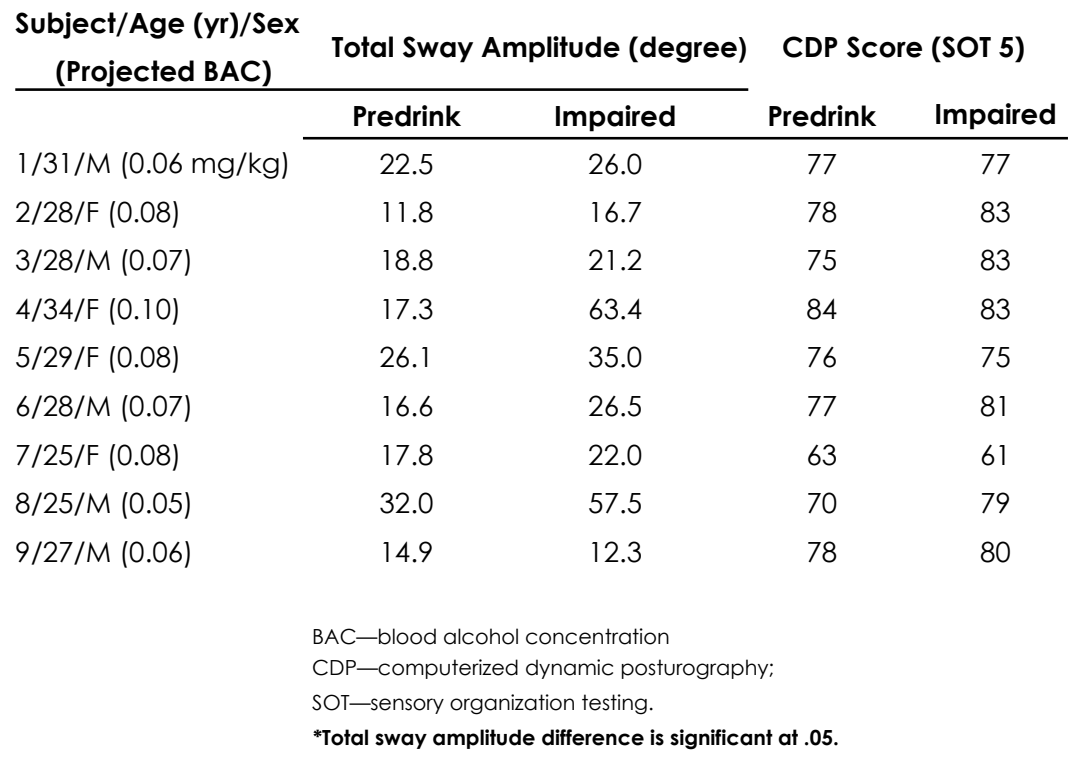

\section{RESULTS}

All subjects reported a slight subjective sensation as a result of their alcohol ingestion. Only one of our subjects (subject 4) was projected to have exceeded legal intoxication (see Table 1). The results across all nine subjects showed a significant $(p<.05)$ increase in total sway using a one-tailed paired t-test. CDP SOT condition 5 scores at 40 and 60 minutes showed no significant change from baseline in any subject. 


\section{DISCUSSION}

Our purpose in this experiment was to determine if ingestion of a small quantity of alcohol induces minimal vestibular impairment in normal subjects that might be detectable with either CDP or Swaystar.

Our study shows that it may be possible to detect subtle dynamic imbalance brought on by alcohol-induced vestibular impairment. We used an estimated blood level calculator to assess the degree of impairment of our subjects. Although we did not monitor actual blood alcohol level and did not use a breathalyzer, we used one of many scientifically derived formulas to estimate $B A C$. These formulas enable researchers to estimate BAC in a range of subjects and are accepted as accurate estimates of intoxication.(12) Our subjects were only minimally impaired according to BAC estimates.

SOT condition 5 is one of the two CDP conditions that maximally stresses the vestibular system, and two previous studies using CDP to measure the effects of alcohol $(3,8)$ used condition 5 as they both found that sway was maximized by the total absence of vision. For those reasons, we used the median of three CDP SOT scores on condition 5. SOT condition 5 turned out to be unhelpful in detecting ethanol-induced unsteadiness in our subjects.

Allum and colleagues showed that, in patients with balance deficits, sway amplitudes increase in both pitch and roll planes.(2) We summed the Swaystar tandem walking sway amplitude scores in both planes to sensitize the assessment. In several of the trials, subjects took a step sideways. Although this is noticeable to an observer, it was not apparent on our recordings as no angular trunk movement is associated with a side step. We regard this as a caveat when assessing balance using Swaystar as gait abnormalities are detected only if they involve rotational (as opposed to translational) movements of the trunk.

Ethanol doses of $100 \mathrm{~mL}$ of whiskey (only slightly more than our doses) affect the VOR; these doses have been shown to induce positional nystagmus in 30 minutes, (13) and this is assumed to be due to a variable rate of diffusion of ethanol into the cupula (semicircular canal) and surrounding endolymph. Swaystar measured changes in VSR in our subjects by measuring increased 
sway amplitude, but we were able to do this only by summing pitch plane and roll plane sway. Perhaps this also reflects the multifactorial nature of posture maintenance (i.e., sometimes pitch plane sway is increased, sometimes roll plane is increased, and sometimes total sway is increased).

\section{CONCLUSIONS}

The effects of alcohol on balance probably arise as a result of a multifactorial influence on balance maintenance. As discussed, alcohol serves to sedate the vestibular signal, $(4-6,8)$ but it also sedates centrally. Central effects occur at the level of the vestibulospinal system, but sedation is also cortical, and this may serve to steady a subject at low doses.(14) Subjective strategies to maintain balance may also differ from one subject to another.

Perhaps individual balance maintenance decisions may be executed at some central control level by our alcohol-impaired subjects. Our head-injured patient (subject 8) performed very poorly. It is unclear what, if any, effects his head injury had on his performance, but it could be speculated that either he had some impairment in his ability to make such decisions or vestibular damage (peripheral or central) was unmasked in him ("decompensated") by the alcohol.

The present study showed that eight of our nine subjects showed increased dynamic sway using Swaystar, which we could not detect on CDP after $89 \mathrm{~mL}$ of ethanol. The difference was significant at $p<.05$. One subject had a threefold increase in sway measured by Swaystar (i.e., during dynamic walking) but no change in her posturography. Perhaps this illustrates the difference between unperturbed stance and ambulation. It was necessary to add sway amplitudes together since performance differences in pitch planes and roll planes were not significantly different. This may support the multifactorial nature of change in gait under different circumstances. Swaystar enables us to assess dynamic rather than static equilibrium when looking for subtle clinical deficits. 


\section{REFERENCES}

1. Mallinson Al, Longridge NS, Wong K. Using Swaystar to measure sway amplitude in an office setting J Otolaryngol 2004;33:17-21.

2. Allum JH, Adkin AL, Carpenter MG, et al. Trunk sway measures of postural stability during clinical balance tests: effects of a unilateral vestibular deficit Gait Posture 2001;14:227-37.

3. Ledin T, Odkvist LM. Effect of alcohol measured by dynamic posturography Acta Otolaryngol Suppl (Stockh) 1991;481:576-81.

4. Cohen B. The vestibulo-ocular reflex arc In: Kornhuber $\mathrm{HH}$, editor Handbook of sensory physiology New York: Springer Verlag; 1974. p. 477-540.

5. Post RB, Lott LA, Beede Jl, et al. The effect of ethanol on the vestibuloocular reflex and apparent concomitant motion J Vestib Res 1994:4:181-7.

6. Gresty MA, Hess K, Leech J. Disorders of the vestibulo-ocular reflex producing oscillopsia and mechanisms compensating for loss of labyrinthine function Brain 1977;100:693-716.

7. Fregly AR. Vestibular ataxia and its measurement in man In: Kornhuber $\mathrm{HH}$, editor Handbook of sensory physiology New York: Springer Verlag; 1974. p. 321-60.

8. Tianwu $H$, Watanabe $Y$, Asai $M$, et al. Effects of alcohol ingestion on vestibular function in postural control Acta Otolaryngol Suppl (Stockh) 1995:519:127-31.

9. Jones AN, Neri A. Age related differences in the effects of ethanol on performance and behaviour in healthy men Alcohol 1994;29:171-9.

10. Nashner LM, Peters JF. Dynamic posturography in the diagnosis and management of dizziness and balance disorders Neurol Clin 1990;8:331-49.

11. Goebel JA, Paige GD. Dynamic posturography and caloric test results in patients with and without vertigo Otolaryngol Head Neck Surg 1989;100:553-8.

12. Brick J. Standardization of alcohol calculations in research Alcohol Clin Exp Res 2006;30:1276-87. 
13. Aschan G, Bergstedt M. Positional alcohol nystagmus in man following repeated alcohol doses Acta Otolaryngol Suppl (Stockh) 1975;330:57681.

14. Nieschalk M, Ortmann C, West A, et al. Effects of alcohol on bodysway patterns in human subjects Int J Legal Med 1999;1 12:253-60. 


\section{CHAPTER TWELVE}

Discussion of visual vestibular mismatch

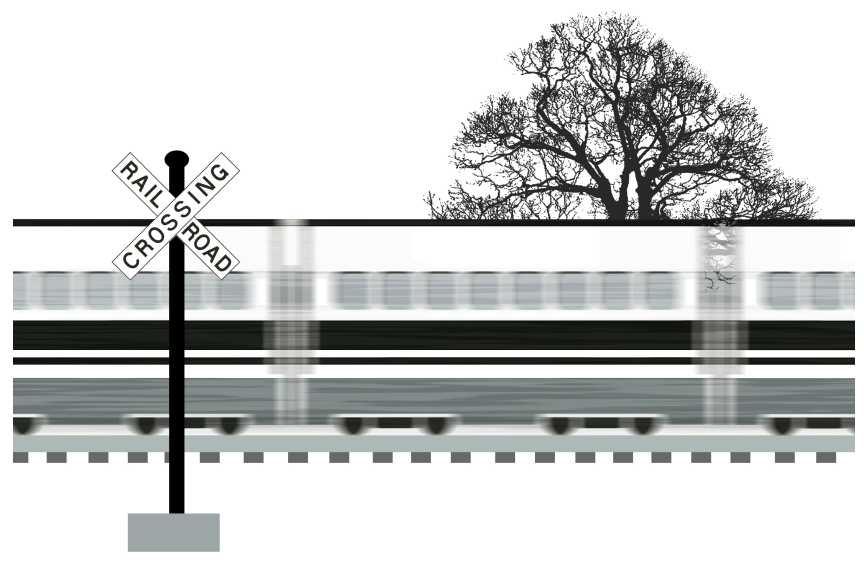


The comorbidity of vestibular disorders and related autonomic signs is well accepted, as nausea and vomiting are frequent symptoms in vestibular disease. There has been a linkage between vertigo and affective symptoms for hundreds of years. Vertigo in the mid $19^{\text {th }}$ century was regarded as being a neurological disease. The term "agoraphobia" was coined in 1871 by Westphal to describe the symptom set described by Benedikt in 1870 as "Platzschwindel" (literally; "vertigo in a public place"). This was characterized as a form of the condition known as "ocular vertigo" (still thought to be of neurologic origin). Benedikt reported on the co-occurrence of vertigo and agoraphobia, but there was debate about whether agoraphobia should be recognized as a type of vertigo, a consequence of vertigo, or a separate clinical entity (Balaban and Jacob, 2001). The relationship between agoraphobia and vertigo was debated for some years, as the sensations of agoraphobia did not conform to the contemporaneous definitions of vertigo. More recent work has correlated symptoms of anxiety and vestibular dysfunction. Jacob et al (1985) reported that abnormalities on vestibular tests occurred in a large proportion of patients with panic disorder. Yardley et al (1994) also identified balance disturbances in patients who had been diagnosed with agoraphobia.

The studies contained in this thesis outline the history of this debate and outline criteria that will aid in diagnosing these patients. Visual stimuli alone can provoke vestibular symptoms. This was clearly outlined in the early literature leading to the initial use of the term "agoraphobia", but it is still important that as much insight as possible be given to the recent rediscovery of this balanceanxiety interface.

It was originally suggested in 1930 (cited in Oman 1998) that the symptoms of motion sickness do not result from motion per se, but from discrepancies in the information provided by different sensory modalities. Guedry (1970) speculated that because of "the invariant correlation between information from otoliths and canals in natural head movements, unnatural stimuli that yield conflicting inputs... are especially potent in the production of motion sickness". He utilized the term "directional mismatch" and suggested that motion sickness might be the byproduct of the adjustment to such stimulations. Experiments detailed in this thesis have suggested strongly that the symptoms of visual vestibular 
mismatch closely parallel the symptoms of motion sickness. Patients regularly volunteer that they have newly developed motion sickness as a part of their symptom set (Mallinson et al, 1996; Mallinson and Longridge 1998 [1], Mallinson and Longridge 1998 [2]). One hypothesis of this thesis is that this arises from balance system pathology, regardless of whether it is of traumatic, nontraumatic, idiopathic or iatrogenic origin. Perhaps the development de novo of motion sickness is the byproduct of the newly developed conflicts suggested by Guedry. Although VVM is not yet fully defined, it seems to relate to a situationspecific symptom set (i.e. only occurring when one is exposed to a certain set of sensory stimuli). A similar symptom set described by Furman (1998) as "space motion discomfort" also alludes to the fact that there is a strong interrelationship between visual and vestibular signals.

It has become evident in the last few years as reported by several investigators (e.g. Bronstein 1995; Mallinson and Longridge 1998; Longridge, Mallinson and Denton 2002) and also as reported by many of patients in subsequent studies, that this subset of symptoms can be debilitating. Frequently symptoms are unrecognized or disregarded during history taking, because vestibular dysfunction can result in a range of visual disturbances, but this is not well understood outside the vestibular community (Bisdorff et al, 2009). Sometimes a symptom set which is debilitating (e.g. intractable nausea, constant sense of movement) can be caused by a very subtle deficit, which often cannot be detected by our current battery of available diagnostic tests. The resulting situation can be frustrating for patients and also for assessors, (especially in the presence of a normal set of assessments) as the patient may be labeled as "normal" despite being unable to carry on with everyday life.

The symptoms described by Bronstein (1995) that he defined as "visual vertigo" (VV) are markedly similar to those seen in VVM patients. Bronstein suggested that the process of compensation from vestibular lesions is associated with visual reliance, and in cases where this reliance is unusually high, a patient can be intolerant of situations involving visual conflict. Pavlou et al (2004) suggested that all vestibular patients rely on visual cues for stability, but that some of them are more susceptible to motion than others. They opined that the terms "visual vertigo", "space motion discomfort" and "visual vestibular mismatch" were three terms that described the same set of symptoms. If it 
could be determined exactly where the symptoms of space motion sickness were being generated, then perhaps it would give some answers about what was ailing Bronstein's patients with visual vertigo, and the patients discussed in this thesis with visual vestibular mismatch. Work by Mallinson and Longridge (2002) (Chapter 7 of this thesis) suggested that caloric-induced nystagmus velocity was not correlated with motion sickness susceptibility. This could infer that graviceptor signal function, not semicircular canal impairment, is instrumental in the development of motion sickness, but it must also be remembered that caloric analysis is an unsatisfactory measure of inner ear function. (While normal low velocity lateral semicircular canal responses are interpreted as suggesting normal inner ear function, this inference must be viewed with caution, as higher physiological velocities needed in normal rapid eye and head movements are not measured by caloric testing.)

As discussed previously in this thesis, the term "visual vestibular mismatch" is preferable to the term "visual vertigo" to describe these patients. It is clear that in some patients (and in many different situational circumstances), symptoms can be distressing.

As this set of symptoms parallels motion sickness so closely, the suggestion is made that there is a common origin. There are clear parallels between this symptom set and motion sickness (Redfern, Yardley and Bronstein, 2001) in healthy humans, as both are provoked by exposure to potentially disorienting motion environments in which the perceptual systems involved in orientation provide ambiguous information about self motion (Yardley, 1992). Similar to motion sickness, it does not require vestibular stimulation as such, but results from the creation of a discongruency of visual and vestibular signals (Mallinson and Longridge, 1998).

It should be emphasized that motion sickness is not a malady of itself. Preber in 1958 suggested that the otoliths play a major role in motion sickness. This was also supported by Quarck et al (1998) who showed that motion sickness susceptibility does not correlate with canal-ocular reflexes but does correlate with otolith-ocular reflexes (1998). Quarck et al also showed that it does not correlate with eye movements or nystagmus characteristics (2000). 
Space motion sickness has been linked to "altered otolithic function in microgravity" (Yates et al, 1998) and is hypothesized to arise "partly due to otolith asymmetry" (Parker, 1998). The otoliths are also implicated in the development de novo of motion sickness (Longridge and Mallinson, 2005). Although there have been these recent advances in understanding motion sickness and its relationship to vestibular symptomatology, the description of the symptoms of visual vestibular mismatch that are detailed in this thesis were first documented (very accurately) by Soranus, whose description of the offending stimuli over 2000 years ago included "watching the flow of a river from a high point".

It has been suggested by Basta et al (2005) that patients suffering otolith damage have impaired postural control and rely primarily on visual information for maintenance of balance. In brief, inner ear dysfunction, from whatever cause, results in an inability of the otoliths to detect movement accurately, and this can lead to nausea and/or sensations of instability. This instability is often reflected on Computerized Dynamic Posturography (Equitest $\AA$ ) as a nonspecific "across the board" deficit (i.e. performance scores on all sensory conditions are slightly less than the lower limits of the normal data base). This was initially thought to be suggestive of aphysiologic behaviour ("malingering") but it has been shown by Longridge and Mallinson (2005) (Chapter 10 in this thesis) that this deficit is legitimate, and parallels the balance deficits measured in all returning astronauts. These deficits are probably arising from the graviceptor otolith system, and it has been "strongly implicated that disrupted processing of otolithic inputs is the source of postural instability upon return from orbital flight" (Black et al, 1999).

Chapter 3 of this thesis (1996) details our study of 18 patients suggesting that their symptoms suggested pathology originating from the inner ear. Three of those patients volunteered that they "felt drunk". This was also echoed in Chapter 4 (1998), as two of the patients in that paper had principal complaints of "feeling drunk". The work by Basta et al, (2005) strongly supported this. They were able to document otolithic disorders with unilateral centrifugation in patients who had suffered minor head trauma, and stated that "Patients with otolith disorders typically present with sensations of feeling drunk". Chapter 11 confirms our suspicions that ethanol affects subjects in a similar manner to the 
complaints voiced by many of our patients, and this indicates pathology possibly originating in the otolith system.

This is one of the reasons that it is important to investigate the effects of alcohol on the human body, and on the balance system. The effects of ethanol occur at different sites, and are biphasic. Besides its well known sedative effects at high dose, it may be a stimulant at lower doses (Nieschalk et al, 1999).

Acute alcohol intoxication affects balance control in numerous ways (Hafstrom et al, 2007). Positional alcohol induced nystagmus ("PAN") was first reported by Flourens in 1826 (Nito et al, 1964) and several experimenters have shown (eg. Nito et al 1964; Money et al 1965) that the reason that PAN develops is because the semicircular canals are sensitive to gravity. (It was concluded at that time that PAN had to be related to semicircular canal response, as it disappears after canal plugging (Nito et al 1964; Money et al 1965)). The understanding of the balance system at that time was that "otoliths are sensitive to gravity, but do not cause nystagmus" (Money et al, 1965)). Subsequent research since the work by Money has developed our understanding of otolithic-canal interaction, and has suggested that his initial statement 45 years ago is erroneous. For example, Gresty and Bronstein (1985) presented evidence for a linearcompensatory eye movement reflex which was probably otolithic. Angelaki et al (1992) showed in a series of lesion and canal plugging experiments that the steady-state ocular nystagmus during OVAR was the result of inputs from the otolith.

Aside from the nystagmus generated in an intoxicated person, there is also an alcohol-related contribution to imbalance of the body (Uimonen et al, 1994). They reported an increase in body sway velocity under the effects of alcohol, and work by Mallinson et al (2008) (Chapter 11 of this thesis) showed increased sway as a result of even low levels of alcohol intoxication. Alcohol has a depressant action on spinal motor neurons, but this cannot account for the motor incoordination of alcohol intoxication, as intoxication continues in humans long after the H-response returns to normal (Chandran et al, 1981). This strongly suggests that at least some of the effects of alcohol are exhibited at the peripheral vestibular level. 
Although intoxicated subjects are obviously affected because of PAN (i.e. semicircular canal stimulation), intoxicated subjects (and also many of the patients discussed in this thesis) report symptoms that the world is tilting, and they also report a false sensation of motion (Hafstrom et al, 2007). This supports otolithic involvement, as the otoliths detect linear acceleration, and orientation of the head with respect to gravity.

Many of the patients with vestibular abnormalities discussed in this thesis report that they have developed an increased sensitivity to alcohol, and another corollary of the thesis is that this results from damage to the balance system. Of concern is that perhaps a patient with a damaged balance system who has consumed an amount of alcohol which would still allow him to drive legally might be impaired to the point where he would be unsafe behind the wheel of a motor vehicle due to this increased susceptibility. This raises ethical concerns with respect to the general community.

The VVM symptom set can be severe. These symptoms are physiologic and not psychogenic. Many patients have concomitant vegetative symptoms, probably related to the influence of the vestibular system on autonomic function. The vestibulo-autonomic regulation is probably responsible for the fact that vestibular dysfunction contributes to anxiety disorders such as panic disorders, and in particular, agoraphobia. This inexplicably occurs in some individuals but not in others. It also remains unclear why there is such a wide range of individual susceptibility to the symptoms of visual vestibular mismatch and to anxiety disorders (Furman, Jacob and Redfern, 1998). It is important to remember that "symptoms that seem psychiatric in nature might be a consequence of an undiagnosed neuro-otologic disorder" (Furman and Jacob, 1997).

If symptoms of VVM were generated from direct trauma to the autonomic nervous system or to the brain, they would have a higher frequency of occurrence in patients who had head injury and/or whiplash type injury. However experiments did not support this conjecture, as it was shown that the rate of newly developed visual vestibular mismatch was $29 \%$ in vestibular patients who had a head blow (Chapter 9), 30\% in patients who had not suffered head trauma (Chapter 9), and $36 \%$ in patients who had undergone intratympanic gentamicin therapy (Chapter 6). 
Earlier work compared patients who had suffered whiplash type injuries and head injury, with patients who had suffered whiplash injuries only (Chapter 4). Although this work was done prior to the development of the scoring system to quantify visual vestibular mismatch, symptom frequency was compared between the two groups, and there was no significant difference seen. It was also shown that in patients referred for dizziness from a wide variety of sources and with a wide array of complaints, those who had suffered head injury, whiplash type injury, or both showed no more tendency for the development of VVM than patients we saw with labyrinthine disease not related to trauma (Chapter 9).

The vertiginous spinning nature of complaints in many patients with inner ear disease locates the dizziness to the inner ear, and in the absence of CNS complaints in these patients, the diagnosis of inner ear disease is made based on their typical voiced complaints (e.g. vertigo, etc). In "straightforward" cases such as these, questions about VVM are not needed to diagnose inner ear disease, and frequently are not asked.

The conclusions drawn from the studies that comprise this thesis are also supported by other investigators who have suggested that visual vestibular mismatch is an indirect (not direct) result of trauma (i.e. the trauma causes vestibular damage). Davies and Luxon (1995) looked at dizziness after head injury, and suggested that the variety of audiovestibular injuries found after head injury suggested damage to the sensory organs of the inner ear. They also suggested that given the high incidence of positional vertigo after head injury, the macula of the utricle from which the otoliths arise is the most frequently affected structure.

The theory has been advanced for 2000 years that there is a close vestibularautonomic interface. But if this is the interface responsible for generating VVM, why is this the case, and what physiological or evolutionary role might such an interface play?

A key role of the central nervous system is to provide for homeostasis (Yates and Miller, 1998). One of the greatest challenges to homeostasis occurs when a human being moves or changes posture. Compensation for such movement requires adjustments by arterial baroreceptors, cardiac baroreceptors, stretch 
receptors in respiratory muscles, and central and peripheral chemoreceptors, to name but a few. However, effective manipulation of these responses and of their magnitude would arguably require "pre-adaptation", or initiation of the responses even before the internal environment has been affected. Yates, Sklare and Frey (1998) also outlined that effective maintenance of homeostasis would require action prior to a movement taking place, and it has been suggested that the ability of the vestibular system to detect head position and movement might act as a feed forward system for this purpose. One mechanism for accomplishing this effectively and at maximum speed would be through the actions of the vestibular system, which detects head position and sends this information into the cerebellum without synapsing. Data also exists suggesting that vestibular stimuli can elicit changes in circulation and respiration that provide for stable blood pressure and blood oxygenation during movement and changes in posture (vestibulosympathetic response) (Yates and Miller, 1998). The response characteristics are similar to those of otolithic afferents (Fernandez and Goldberg, 1976) and suggest that the otolith organs are predominantly responsible for producing the vestibulosympathetic response. Thus, the effects of the vestibular system on sympathetic outflow and blood pressure may be acting to offset movement-related challenges to the circulatory system.

"Referred pain" is a concept which is seen in many parts of the body. It is characterized by the fact that it is not felt at the site of origin, but remote from it (Mense, Simons and Russell 2001). Typically the area of referred pain is discontinuous with the site of the lesion. Balaban and Jacob (2001) have suggested that the signs and symptoms that accompany vestibular dysfunction can readily be attributed to specific organs (i.e. they are the organs that are producing the symptoms) but these signs and symptoms can be labeled as referred somatic and visceral manifestations of vestibular dysfunction (Balaban 1999). The "remoteness" of traditional vestibular symptoms is to be expected, as there is no single sense organ that we can identify consciously and intuitively as the source of normal sensations of movement and maintenance of balance. However the importance of the role of the production of these symptoms (followed by the invoked anxiety and situational avoidance strategies) may be 
a compensatory strategy that has the normal function of preventing exposure to potentially dangerous situations or circumstances.

We formed the impression that VVM can arise from the inner ear. In the patients we see referred for vestibular disease, this symptom set is commonly seen, as shown by the papers discussed in this thesis. In particular, our impression is supported by our study (Chapter 6) which showed that VVM can develop de novo after intratympanic gentamicin injections.

In our clinic we see a preselected group of patients suspected of having vestibular disease. These patients are often "prescreened", in that central disease is unlikely, because neurologists who refer to our clinic have excluded neurological disease. Our experience with VVM is therefore based on otoneurological disease. Referring physicians would probably have detected significant central disease. This means that central disease has to be subtle because a referring physician would have failed to recognize a neurological component and referred the patients instead for otoneurological assessment. For this reason we rarely see VVM in conjunction with overt neurological disease.

Basta et al (2005) stated that "disorders of the otolithic apparatus are clinical entities which have proven difficult to diagnose in the past" and outlined a typical otolithic disorder patient as presenting with sensations such as "walking on pillows" or "feeling drunk". They also outlined that Computerized Dynamic Posturography Sensory Organization Testing can "clearly indicate an otolith disorder", and that these disorders are often seen after minor head injury. It is important to remember that normal assessments do not rule out peripheral vestibular disease, and also in some patients a lesion may exist in central vestibular pathways or in cortex. Because our present tests are limited, we are unable to evaluate this aspect of the vestibular system. In summary, Basta et al (2005) suggest that in patients with documented otolithic pathology, characteristic postural control complaints and characteristic posturography SOT abnormalities, strong suspicions are raised about otolithic pathology. Their work supports the conclusions of this thesis.

In a groundwork paper, the Barany Society Vestibular Disorders Classification Committee has recently generated a first iteration of a classification of vestibular disorders (Bisdorff et al, 2009). The committee is to be commended 
on their excellent work in attempting to "promote development of an implementable, international and interlinguistic classification of vestibular disorders". It has also been appropriately hesitant in "labeling" the symptom set or defining it, beyond stating that all definitions developed should be "broad yet specific"; easy to translate into different languages, and also "nonoverlapping and non-hierarchical". It is also emphasized that definitions be developed that reflect the fact that the pathogenesis of almost all symptoms is likely to be incompletely understood (Bisdorff et al, 2009).

The committee has recognized the fact that even "core vestibular symptoms" such as "vertigo" and "dizziness" are not served well by the terminology that is presently used. There is no consensus about the use of the term "vertigo", as it has been shown to have diverse meanings for patients, generalist physicians and specialist physicians. The committee has wrestled with a definition of the word, as previous attempts to define it have raised controversy. While some vestibular specialists have utilized the term to refer to a sense of spinning only (a commonly accepted usage of the term in North America), the custom in Europe is to utilize the term to refer to any false sense of motion of self or surroundings. The compromise of the terminology committee was to recommend that "vertigo" always be categorized as "spinning", "non-spinning" or both. Wisely, the committee has recognized that the terms presently in use to describe vestibular disease can be misleading, even to subspecialist practitioners, and that these patients and their presenting symptom sets are not always well understood by those outside the vestibular community.

As has been outlined in this thesis and in many other excellent studies, it is clear that vestibular dysfunction can result in a range of visual disturbances. This visual vestibular interaction (which also involved other sensory modalities) is reasonably well accepted and understood within the vestibular community. The committee has recommended the terms "visually induced vertigo", as well as "visually induced dizziness". "Visual-vestibular mismatch" fits into this grouping, as does visual vertigo.

Recognizing the newly developed understanding of the subject, the committee unanimously felt that the concepts of visually induced vertigo and visually induced dizziness should be dealt with as separate entities, partly as an "explicit attempt to promote awareness around this issue". 
It can be seen that the committee has made progress in defining the concept of visual-vestibular symptoms, and it has been careful enough to define "visually induced vertigo" as a visually-induced illusion of a circular (i.e. rotational) or linear (i.e. vectional) self motion. It has also defined "visually-induced dizziness" which is delineated as visually-induced illusion of a movement which is not rotational or vectional. The committee further outlined that one symptom does not necessarily pre-empt the other, as these symptoms can co-exist or occur sequentially. It can be seen that categorization of a patient requires that a prolonged in-depth history be taken.

The committee was also careful to outline its shortcomings to this point. Wisely on a first iteration, it has chosen to avoid issues which are clearly extremely complex. One of the deliberate decisions it made was not to operationally define the neurovegetative or neuropsychiatric symptoms. The committee recognizes that this may be a separate entity and expressly outlines that "visually induced vertigo", [and visually induced dizziness] should both be distinguished from motion sickness. This is a valid distinction, as motion sickness per se is not a pathological malady, but as outlined previously, we regard the development de novo of motion sickness to be suggestive of newly developed vestibular impairment. In addition, the "visceral feeling of nausea" which the committee feels should not be incorporated into these initial categories is a symptom set developed by many of our patients. Sometimes these symptoms are the only ones reported by patients, and we feel that this might reflect the predominance of one symptom, to the point where more minor symptoms are not reported, even during in-depth history taking. Again the committee is commended for recognizing that this symptom set (i.e. neurovegetative symptoms) is part of the vestibular spectrum, and it has stated the importance of dealing with it, perhaps in the next iteration of the classification algorithm. It did outline the importance of promoting awareness around this issue, and suggested that further iterations will be made after soliciting input from the vestibular community, and making attempts to try and define diagnostic criteria.

One of the general steps taken by the committee that must also be applauded was to recognize the potential for misleading practitioners, and to be aware of the poor understanding we have of the whole concept of sensory integration, 
the reasons for this complex process, and its purpose in the normally functioning human.

The work in this thesis strongly supports the complex nature of visual vestibular interaction, and furthermore suggests that the symptom set of visually induced vertigo and visually induced dizziness represents balance system disease arising from the inner ear graviceptors, and also shows that it can be very debilitating. If the hypothesis is correct, then we must turn our efforts towards developing methods of measuring otolithic function and detecting otolithic/SCC interaction. To be generally useful, assessment methods must be affordable, able to supply clinical information in a short period of time, and above all must be tolerable for patients, many of whom are unwell and perhaps frail.

Future directions must include the development of cost effective methods of assessing the balance system more fully, and also more specifically. Technological advances used to explore the balance system include the unilateral centrifugation test (Wuyts et al, 2003). In this test, subjects are rotated about an earth vertical axis. During the ongoing rotation, the subject is gradually translated to either side along an interaural axis, so that one utricle becomes aligned with the axis of rotation, and at this point is subject to gravitational forces only, while the contralateral utricle is subjected both to gravity and to centrifugal acceleration. This technique allows for measurement of the sensitivity of each utricle, and also the difference between utricles (this can be construed as a utricular analogy to the caloric test). To date, this assessment is only available at a few select centres, as the cost of equipment is high.

A simpler easy to administer and much cheaper utricular assessment tool is the rod and frame test developed by Hafstrom et al (2004). This is an "enhanced" method of assessing subjective visual vertical (SVV), which measures the degree to which a subject uses available visual cues to locate earth vertical. It uses an obliquely hung picture frame mounted in an otherwise dark room, so that the tendency of a subject to rely on this erroneous visual cue during SVV testing can be measured. Its down side is that it does require patient participation and is therefore less objective than the unilateral centrifugation tests described by Wuyts et al (2003). 
Ocular counterrolling is an accepted otolithic measurement, but has been limited by the lack of effective techniques for accurately measuring rotation of the eyeball, and wide variations of normal. Work is presently being carried out to develop software with video camera methods and also iris recognition technology in the hope of quantifying this in an accurate and hopefully clinically relevant manner. 


\section{CHAPTER THIRTEEN}

\section{Conclusions}

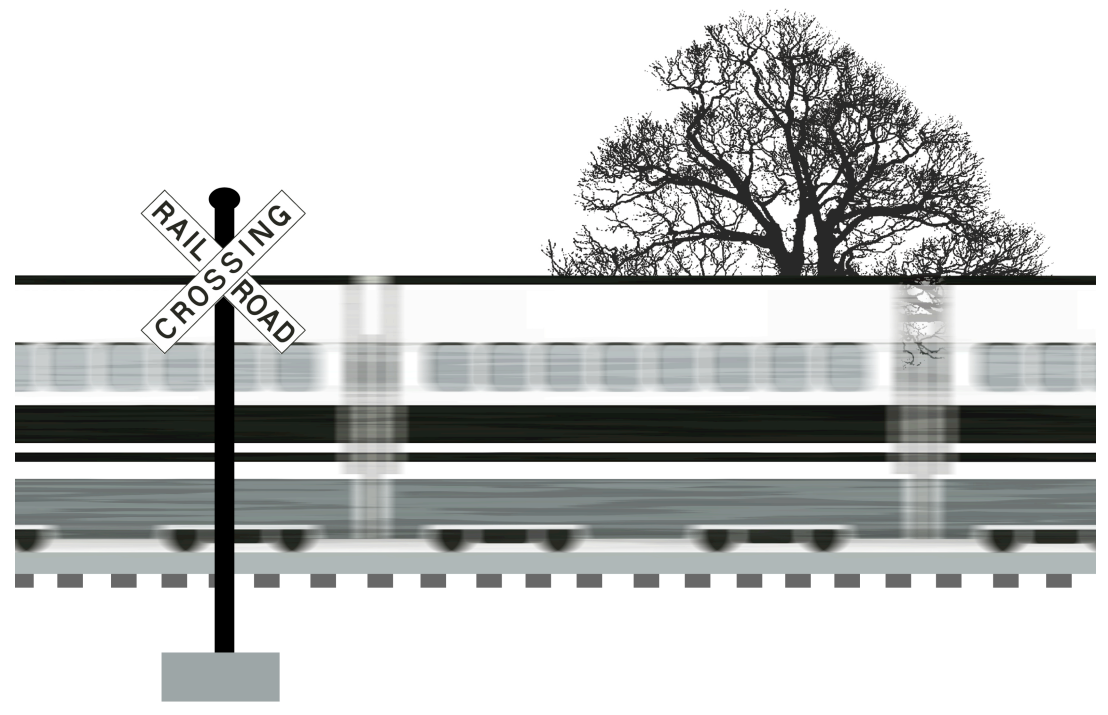


The logical series of experiments that comprise this thesis supports the following conclusions related to newly developed visually induced vertigo and visually induced dizziness. This symptom set arises as a result of pathology in the balance system, to the point where it can no longer act as the "template" against which other sensory information is compared. The result is an inappropriate reliance on environmental visual cues, even under circumstances in which they are orientationally inaccurate. Elucidation of these symptoms from a patient requires that a comprehensive history be taken in a non-leading manner.

I suggest that from this thesis, the following statements can be made:

1. In addition to traditional complaints voiced by patients who are suffering from vestibular pathology, there is a family of non-traditional complaints which are legitimate, and can range from being mildly irritating to being totally incapacitating.

2. These symptoms can arise after head trauma, but are not directly related to neurological damage.

3. Symptoms can occur in isolation or in conjunction with other commonly accepted symptoms of vestibular disease (e.g. vertigo, etc). They can sometimes occur idiopathically.

4. Symptoms can occur as a result of head injury, but identical complaints can occur as a result of whiplash alone, which suggests strongly that otoliths are damaged similarly by both of these types of decelerative forces.

5. Symptoms can be caused as a result of deliberate iatrogenic intervention to the inner ear.

6. The complaints include both autonomic and vestibulospinal symptoms.

7. The symptoms are not semicircular canal in origin, as standard caloric testing is rarely abnormal, and patients generally do not complain of symptoms that are traditionally thought to be of semicircular canal origin. (i.e. spinning). The caveat is the limitations of semicircular canal testing. 
8. Symptoms mimic

a. the effects of alcohol on the body

b. physiological responses to the effects of microgravity on the body

c. The sensation and vague imbalance caused by Computerized Dynamic Posturography assessment

d. The complaints of imbalance voiced by older people

e. The common malady known as motion sickness

9. As all five of the above situations are probably caused by otolithic disturbances, the findings support the hypothesis that the symptom set included in the definitions of visually induced vertigo and visually induced dizziness can originate from the otoliths of the inner ear, and otolithic pathology can be responsible for the imbalance in these patients and related autonomic symptoms that they suffer.

10. The caveat to my conclusions is that the population of patients seen precludes an understanding of the relationship between visually induced vertigo (and also visually induced dizziness) and neurological disease, which certainly may play a role in some patients in the development of their symptoms. 


\section{INDEX}

I am the first author on 6 of the 9 papers referred to in this thesis and the second author on the other 3 . 


\section{BIBLIOGRAPHY}

1. Angelaki DE, Perachio AA, Mustari MJ, Strunk CL. Role of irregular otolith afferents in the steady-state nystagmus during off-vertical axis rotation. J Neurophysiol. 1992 Nov;68(5):1895-900.

2. Balaban CD, Jacob RG. Background and history of the interface between anxiety and vertigo. Anxiety Disorders 2001;15:27-51.

3. Balaban CD, Porter JD. Neuroanatomic substrates for vestibuloautonomic interactions. J Vest Res 1998:8(1):7-16.

4. Balaban CD. Vestibular autonomic regulation (including motion sickness and the mechanism of vomiting). Current Opinion in Neurology 1999;12:29-33.

5. Ballantyne J, Groves J. Scott-Brown's Diseases of the Ear, Nose and Throat. (4th edition) Butterworth and Company London, UK 1979. Volume 1 Basic Sciences. Chapter 6: Benson AJ, King PF. The ears and nasal sinuses in the aerospace environment. p. 205-243.

6. Barany R, Ibershoff AE. Physiology and pathology of the semicircular canals; being an excerpt of the clinical studies of Dr. Robert Barany with notes and addenda gathered from the Vienna Clinics (1910). P.B. Hoeber, New York (1910).

7. Barany, R; Nobel Lecture "Some new methods for functional testing of the vestibular apparatus and the cerebellum" (September 11, 1916).

8. Basta D, Clarke A, Ernst A, Todt I. Stance performance under different sensorimotor conditions in patients with post-traumatic otolith disorders. J Vest Res 2007; (17):25-31.

9. Basta D, Todt I, Scherer H, Clarke A, Ernst A. Postural control in otolith disorders. Human Movement Science 2005;24(2):268-279.

10. Benson AJ, King PF. The ears and nasal sinuses in the aerospace environment. In Scott-Browne's diseases of the ears nose and throat. Vol 1. Basic Science. London. Butterworth's. 1979:205-243.

11. Bisdorff A, Von Brevern M, Lempert T, Newman-Toker DE. Classification of vestibular symptoms: Towards an international classification of vestibular disorders. J. Vest Res 2009;19:1-13. 
12. Black FO, Paloski WH. Computerized Dynamic Posturography: What have we learned from space? Otolaryngol Head Neck Surg 1998;118:S45-S51.

13. Black FO, Paloski WH, Reschke MF, Igarashi M, Guedry F, Anderson DJ. Disruption of postural readaptation by inertial stimuli following space flight. J. Vest Res 1999:(9):369-378.

14. Bronstein AM. Suppression of visually evoked postural responses. Exp Br Res 1986;63:655-658.

15. Bronstein AM. The visual vertigo syndrome. Acta otolaryngologica 1995;520(Suppl):45-48.

16. Chandran AP, Marya RK, Baini BK. Effect of ethanol on H-reflex in unanaesthetized rabbits. Physiol Behav 1981 Jun;26(6):967-970.

17. Davies RA, Luxon LM. Dizziness following head injury: a neuro-otological study. J Neur 1995;242:222-230.

18. Dunn PM. Soranus of Ephesus (circa AD98-138) and perinatal care in Roman times. Arch Dis Child Fetal Neonatal Ed. 1995 Jul;73(1):F51-2.

19. Equitest System Version 4.0 Data Interpretation Manual. Clackamas USA, Neurocom International. 1994.

20. Fernandez C, Goldberg JM. Physiology of peripheral neurons innervating otolith organs of the squirrel monkey. 3: Response dynamics. J Neurophys 1976; 39:996-1008.

21. Furman JM. Role of posturography in the management of vestibular patients. Otolaryngol Head Neck Surg 1995; 1 12:8-15.

22. Furman JM, Cass SP. Balance disorders. A case-study approach. Philadelphia USA, FA Davis 1996.

23. Furman JM, Jacob RG. Psychiatric dizziness. Neurology 1997:48:1161-1166.

24. Furman JM, Jacob RG, Redfern MS. Clinical evidence that the vestibular system participates in autonomic control. J Vest Res 1998;8 (1):27-34.

25. Furman JM, Redfern MS. Effect of aging on the otolith-ocular reflex. J. Vest. Res 2001;11:91-103.

26. Goebel JM. Practical management of the dizzy patient. Hagerstown USA, Lippincott Williams and Wilkins 2008. 
27. Gresty MA, Bronstein AM. Otolith stimulation evokes compensatory reflex eye movements of high velocity when linear motion of the head is combined with concurrent angular motion. Neurosci Lett. 1986 Apr 11;65(2):149-54.

28. Guedry FE. Conflicting sensory orientation cues as a factor in motion sickness. Fourth Symposium on the role of the vestibular organs in space exploration. 1970. P 45-52. National Aeronautics and Space Administration, Washington DC.

29. Guerraz M, Yardley L, Bertholon P, Pollak L, Rudge P, Gresty MA, Bronstein AM. Visual vertigo: symptom assessment, spatial orientation and postural control. Brain 2001;124:1646-1656.

30. Hafstrom A, Fransson P-A, Karlberg M, Magnusson M. Ipsilesional field dependency for patients with vestibular schwannoma. Neuroreport 2004;Oct 5 15(14):2201-2204.

31. Hafstrom A, Modig F, Karlberg M, et al. Increased visual dependence and otolith dysfunction with alcohol intoxication. Neuroreport 2007:Mar 5 18(4):391-394.

32. Jacob RG, Furman JM, Durrant JD, Turner SM. Panic, agoraphobia and vestibular dysfunction. Am J Psychiatry 1996;153:503-512.

33. Jacob RG, Moller MB, Turner SM, Wall C III. Otoneurological examination of panic disorder and agoraphobia with panic attacks: a pilot study. Am J Psych. 1985;1 142: 715-720.

34. Ledin T, Odkvist LM. Effect of alcohol measured by dynamic posturography. Acta otolaryngologica Suppl. 1991;481:576-581.

35. Longridge NS. The value of nausea and vomiting due to Meniere's disease - a theory. J Otolaryngology 1983 Dec;12(6):403-4.

36. Longridge NS, Mallinson Al. Visual vestibular mismatch in work related vestibular injury. Otol Neurotol 2005;26:691-694.

37. Longridge NS, Mallinson Al. Clinical Romberg testing does not detect acute vestibular disease. Otol Neurotol 2010 Jul;31 (5):803-6.

38. Longridge NS, Mallinson Al, Denton A. Visual vestibular mismatch in patients treated with intratympanic gentamicin for Meniere's disease. J Otolaryngol 2002 (Feb);31 (1):5-8.

39. Maitland TG. General observations on sea-sickness and the labyrinthine theory. Br Med J 1931;1:171-176. 
40. Mallinson Al, Longridge NS. Specific vocalized complaints in whiplash and minor head injury patients. Am J Otol 1998;19:809-813.

41. Mallinson Al, Longridge NS. Dizziness from whiplash and head injury. Differences between whiplash and head injury. Am J Otol 1998;19:814-818.

42. Mallinson, Al, Longridge NS. Caloric response does not decline with age. J Vest Res 2004;14(5):393-396.

43. Mallinson, Al, Longridge NS, Morley RE. Evaluation of the effects of ethanol on static and dynamic gait. J Otolaryngology Head Neck Surg 2008 Dec;37(6):856-859.

44. Matthews, WB. Practical Neurology. Oxford, Blackwell. 1963.

45. McCabe BF. Diseases of the end organ and vestibular nerve. In Naunton RF (ed.) The vestibular system. New York. Academic Press; 1975:299-302.

46. Mense S, Simons DG, Russell IJ. Muscle Pain: understanding its nature, diagnosis and treatment. 2001 Lippincott, Williams and Wilkins. Philadelphia 2001.

47. Money KE, Johnson WH, Corlett BMA. Role of semicircular canals in positional alcohol nystagmus. Am J Physiol 1965;208(6):1065-1070.

48. Nieschalk M, Ortmann C, West A, Schmäl F, Stoll W, Fechner G. Effects of alcohol on body-sway patterns in human subjects. Int J Leg Medicine 1999;1 12:253-260.

49. Nito Y, Johnson WH, Money KE, Ireland PE. The non-auditory labyrinth and positional alcohol nystagmus. Acta Otolaryngol. 1964 Jul;58:65-7.

50. Oman CM. Sensory conflict theory and space sickness: our changing perspective. J Vest Res 1998;8(1):51-56.

51. Oman CM, Lichtenberg BK, Money KM, McCoy RK. M.I.T/Canadian vestibular experiments on the Spacelab-1 mission: 4. Space motion sickness: symptoms, stimuli and predictability. Exp $\mathrm{Br}$ Res 1986;64:316-334.

52. Paige GD. Senescence of human visual-vestibular interactions. 1. Vestibulo-ocular reflex and adaptive plasticity with aging. J Vest Res 1992;2:133-151.

53. Parker DE. The relative roles of the otolith organs and semicircular canals in producing space motion sickness. J Vest Res 1998;8(1):57-59. 
54. Parker DE, Reschke MF, Arrott AP, et al. Otolith tilt-translation reintepretation following prolonged weightlessness: implications for preflight training. Aviat Space Environ Med 1985;56:601-606.

55. Pavlou M, Lingeswaran A, Davies RA, Gresty MA, Bronstein AM. Simulator based rehabilitation in refractory dizziness. J Neurol 2004;251:983-995.

56. Practical Neurology. Matthews WB. Oxford, Blackwell 1963.

57. Preber L. Vegetative reactions in caloric and rotatory tests. A clinical study with special reference to motion sickness. Acta Otolaryngol Suppl (Stockh) 1958;144:1-119.

58. Quarck G, Etard O, Darlot C, Denise P. Motion sickness susceptibility correlates with otolith- and canal- ocular reflexes. Neuroreport 1998 Jul 13;9(10):2253-2256.

59. Quarck G, Etard O, Oreel M, Denise P. Motion sickness occurrence does not correlate with nystagmus characteristics. Neuroscience Letters 2000 Jun 16;287(1):49-52.

60. Redfern MS, Yardley L, Bronstein AM. Visual influences on balance. Anxiety disorders 2001;15:81-94.

61. Romberg MH. Lehrbuch der Nervenkrankheiten des Menschen, Vol 1. Berlin, 1846. (English translation, London, Sydenham Society, 1853.)

62. Tianwu $H$, Watanabe $Y$, Asai $M$ et al. Effects of alcohol ingestion on vestibular function in postural control. Acta Otolaryngologica (Stockh) 1995;Suppl 519:127-131.

63. Uimonen S, Laitakari K, Bloigu R, Reinilä M, Sorri M. Static posturography and intravenous alcohol. J Vest Res 1998;4(4):277-283.

64. Wuyts FL, Hoppenbrouwers M, Pauwels G, Van de Heyning PH. Utricular sensitivity and preponderance assessed by the unilateral centrifugation test. J Vest Res 2003;13(4-6): 227-234.

65. Yardley L, Lerwill H, Hall M, Gresty M. Visual destabilization of posture. Acta otolaryngologica 1992;112:14-21.

66. Yardley L, Luxon L, Bird J, Lear S, Britton J. Vestibular and posturographic test results in people with symptoms of panic and agoraphobia. J Audiological Medicine 1994;3:48-65. 
67. Yates $B J$, Miller AD. Physiological evidence that the vestibular system participates in autonomic and respiratory control. J Vest Res 1998;8(1): 17-25.

68. Yates BJ, Sklare DA, Frey MAB. Vestibular autonomic regulation: Guest editorial. J Vest Res 1998;8(1):1-5.

69. Zwerling I: A note on Wendt's views of the importance of psychological factors in motion sickness. J Aviat Med 1949 Feb;20(1):68-71. 


\section{APPENDIX ONE}

Are you made unwell by

- going on an escalator

- watching traffic at an intersection

- being in a supermarket

- walking in a shopping mall

- $\quad$ seeing checkerboard floor patterns

"VVM POSITIVE" = 3, 4, OR 5 POSITIVE ANSWERS

"VVM NEGATIVE" = 0, 1 OR 2 POSITIVE ANSWERS

It must be remembered that there are some limitations to the questionnaire:

- A patient may not have the English skills to answer the questions (or to give an accurate history)

- A questionnaire might be leading or suggestive

- A patient might not have been exposed to the offending stimuli

- A patient might be "overly cooperative" and supply positive answers without thinking 


\section{CURRICULUM VITAE}

Arthur Mallinson was born in Toronto, Canada on April 20, 1952. He holds a B.Sc. in Biological Sciences and an M.Sc. in neurophysiology, both from Simon Fraser University in Burnaby, Canada.

For the last 30 years he has been worked as a neurophysiologist in the Neurootology unit at Vancouver General Hospital, a diagnostic unit in a tertiary care teaching hospital. He performs clinical vestibular assessments and also serves as a consultant to other centres across Western Canada in interpreting difficult or unusual vestibular assessment results. He is a clinical instructor in the Faculty of Medicine at the University of British Columbia, and teaches vestibular physiology and clinical assessment to otolaryngology residents, medical students, audiology students, visiting clinicians and other paramedical professionals.

In the past Art has also been active in developing and teaching into the Electrophysiology program at the British Columbia Institute of Technology, which is the only English language program in Canada of its kind. He has also served as a Lecturer and Laboratory Demonstrator/Assistant, teaching Neuroanatomy/ Neurophysiology in the School of Rehabilitation Medicine, at the University of British Columbia.

He was involved in the initiation of the intra-operative monitoring program at Vancouver General Hospital, and also helped develop the ototoxicity monitoring program at the hospital.

Art has been performing and personally interpreting Computerized Dynamic Posturography assessments for 22 years, including hundreds of medical legal posturography assessments. He is the co-author of a booklet about medical legal evaluation of balance and also the co-author of a learning module on vertigo for the British Medical Journal.

Art has been actively involved in ongoing research for the last 30 years with his colleague Dr. Neil Longridge. He is a member of the Barany Society, the premier world society on dizziness and balance. He is also a member of the International Society for Posture and Gait Research (formerly called the International Society of Posturography). He serves on the editorial review board for five journals (Journal of Vestibular Research, Gait and Posture, Otology and 
Neurotology, Experimental Brain Research, Clinical Neurophysiology). He has been an invited speaker at a number of conferences, and has designed and given many seminars on vestibular assessment and evaluation to medical and paramedical professionals. 


\section{REFEREED PUBLICATIONS}

1. Mallinson Al, Longridge NS, Dunn HG, McCormick AQ. Vestibular studies in Pelizaeus-Merzbacher disease. J Otolaryngol. 1983;12(6): 361-364.

2. Longridge NS, Mallinson Al. Discussion of the dynamic illegible E test: A new method of screening for aminoglycoside vestibulotoxicity. Otolaryngol Head Neck Surg 1984;92:672-677.

3. Longridge NS, Mallinson Al. Arnold-Chiari malformation and the otolaryngologist: Place of magnetic resonance imaging and electronystagmography. Laryngoscope 1985;95:335-339.

4. Longridge NS, Mallinson Al. The dynamic illegible E test - a technique for assessing the vestibulo-ocular reflex. Acta Otolaryngol 1987;103:273-279.

5. Longridge NS, Mallinson Al, MacLeod PM. Machado-Joseph disease: The vestibular presentation. J Otolaryngol 1987;16(2):93-95.

6. Longridge NS, Mallinson Al. The dynamic illegible E test - a simple technique for assessing the ability of the vestibulo-ocular reflex to overcome vestibular pathology. J Otolaryngol 1987;16(2):97-103.

7. Hamman RR, Mekjavic I, Mallinson Al, Longridge NS. Training effects during repeated therapy sessions of balance training using visual feedback. Arch Phys Ther Rehab 1992;73:738-744.

8. Mallinson Al, Longridge NS, Peacock C. Dizziness, imbalance, and whiplash. J. Musculoskeletal Pain 1996;4(4):105-112.

9. Mallinson Al, Longridge NS. Specific vocalized complaints in whiplash and minor head injury patients. Am J Otology 1998;19:809-813.

10. Mallinson Al, Longridge NS. Dizziness from whiplash and head injury: (Differences between whiplash and head injury). Am J Otology 1998;19:814-818.

11. Longridge NS, Mallinson Al. Low dose intratympanic gentamicin treatment for dizziness in Meniere's disease. J Otolaryngol 2000;29(1):35-39.

12. Gill C, Mallinson Al, Longridge NS. Effects of dimenhydrinate on computerized dynamic posturography. J Otolaryngol 2000;29(6):337-339.

13. Carter, ND, Khan KM, Petit MA, Heinonen A, Waterman C, Donaldson MG, Janssen PA, Mallinson A, Riddell L, Kruse K, Prior JC, Flicker L, McKay HA. Results of a 10 week community based strength and balance training 
programme to reduce fall risk factors: a randomized controlled trial in 65-75 year old women with osteoporosis. Br J Sports Med 2001 Oct;35(5) $348-51$.

14. Longridge NS, Mallinson Al, Denton A. Visual vestibular mismatch in patients treated with intratympanic gentamicin for Meniere's Disease. J Otolaryngology 2002;31 (1):5-8.

15. Liu-Ambrose T, Eng JJ, Khan KM, Mallinson A, Carter ND, McKay HA. The influence of back pain on balance and functional mobility in 65-75 year old women with osteoporosis. Osteoporosis International 2002;13:868-873.

16. Carter ND, Khan KM, Mallinson A, Janssen PA, Heinonen A, Petit MA, McKay HA. Knee extension strength is a significant determinant of static and dynamic balance as well as quality of life in older communitydwelling women with osteoporosis. Gerontology 2002;48:360-368.

17. Mallinson Al, Longridge NS. Motion sickness and vestibular hypersensitivity. J Otolaryngology 2002;31 (6):381-385.

18. Mallinson Al, Longridge NS, Wong K. Using Swaystar to measure sway amplitude in an office setting. J. Otolaryngology 2004;33(1):17-21.

19. Mallinson, Al, Longridge NS. Caloric response does not decline with age. J Vest Res 2004;14(5):393-396.

20. Mallinson Al, Longridge NS. A new set of criteria for evaluating malingering in work related vestibular injury. Otol Neurotol 2005 Jul;26;(4):686-690.

21. Longridge NS, Mallinson Al. Visual vestibular mismatch in work related vestibular injury. Otol Neurotol $2005 \mathrm{Jul} ; 26 ;(4): 691-694$.

22. Longridge NS, Mallinson Al. "Across the board" posturography abnormalities in vestibular injury. Otol Neurotol 2005 Jul;26;(4):695-698.

23. Mallinson Al, Longridge NS, Morley, RE. Evaluation of the effects of alcohol on static and dynamic gait. J Otolaryngol 2008;37(6):856-859.

24. Mallinson Al, Longridge NS. Increasing the usefulness of tandem walking evaluation. J Otolaryngol 2008;37(6):860-864.

25. Longridge NS, Mallinson Al. Clinical Romberg testing does not detect vestibular disease. Otol Neurotol 2010;31:803-806

26. Phillips J, Longridge NS, Mallinson Al, Robinson G. Migraine and vertigo: a marriage of convenience? Headache 2010 Sep;50(8): 1362-5. 
27. Mallinson Al, Longridge NS, Pace-Asciak P, Ngo R. Measuring caloric response - comparison of four different analysis techniques. J Vest Res 2010;20(6):419-426. 


\section{NON-REFEREED PUBLICATIONS AND CASE REPORTS}

1. Mallinson Al, Longridge NS. ENG of the month - computed tomography and electronystagmography in conflict with minor symptoms and signs. Ann Oto Rhinol Laryngol 1984;93(5):525-527.

2. Mallinson Al, Longridge NS. ENG of the month - findings in a posterior fossa lesion. Ann Otol Rhinol Laryngol 1984;93(2):195-196.

3. Mallinson Al, Longridge NS. Visual vestibular mismatch in whiplash and Meniere's disease. In Claussen C-F, Haid C-T, Hofferberth B (eds) Equilibrium Research, clinical equilibriometry, and modern treatment. Elsevier Science BV 2000.

4. Kaur H, Westerberg BD, Mallinson A, Calne D. Progressive supranuclear palsy as a cause of balance disorders (Case report). J Otolaryngol 2003;32(1):114-117.

\section{BOOKLETS}

Mallinson, Al, Longridge NS. Differentiating real from aphysiologic balance control using Computerized Dynamic Posturography. Neurocom Publications, Clackamas OR. July 2008.

\section{LEARNING MODULES}

Phillips, J, Mallinson Al. Vertigo: an update on diagnosis and management. BMJ British Medical Journal (BMJ web based module) 2010. 


\section{ACKNOWLEDGEMENTS}

I am first of all extremely grateful to Maastricht University for allowing me to pursue this degree, and I would like to convey my sincere thanks to the members of the faculty and especially members of my committee who have supported me through this journey. A special word of thanks must go to prof. dr. Kremer who was my initial contact at Maastricht University and whose efforts enabled me to begin my journey. I am indebted as well to prof. dr. Stokroos for chairing my examining committee and spending the time to read my work.

It has been an honour and a privilege to be researching in the same field as the distinguished scientists gathered at Maastricht University to take part in my thesis defence. I value them as inquisitive researchers and colleagues but also value them as friends. They make the pursuit of knowledge much more enjoyable and extremely satisfying.

Several specific people need to be singled out for their encouragement. Prof. dr. Philippe Perrin has always been eager to share his knowledge and insight with me and to look at a research challenge in a different way. Prof. dr. Mans Magnusson has been an inspiration and an encouragement for many years, and has convinced me that scientists who think differently are not necessarily wrong and may in fact be increasing their contribution to science because they think differently. He has also emphasized to me that research must be enjoyable and if this is not the case, it is one's duty to make it enjoyable.

Despite our geographical separation, my promotor, prof. dr. Herman Kingma, has always shown by example how important it is to be passionate in pursuing one's interests. As my friend and research colleague over the years, he has been insightful and inquisitive, and as my promotor he has continually encouraged me, guided me and emphasized the importance of always trying to formulate new questions, and pursue answers to them, especially in a field where so little is understood. For his efforts on my behalf to help me complete this journey, he has my deepest gratitude.

Research endeavours always start with interests kindled and nurtured by others, and there are several people who have served this purpose in my research. A debt of gratitude goes out to prof. dr. Adolfo Bronstein whom I first met over 20 
years ago, and who has always inspired me and served as a colleague, collaborator, sounding board and friend. We have shared many good times together and enjoyed fascinating stories and thoughts about research ideas, patients and future endeavours. Thanks also must go to Dr. Lewis Nashner, and Dr. Owen Black, whose work has fascinated me and inspired me for over 25 years.

In order to pursue this research endeavour successfully, while at the same time being a father, a husband and working in a busy diagnostic clinic, I have had the good fortune to have a solid source of encouragement, mentor, teacher and understanding medical director who is also a highly regarded clinician in my colleague, Dr. Neil Longridge. As research partners we have shared ideas and countless enthusiastic hallway conversations prompted by a particularly fascinating clinical case. Many thanks for all your support, Neil.

On a personal note, the joy of research is heightened immeasurably when you are a father to three wonderful, intelligent children who always listen and consistently show an interest in my latest research project. For Christopher, Daniel and Kyle, I am forever thankful.

And finally, to my amazing wife Tish, who has been my partner in all things for over 40 years, this is for you. 